\title{
The Consequences of Student Loan Credit Expansions: \\ Evidence from Three Decades of Default Cycles
}

\author{
Adam Looney ${ }^{\dagger}$ and Constantine Yannelis ${ }^{\dagger}$
}

June $2019^{*}$

This paper studies the link between credit availability and student loan repayment using administrative federal student loan data. We demonstrate that expansions and contractions in federal student loan credit to institutions with high default rates explain most of the time series variation in student loan defaults between 1980 and 2010. Expansions in loan eligibility between 1976 and 1988 led to the entry of new, high-risk institutions, and default rates exceeding 30 percent in the late 1980s. Credit access was subsequently tightened through strict institutional and student accountability measures. This contracted credit availability at the highest default rate institutions, which in turn caused an exodus of institutions with high default rates, resulting in lower default rates on student loans. After 1992 , the cycle was repeated, with credit access gradually loosened by unwinding many of the pre-1992 reforms. We confirm this time series narrative by examining discrete policy changes governing access to credit to show that tightening credit supply led to the closure of high-default schools and the relaxation of accountability rules resulted in their expansion. Our estimates imply that $85 \%$ of the increase in default between 1980 and 1990, and $95 \%$ of the decrease in default between 1990 and 2000 is driven by schools entering and exiting loan programs. One-third of the recent increase in default is associated with the entry of online programs following the relaxation of rules for lending to online schools, and another third is associated with the abolition of rules limiting the share of revenue coming from federal programs.

JEL Classification: D14, G28, H52, H81

Keywords: Student Loans, Credit Expansion, Human Capital, Loan Default

\footnotetext{
$\dagger$ The Brookings Institution, 1775 Massachusetts Ave NW, Washington, DC 20036, alooney@brookings.edu

$\dagger$ University of Chicago Booth School of Business and NBER, 5807 S Woodlawn Ave, Chicago, IL 60637, constantine.yannelis@chicagobooth.edu

* The authors wish to thank Nick Bloom, Raji Chakrabarti, Natalie Cox Bachas, Michael Dinerstein, Darrell Duffie, Jean Healwege, Sabrina Howell, Caroline Hoxby, Adam Isen, Donghoon Lee, John Mondragon, Holger Mueller, Taylor Nadauld, Miguel Palacios, Rob Richmond, Maxime Roy, Amir Sufi, Wilbert van der Klaauw, Emil Verner and David Wessel for helpful comments and discussions, as well as seminar participants at the Columbia Workshop in New Empirical Finance, the SFS Cavalcade, the Western Finance Association, the University of Chicago Booth School of Business, the New York University Stern School of Business, the Penn State Smeal College of Business, the Federal Reserve Bank of New York, the Federal Reserve Board of Governors, the BYU Marriott School of Business, the Midwest Finance Association, the University of Calgary Haskanye School of Business and the University of Miami Business School. We are grateful to Katerina Nikalexi, Jun Xu and Emily Zhang for excellent research assistance. Adam Looney gratefully acknowledges support of this project from the Arnold Foundation. Any views or interpretations expressed in this paper are those of the authors and do not necessarily reflect the views of the Treasury or any other organization.
} 
I. Student Loans, Access to Credit and Repayment

Between 2004 and 2018, the outstanding volume of student loan debt leapt from $\$ 250$ billion to $\$ 1.5$ trillion, making student loans the largest non-mortgage source of household debt in the United States. Many borrowers struggle to repay their student loans, and default and delinquency rates remain high well after the recession, in contrast to most forms of household debt, which have since recovered. In 2018, student loans had the highest delinquency rate of any form of household debt (Federal Reserve Bank of New York 2018). Additionally, student loans exhibit time series patterns very different from other forms of household debt, and there is little work on the underlying drivers of variation in student loan default over time, and whether federal policy drives these patterns. Understanding what drives student loan default is key in designing policy responses to alleviate the student loan crisis.

In this paper, we argue that legislative changes in federal financial aid policies drive most of the time series variation in default rates, by expanding student loan credit and other aid to new and riskier types of programs, often at for-profit schools, where students have higher default rates. We first provide a narrative history of federal loan policy from 1970 to 2015, which we complement with evidence from several policy changes. Our analysis reveals that almost all the time series variation in student loan default is the result of expansions and contractions in the supply of federal credit. Changes in credit availability are transmitted to student outcomes because expansions in loan availability led to entry and expansions of new, often high-risk institutions. Contractions in credit, in the form of accountability policies - a form of institutional underwriting - led to exit or contraction of high-risk institutions.

We show that much of the entry of institutions is tied to the entry of state guarantee agencies, following amendments to the Higher Education Act in 1976 which incentivized states to reimburse losses to lenders. We show that the entry of state guarantee agencies leads to sharp spikes in the entry of new institutions to federal borrowing programs. To confirm that the time series relationship between federal credit policy, institutional composition, and default rates is causal, we examine the impact of several specific federal policy changes that expanded or contracted access to credit for certain institutions, but not 
others. We use these changes to identify the effects of access to credit on school entry, exit, or expansion using a difference-in-difference design, utilizing sharp cutoffs in access to credit based on institutional characteristics or outcomes used in high-stakes accountability systems. Newly sanctioned institutions rapidly contract and exit, sending defaults falling; when constraints are lifted, affected institutions expand rapidly, and defaults surge. Today's crisis largely stems from repeal or reduction in accountability measures between 1998 and 2006, and expansions in federal aid and loan limits in the mid 2000s.

Our study draws on administrative data from the universe of federal student loan borrowers. We construct a new school-level dataset, built from the National Student Loan Data System (NSLDS.) The dataset includes all schools that were ever eligible for federal student loans between 1970 and 2014. We complement this data with several other schoollevel sources from the Department of Education, which allow us to measure exposure to various federal policies.

Our analysis examines a difficult tradeoff in subsidized lending programs between access to credit and the default risks imposed on borrowers or taxpayers. While loan guarantees or subsidies can improve welfare by alleviating credit constraints and financing efficient investments (Stiglitz and Weiss 1981, Mankiw 1986), loan subsidies can also reduce welfare if they encourage low return investments. In examining this tradeoff empirically, our work is perhaps closest in spirit to Mian and Sufi's (2009) study of the subprime mortgage crisis in which securitization led to a rapid expansion in the supply of high-risk mortgages, which in turn led to increases in default rates. In the student loan context, the challenge policy-makers grapple with is finding the appropriate balance between access to educational opportunities, and risks of burdening borrowers and taxpayers with the consequences if those educational opportunities prove to be low-quality and low-value. ${ }^{2}$

In our narrative analysis, we focus on three distinct eras in which federal policy changes expanded, contracted, and re-expanded student loan credit: the mid-1980s, the early 1990s, and the 2000s. Over these periods, federal policy changes precipitated large changes in the

\footnotetext{
${ }^{2}$ As one example of policymakers grappling with this tradeoff, the proposed Promoting Real Opportunity, Success, and Prosperity through Education Reform (PROSPER) Act proposes sweeping changes to accountability rules regulating access to federal student loans. The proposed legislation both increases credit access by reducing restrictions on for-profit colleges and online institutions, while eliminating aid to programs with low loan repayment rates.
} 
number of borrowers, the volume of loans, and the entry and exit of institutions, and, soon after, changes in student loan default rates. In the mid-1980s, eligibility for federal loans was expanded to independent (older) borrowers, students without high school degrees, and federal borrowing ceilings were increased. Most importantly, states were incentivized to set up guarantee agencies, which encouraged lenders to participate in federal student loan programs (Gladieux 1995). This expansion led to a surge of new institutions to serve these newly-eligible borrowers, particularly in the for-profit sector. These new institutions and the student borrowers they enrolled proved to be low-quality and huge numbers of their borrowers defaulted; nationwide the default rate exceeded 30 percent in 1989 (Looney and Yannelis 2015).

Growing defaults resulted in a series of legislative changes imposing new accountability rules limiting financial grant and loan aid to higher-risk institutions in the early 1990s. New default rate sanctions were implemented starting in 1990, which cut access to federal student loan and grant programs from institutions whose two-year default rate exceeded 30 percent for three consecutive years. ${ }^{3}$ This led to a massive exodus of institutions - mostly for-profits - with high default rates. The exit of these high-risk institutions contributed to a sharp decrease in student loan default rates. More recently, the unwinding of many of those accountability measures starting in 1998 contributed to an increase in for-profit enrollment and increases in borrowing among non-traditional students, leading to high rates of default during and after the Great Recession.

The historical evidence is also notable for the absence of time-series variation in default rates within institutions, particularly 4-year public and private institutions, even during recessions, over periods when tuitions or debt burdens increased, or when alternative repayment plans were introduced. Almost all of the time series variation in aggregate defaults is driven by the entry and exit of schools, directly after expansions and contractions in federal credit policy, not by economic conditions, tuition inflation, or other aggregate factors. This emphasizes the role of institutions themselves, particularly the role of forprofit institutions.

\footnotetext{
${ }^{3}$ The threshold percentage varied over time and was later reduced to 25 percent in 1998 . Additionally, institutions with two-year cohort default rates exceeding 40 percent in one year were subject to loss of Title IV funds.
} 
To corroborate the time series relationship between federal credit policy, institutional composition, and default rates, we exploit federal rules that change access to credit for certain institutions to identify the effects of access to credit on school borrowing, both in closure and expansion. First, we study the entry of state guarantee agencies following the 1976 Higher Education Act amendments, which incentivized states to expand credit access by creating institutions to guarantee student loans. This effectively protected lenders from default risks, and led to the entry of high-default schools. Second, in 1990 rules were enacted, eliminating access to federal loans to students at high default schools, and took effect based on students who left school in 1988. We employ a difference-in-difference estimator, utilizing sharp cutoffs in the statutory threshold at which access was denied, and find that the rules caused institutions to stop participating in federal loan programs, which in turn led to schools' closures, and a reduction in student loan defaults.

In a similar analysis, we examine the recent expansion of online education and loosening restrictions on schools receiving more than $90 \%$ of their revenue from government sources. First, we explore loosening access to credit for distance education, including online courses. Prior to 2006, schools could have no more than $50 \%$ of their students enrolled in online or correspondence courses. We show that the removal of these rules led to sharp increases in enrollment growth in online institutions, and that these schools account for approximately one-third of the increase in new student loan defaults between 2000 and 2010. We next turn to loosening restrictions on schools receiving all of their revenue from federal sources. After 2008, newly-available Post-9/11 GI Bill benefits increased the availability of non-Title IV funding sources, particularly at for-profit schools where 39 percent of all GI Bill benefits were used. The policy effectively relaxed the 90/10 rule requiring schools to receive less than $90 \%$ of their revenue from government sources to participate in federal student loan programs, as GI benefits were not counted under the $90 \%$ threshold. This new funding source allowed institutions that had been constrained by limits on Title IV aid to expand, leading to increased borrowing and defaults. Difference-indifference estimates indicate that online schools and schools near the $90 \%$ threshold grew at a much faster rate relative to other institutions. In sum, the rigorous examination of the effects of these policy changes reinforces our view that the time series changes we document are the result of federal policies. 
To quantify and summarize the magnitude of the contribution of federal policy, we conduct a decomposition which shows that approximately $85 \%$ of the increase in student loan defaults between 1980 and 1990 is driven by schools that enter loan programs, whilst $95 \%$ of the decrease in defaults between 1990 and 2000 is driven by schools exiting the sample following the imposition of restrictions on high-default schools. The results from the decomposition closely align with magnitudes from our difference-in-difference estimates exploiting cutoffs sanctioning high default schools. Turning towards the period between 2000 and 2010, during which default rates rose sharply, decomposition estimates indicate that the relaxation of restrictions on online borrowing and loosening the 90/10 rule each account for approximately one-third of the increase in loan defaults. ${ }^{4}$

This paper primarily links to the growing empirical literature on student loans and human capital investment. Recent work has focused on liquidity constraints and the returns to student borrowing (Amromin, Eberly and Mondragon 2018; Bachas 2016; Bleemer et al. 2014; Avery and Turner 2012; Kargar and Mann 2018; Looney and Yannelis 2015; Lucca, Nadauld and Shen 2018; Mueller and Yannelis 2019; Solis 2017) and modeling human capital investment programs (Lochner and Monge-Naranjo 2011; Palacios 2014). Our work suggests that how and to which institutions federal loan credit is supplied has important implications for the outcomes of students and the costs to taxpayers. Our work suggests that it is important to examine how, and to which institutions, federal loan credit is supplied in order to properly assess the implications of the outcomes of student defaults and to costs to taxpayers. Indeed, we show that this explains most of the time series variation in default.

This paper is closely related to prior work by Looney and Yannelis (2015), in which we showed that approximately half of the increase in student loan defaults between 2000 and 2010 was accounted for by increases in the number of borrowers at for-profit institutions. We build on that analysis to ask why the market suddenly changed to cause increases in borrowing among non-traditional and for-profit borrowers over that period. Our work therefore helps interpret the implications of the large literature by examining differences

\footnotetext{
${ }^{4}$ While Looney and Yannelis (2015) argue that more than half of the increase in defaults during this time period is due to the increase in for-profit enrollment, and Mueller and Yannelis (2019) argue that approximately one quarter of the increase is due to adverse labor market events, this paper focuses on the underlying cause of the increase in for-profit enrollment - credit supply expansion.
} 
in student outcomes across institutions. Armona, Chakrabarti, and Lovenheim (2017) find that increases in local enrollment in for-profit colleges lead to increases in student borrowing and a higher likelihood of default. Comparing for-profit GE certificate students to a demographically-similar group of high school students who never attended college, Cellini and Turner (2018) find little to no earnings gain from attending. Unlike most other forms of higher education, they find that on average, students' investments in for-profit certificate programs are unlikely to generate net benefits over their lifetime. Cellini, Darolia and Turner (2018) find that when for-profits close due to sanctions, public colleges enroll many students that formerly attended for-profits. A consistent finding in this literature is that the post-college earnings of for-profit college students are typically lower than - and, at best, equal to - the earnings of similar students in public institutions, despite the fact that students pay more and accumulate more debt to attend (Deming, Goldin, and Katz 2012). Our results suggest that federal loan subsidies are ultimately responsible for expanded enrollment and borrowing in these low-return sectors.

This paper also adds to the growing literature on the impacts of credit expansions on loan outcomes and market behavior, which has primarily focused on the mortgage market (e.g Adelino et al. 2017; DiMaggio and Kermani 2017; Favara and Imbs 2015; Keys et al. 2010; Kiyotaki and Moore 1997; Mian and Sufi 2009; Rajan and Ramcharan 2012). To our knowledge, this is the first paper to study credit expansions in the student loan market. Just as that literature finds that expansions in credit from, for instance, worse screening or underwriting, can lead to booms and busts, we show that education credit supply has similar effects on entry, exit, aggregate borrowing and default in the student loan market. While there is still significant debate about what drives time series variation in mortgage default, our study demonstrates that most of the time series variation in student loan default is driven by changes in credit supply.

The remainder of this paper is organized as follows. Section II discusses data and the institutional background. Section III provides a theoretical framework to motivate the subsequent empirical analysis. Section IV presents a narrative analysis of changes to federal student loan programs. Section $V$ presents causal evidence of the effects of specific policies, notably the establishment of state guarantee agencies and rules limits credit access to high-default institutions. Section VI decomposes changes in default and enrollment over time. Section VII concludes. 


\section{Data and Institutional Background}

\section{Student Loans}

In 2019, student loans were the largest source of non-mortgage household debt in the United States, with approximately \$1.6 trillion in outstanding debt held by approximately 45 million borrowers. The vast majority of student loans in the United States are either directly disbursed or, prior to 2010, guaranteed by the federal government. These loan programs were established by the Higher Education Act (HEA) of 1965 and altered by subsequent amendments. ${ }^{5}$

Historically there have been two closely related loan programs, the Federal Family Education Loan (FFEL) program, and the Direct Loan (DL) program. The FFEL program was created by the HEA act of 1965, and it existed in tandem with the DL program after 1992 when a reauthorization of the HEA created the direct lending program. The FFEL program stopped disbursing loans in 2010 following the passage of the Health Care and Education Reconciliation Act, although loans under this program continue to be serviced. The FFEL and DL programs have identical caps on loan volumes and interest rates, and disbursement rules, the main difference between the two programs is the source of funds. Under the FFEL program, private banks provided funds, which were guaranteed by the federal government, and under the DL program the US Treasury directly provided the funds for education loans.

Federal student borrowers are required to fill out a Free Application for Federal Student Aid, or FAFSA form, which can impact loan caps and interest rates through a complex formula. Based on the results of the FAFSA form, schools send financial aid offers which outline student borrowing options. The vast majority of students who choose to borrow take loans up to the limits (Lucca, Nadauld and Shen 2017). Students must complete entrance and exit counseling and sign a promissory note. Traditionally most students were on ten year fixed or variable interest rate repayment plans, but increasingly students have chosen income-driven repayment plans which tie payments to a borrowers' income.

\footnotetext{
${ }^{5}$ Prior to the Higher Education Act, some small federal student loan programs existed under the National Defense Education Act of 1958, which was aimed at promoting investments in science and technology to counter a perceived Soviet advantage in these fields.
} 
Repayment typically begins six months after a student graduates or otherwise separates from an institution. Loan servicing is contracted to private companies. A loan goes into default if a payment is more than 270 days late. We define the two-year cohort default rate for, say, the 2012 cohort as the fraction of individuals who entered repayment in fiscal year 2012 and who defaulted within two years of their repayment date.

Unlike private consumer loans, there is no underwriting for most federal student loans. Instead, eligibility is determined largely by enrollment at accredited institutions that participate in the Title IV program. Interest rates and loan limits are set by Congress, and differ by class year enrolled and a borrowers' graduate student and dependency status. Students in higher class years have higher loan limits, as do students who are considered independent of their parents for financial aid purposes. Additionally, graduate students have higher loan limits. Historically, underwriting was implicitly provided by the now defunct Student Loan Commissioner and the Department of Education. This effectively restricted access to federal loans to selective schools that produced students less likely to default. These policies varied substantially over time and are discussed in section IX. Amromin and Eberly (2016) provide a further discussion of many institutional features of federal student loan programs.

\section{Data}

We use administrative data on student loans from the National Student Loan Data System (NSLDS), which is the main source that the Department of Education uses to track federal student loan borrowers. The NSLDS contains information reported from a variety of sources to the Department of Education, including schools, loan servicers and guarantors. Schools and servicers are required to report new information to the NSLDS within 30 to 120 days of the new information arriving. The NSLDS is also used by borrowers to check their loan information, and by schools and servicers to administer lending and service outstanding loans.

The analysis is based on a 4 percent random panel sample of the NSLDS, which is used by the U.S. Departments of Education, the Congressional Budget Office, and Treasury for policy analysis, research, and budget estimation. The sample is a panel, and the same 
borrowers are tracked over time. ${ }^{6}$ The sample does not include data on Perkins loans, which are available to low-income students and account for approximately 1\% of loans in 2014 (College Board 2014). Basic loan information is available from 1969 onwards. The main analysis sample is a school-level panel from 1970 to 2014 aggregated from the individual microdata. $^{7}$

All outcomes are measured at the end of each fiscal year, except for default, which is reported as the date default occurs. We measure default using the cohort default rate, a standard outcome measure that the Department of Education uses in its institutional accountability systems. We estimate the two-year cohort default rate as the fraction of student borrowers who default on at least one of their federal loans within two years of entering repayment.

In all subsequent analysis, the unit of observations is at the school cohort year level. For example, we measure outcomes for all students who left Stanford University in 1990. We assign borrowers to repayment cohorts by the last year that a borrower's loan enters repayment. We define new entrants as first-time borrowers and assign them to entry cohorts based on the first year that a loan was originated. We define entry cohorts by the first institution attended and exit cohorts by the last institution attended. Defining borrowers by the first and last institution they attended abstracts from the fact that educational careers can sometimes involve spells of borrowing at three or more institutions.

We define school entry as the first year in which a school appears in the NSLDS. We define school exit as the final year in which a school appears in the NSLDS. We exclude the first two years in the full sample, 1970 and 1971, from our definition of school entry to avoid counting schools that are consistently participating in federal student loan programs as new entrants. Similarly, we exclude the last two years in the sample, 2013 and 2014, from our definition of school exit. For privacy reasons, we drop cells with less than 50 individuals,

\footnotetext{
6 The school-level analysis sample was constructed from the Treasury sample. The individual level microdata and sample construction are described in detail in Looney and Yannelis (2015). The panel is constructed by drawing forty combinations of the possible thousand combinations of the last three digits of borrowers' Social Security numbers.

${ }^{7}$ Data exists until 2016, but our primary measure of default, two-year cohort default rates, is forward looking so we restrict the sample to 2014 to ensure comparability of schools across years.
} 
which corresponds to schools with less than 1,250 student borrowers. Thus, if anything we will underestimate the entry and exit of schools, as new entrants tend to be smaller. ${ }^{8}$

There are 11,653 unique institutions ever existing in our sample. In the 2014 fiscal year, in our sample there are 4,435 institutions with new active borrowers, which is slightly less than the 4,627 Title IV degree-granting institutions reported by the National Center for Education Statistics. ${ }^{9}$ Some Title IV eligible schools choose not to participate in federal loan programs and some very small institutions are excluded based on confidentiality limitations.

Data on school closures is obtained from the Department of Education Closed School Weekly Search Files, which include data on school and school branch closures from 1986 onwards. We classify a school as closing if any branch closes. The closed school files are maintained to meet student loan compliance rules. In particular, loans can be discharged if schools or school branches close. There wre 15,120 school branch closures in the US between January 1986 and September 2018, with 3,375 occurring at unique institutions. Of these, 4,923 school branches closed between 1986 and 2000.

We also collect data from the Department of Veterans Affairs providing distributions of Post-9/11 GI Bill benefits by institution by year, and data from the Integrated Postsecondary Education Data System (IPEDS) giving online enrollment by institution. This data is available only for proprietary (for-profit) schools.

\section{Theoretical Framework}

We motivate our subsequent empirical analysis with a simple model of credit supply, incorporating entry of schools and shifts in default. Our model focuses on the entry and exit of for-profit schools, which both simplifies the model and is consistent with the observed patterns in the data. A key component of our model is that, due to federal loan guarantees, increases in credit access increase school profitability without corresponding default risks being internalized by institutions.

\footnotetext{
${ }^{8}$ Appendix table A.1 provides variable descriptions for the main analysis variables. Appendix table A. 2 provides summary statistics for the main analysis variables used.

${ }^{9}$ See the NCES for more data on the number of colleges in the United States.
} 
Students are characterized by their inherent risk $\theta_{i}$, which can be a factor of their own characteristics or the school that they attend, and is drawn from a distribution $g(\theta)$. We assume that risk type is private information, which leads to a collapse of the private market (Mankiw, 1986; Stiglitz and Weiss, 1981) and that profit-maximizing schools can enter and exit (Cellini, 2010; Bresnahan and Reiss, 1991). The government guarantees loans for borrowers up to some level $\bar{\theta}$.

Student demand is a function of the threshold for loans $\bar{\theta}$. The total number enrolled at a school $s$ at time $t$ is

$$
Q_{s t}(\bar{\theta})=f_{s t}(\bar{\theta})+f_{s t}^{g}
$$

where $f_{s t}(\bar{\theta})$ is the number of enrollees who borrow, which depends on $\bar{\theta}$ and $f_{s t}^{g}$ is the fraction who enroll and do not borrow, which does not depend on $\bar{\theta}$. Schools are either non-profit or for-profit. Non-profit schools' entry and exit decisions are unaffected by changes to credit supply.

We assume that all students at for-profit colleges borrow. This assumption is very much in line with reality. For example, Deming, Goldin and Katz (2012) note that $99 \%$ of students at for-profit colleges applied for federal loans and grants. For-profit schools calculate expected market demand $Q_{s t}(\bar{\theta})=f_{s t}(\bar{\theta})+f_{s t}^{g}$, which is also a function of credit supply. Schools' profits are given by

$$
\Pi_{s t}=\left[P_{t}-A V C_{s t}\right] Q_{s t}(\bar{\theta})-F_{s}
$$

Where $P_{t}$ is the tuition paid by schools at time $t$, which is typically close to the cap of federal loans (Lucca, Nadauld and Shen 2018; Eaton, Howell and Yannelis 2018) and $A V C_{s t}$ are a school's average costs, and $F_{s}$ are fixed costs. Due to federal loan guarantees, average costs to the school are not a function of borrowers' riskiness. Under free entry in a competitive equilibrium, schools will enter until there are zero profits. It thus follows that an increase in $\bar{\theta}$ will increase profitability, and encourage entry. Conversely decreasing $\bar{\theta}$ can cause marginal schools' profits to become negative, and cease operations.

Because schools enter until profits are zero, we can linearize the profit equation (Bresnahan and Reiss, 1991; Cellini, 2010) and a schools' decision to enter is a function 


$$
E_{s t}=\beta \bar{\theta}+\psi\left(A V C_{s t}, P_{t}, X_{s t}\right)+v_{s t}
$$

A school's entry $E_{s t}$ is determined not only by $\bar{\theta}$, but by some function $\psi($.$) of A V C_{s t}, P_{t}$ and $X_{s t}$, where $X_{s t}$ captures other determinants of demand and entry that may or may not be correlated with the error $v_{s t}$. Equation (3) motivates our main estimating equation, and we exploit policy changes to obtain variation in the risk of borrowers that is uncorrelated with other determinants of entry.

We also decompose the number of defaults. Increasing credit access affects both the average default rate at a school, and the number of borrowers at an institution. The number of defaults at each for-profit school is given by

$$
D_{s t}=f_{s t}(\bar{\theta}) \theta_{s t}(\bar{\theta})
$$

The term $\theta_{s t}(\bar{\theta})=\int_{0}^{\bar{\theta}} \theta_{i} g_{s t}(\bar{\theta}) \mathrm{d} \theta_{i} \quad$ denotes the average default rate at a school, which is a function of the guarantee threshold $\bar{\theta}$, and note that $f_{s t}(\bar{\theta})$ may be zero, capturing extensive margin effects. The total number of borrowers from $N$ schools in the market is given by $L_{t}=\sum_{s=1}^{N} f_{s t}(\bar{\theta})$. The total number of defaults from $N$ schools in the market is given by $D_{t}=\sum_{s=1}^{N} f_{s t}(\bar{\theta}) \theta_{s t}(\bar{\theta})$ and the default rate is given by $\frac{D_{t}}{L_{t}}$. Thus the effect of increasing the supply of credit on the total number of defaults is given by

$$
\frac{\partial D_{t}}{\partial \bar{\theta}}=\sum_{s=1}^{N} f_{s t}^{\prime}(\bar{\theta}) \theta_{s t}(\bar{\theta})+f_{s t}(\bar{\theta}) \theta_{s t}^{\prime}(\bar{\theta})
$$

The term on the left captures the effect on the total number of new borrowers stemming from expanded access to credit and the entry of new borrowers, and the term on the right captures the effect on the overall default rate stemming from the increase in riskier average borrower type.

\section{Credit Cycles over the History of the Federal Loan Program}

This section establishes that time series variation in default rates is largely driven by the composition of institutions and borrowers participating in the federal loan programs, which is in turn driven by federal credit policies. We start with a summary of broad patterns in enrollment and default rates over the history of the loan program to motivate our analysis 
of the relationship between changes in credit availability to riskier institutions and borrowers, and subsequent effects on student loan default rates.

An earlier crisis in student loans occurred more than 25 years ago and followed a strikingly similar path to the more recent experience. Default rates in the federal student loan system peaked in the late 1980s and early 1990s, at levels far higher than the recent experience. In the run up to that crisis, just like in the late 2000 s, as credit supply increased and the number of borrowers from for-profit institutions increased. Figure 1 shows the fraction of borrowers who default within two years of entering repayment, shown by the red dashed line. Of the borrowers leaving school and entering repayment in 1990, 31 percent defaulted within two years of entering repayment. In contrast, in 2012, two-year default rates were about 12 percent.

Changes in default rates are immediately preceded by rapid changes in the share of borrowers in the for-profit sector. Figure 1 also plots the share of borrowers who had attended for-profit institutions (the blue, solid line). Borrowing in the for-profit sector closely leads the rise in default rates, both in the late 1980s and again in the 2000s. And, as the for-profit share falls, as it did in the early 1990s and starting to after 2010, default rates fall. Figure 1 shows that much of the time series variation in default rates lags changes in the composition of schools that borrowers attend. ${ }^{10}$ In fact, using 40 years of data, the majority of the time series variation in default rates (91 percent) can be predicted using only the lagged share of for profit-borrowers and a time trend. Indeed, Table 1 shows that the $R^{2}$ from the regression of the two-year cohort default rate on the two-year lag of the for-profit share and a linear time trend is 0.91 . The $R^{2}$ of the regression using only the time trend is 0.02 . Using the three-year cohort default rate, and a three-year lagged for-profit share, results in a similar finding: an $R^{2}$ of 0.87 .

Changes in default rates are also largely driven by institutions that enter or exit the loan program; default rates at institutions that continuously participate in the program vary little over time. Figure 2 illustrates the default rates of institutions that participate in federal loan programs continuously over the entire period compared to institutions that enter or exit

\footnotetext{
${ }^{10}$ We refer to changes in composition of borrowers in terms of both characteristics of students and the schools that they attend. The analysis conducted in this paper largely focuses on institutional changes and policies that targeted schools.
} 
participation. The dashed line shows schools that entered or exited the federal student loan program after 1971. We see a pattern quite similar to that shown in Figure 1, with a sharp spike in default rates during the 1980s and a fall during the 1990s. Between 1980 and 2000 the share of enrolled borrowers at these schools ranges from approximately a quarter to a half. The solid line shows the two-year cohort default rate for schools that entered the sample prior to 1970 and remain open through 2015. In contrast to schools that enter the sample, we do not see the sharp increase and decrease in default rates for this group of schools that are consistently in federal loan program. Figure 2 demonstrates that the aggregate time series patterns reproduced in figure 1 are generated by the subgroup of borrowers at institutions that entered or exited federal loan programs after their inception.

As is shown in figure 2, there is very little variation in default rates for schools that were consistently in the sample. Schools that have participated in the loan program since its inception are mostly four-year public and private institutions with strong academic reputations. In fact, there is very little variation in default rates within such schools overall, even during periods of recession. Appendix figure A.1 shows the average change in a school's two-year cohort default rate $\left(C D R_{s, t}-C D R_{s, t-1}\right)$ between 1971 and 2010. Between 1982 and 1990 the two-year cohort rate rose by 20 percentage points. However, at schools that enter the sample, the cumulative change in annual within school default rates was only 12.8 percentage points at schools that enter the sample, and 2.4 percentage points at schools that were consistently in the sample. Both increases are well below the total aggregate change in default rates. The fact that there was little within school variation foreshadows a point that we will illustrate later, that most of the aggregate increase and decrease in default rates was driven by the entry and exit of schools into borrowing, rather than within-school changes in default rates. ${ }^{12}$

\footnotetext{
${ }^{12}$ Alternative explanations are explored in the appendix. Table A.3 shows that unemployment rates, the number of available repayment plans and per-student borrowing are only very weakly correlated with aggregate default rates. Including these variables in time series regressions results in weak correlations and low explanatory power, in contrast to the for-profit share which explains most of the time series variation. Figures A.2, A.3 and A.4 provide corresponding graphical evidence, which again indicates little visual relationship between the aforementioned variables and default rates.
} 
The First Credit Expansion 1978-1989

Why were schools entering and exiting? One compelling hypothesis is federal policy changes regarding financial aid eligibility. Immediately prior to the first student loan crisis, a number of policy changes in the late 1970s and mid 1980s increased the number of institutions accessing federal student loans and the types of eligible borrowers. The Department of Education provides a detailed chronology of these policy changes. The most important of these policy changes were incentives which led to the expansion of state guarantee agencies, which incentivized lenders to participate in the student loan program. ${ }^{13}$

The Higher Education Amendment Acts of 1976 provided incentives for states to create guarantee agencies, which reimburse defaulted dollars to private lenders. As is discussed in the following subsection, this accounted for much of the increase in credit and defaults. However, other policy changes also expanded credit access to borrowers. The Middle Income Student Assistance Act in 1978 allowed students to access subsidized federal student loans regardless of family income, a policy that was quickly reversed. The Higher Education Act amendments of 1980 expanded loan eligibility to parent borrowers and supplemental borrowing for graduate students, enhanced the rate of return guaranteed to banks for making student loans, and liberalized financial aid policies. In 1986, the establishment of the Supplemental Loans to Students (SLS) program extended loans to graduate and independent undergraduate borrowers and substantially increased the supply of credit to institutions that offered education to non-traditional undergraduate students (largely for-profit programs). Table 2 presents a timeline of policy changes associated with student loan supply expansion and contraction.

In addition to further incentives for states to set up guarantee agencies under The Higher Education Act amendments of 1976, The Higher Education Act amendments of 1980 gave Sallie Mae broad authority and flexibility to guarantee loans and meet lenders' liquidity needs. The amendments allowed any qualified student to borrow under federal student loan programs. Sallie Mae was allowed to enter into agreements with eligible institutions to

\footnotetext{
13 The ability to securitize student loans played a large role in expanding credit access. In 1972 Congress created the Student Loan Marketing Association, or Sallie Mae, as a Government Sponsored Enterprise. Sallie Mae was allowed to sell securities in the federal agency market, including a billion-dollar line of credit to the U.S. Treasury and the authority to student loan backed securities to the Federal Financing Bank. These securities also had preferential tax treatment, with exemptions from taxation on interest income and from reporting to the SEC (Sallie Mae 1981).
} 
make loans directly to their students and to state guarantee agencies in cases where private lenders did not agree to disburse guaranteed funds. The effect of these amendments was to make funds more readily available to lenders and students (Sallie Mae 1980).

These changes led to a large influx of institutions participating in the federal loan program in the early 1980s, many of which were for-profit institutions and other institutions that would prove to have high default rates (Gladieux 1995). Although the elimination of income limits for subsidized loans was quickly reversed, sharply reducing the number of higher-income borrowers at relatively selective institutions, subsequent legislative changes expanded loan eligibility to non-traditional undergraduate borrowers, such as older borrowers, borrowers enrolled in part-time programs and even borrowers without a high school degree. Loan limits were increased for graduate borrowers, which led to rapid increases in the number of non-traditional borrowers at newly-eligible institutions. For instance, after the creation of the SLS program in 1986, the share of SLS borrowers at forprofit schools increased from 8 percent in 1986, to 50 percent in 1987, and to more than 61 percent in 1988 (US Senate 1991).

Figure 3 shows that the increase in the number of borrowers from the late 1970s to the midto late-1980s was largely concentrated among for-profit borrowers. The figure shows the total number of new federal borrowers attending for-profit institutions, community colleges, less-selective four-year public and private institutions, and more selective and graduate borrowers at four-year public and private institutions. Essentially all of the compositional changes in the borrowing population at that time occurred because of the surge of for-profit borrowers. In other words, the surge in defaults (and the subsequent decline) was immediately preceded by rising (and then falling) for-profit enrollment.

Moreover, the enrollment changes in the 1980s and 1990s are largely the result of changes in the supply of educational institutions. The expansion of loan eligibility at new institutions (including new for-profit institutions) and to non-traditional borrowers financed the rapid entry and expansion of new, high-risk institutions. Figure 4 shows the number of postsecondary educational institutions entering and exiting participation in the federal Title IV loan system each year. The left panel shows the total number of institutions. The figure shows a surge of new entrants in 1980 and a small spike in 1986, soon after changes in the Higher Education Act revised eligibility, subsidies, and loan limits. The 
right-hand panel of figure 4 decomposes entrants and exits into schools with below and above median default rates, where the default rate is defined as the lifetime average twoyear cohort default rate of students. As the right panel shows, the vast majority of new entrants in the 1980 s were institutions with above-median default rates. ${ }^{14}$

To summarize, at the beginning of the loan program through the 1970 s, there were very few schools one needed to borrow to attend, those schools were selective, and their students were affluent to begin with and economically successful after college. As a result, the student loan program was able to avoid high default rates without having to impose much, if any, underwriting of loans. In effect, the admissions departments provided the underwriting. But as loan eligibility was extended beyond those initial institutions and to non-traditional borrowers, certain institutions saw an opportunity in the absence of underwriting and expanded lending to take advantage of the easy credit, which led to high rates of default. Hence, the institutions entering in the late 1970s and early 1980s, and which expanded rapidly after 1980, included many high-risk institutions, including a significant number of for-profit institutions. The students at many of these new institutions defaulted on their loans at high rates, often soon after separating from the school.

\section{The Role of Guarantee Agencies}

In the 1970s and 1980s, the principal and interest on federal student loans was guaranteed by either (i) the federal government (ii) state agencies or (iii) private non-profit foundations (Sallie Mae 1981). Guarantee agencies played a critical role in the expansion of student lending. Before the creation of the Direct Loan program in 1992, funds for federal student loans came from private sources, but any losses were reimbursed by guarantee agencies. Put simply, the federal government would offer pay private lenders a guaranteed above market return to insure lenders again underpayment in the event a student defaults on their loan. In the early dates of the federal student loan program, reimbursement rates for dollars charged-off varied from state of state, with many states declining to create guarantee agencies.

\footnotetext{
${ }^{14}$ Most post-1970 new entrants have above-median default rates because they are compared both to other new entrants as well as institutions that had participated in 1970 or earlier.
} 
The Higher Education Act amendments of 1976 provided the first incentives for states to create guarantee agencies, including federal seed money, the ability to sell tax exempt bonds to purchase student loan securities, administrative allowances and a 100 percent reimbursement guarantee for five years following the creation of a guarantee agency (Sallie Mae 1977). Students without high school degrees were also made eligible for federal student loans (Gladieux 1995). The expansion of state guarantee agencies increased credit supply and sparked the entry of new institutions into loan programs in each state. As the Sallie Mae (1979) annual report noted, "Financial incentives and administrative efficiency provided by new state and private guarantee agencies encouraged new and continued lender participation." By 1979, 82 percent of all government student loans were guaranteed by state agencies.

The states creating guarantee agencies accounted for most of the growth in new school entry. Figure 5 shows the number of schools entering each year in states that had a guarantee agency prior to 1975 and in states that established a guarantee agency after 1974. The figure shows that more schools entered each year in the states with guarantee agencies prior to 1975. (In these states, most agencies were established with the federal student loan program in the late 1960s.) Following the passage of the Higher Education Act amendments of 1976, the number of schools entering in states with newly-established guarantee agencies jumps, even surpassing the number of entering schools in states that already had guarantee agencies.

The Higher Education Act amendments of 1976 and 1980 also removed additional screening criteria for student borrowers, such as requiring high school diplomas, and the increased generosity if federal reimbursements may have encouraged state agencies to increase the generosity of their guarantee programs. ${ }^{15} \mathrm{Hence}$, while the increase in schools is sharper in states that establish guarantee agencies, there is also an increase in school entry in states that had guarantee agencies prior to 1975 .

\footnotetext{
${ }^{15}$ Figure A.5 shows that the share of states with a student loan guarantee agency increased from approximately half in 1970, to all states by 1983. Appendix table A.4 lists the years in which states established guarantee agencies. These are identified by the first time a guarantee agency appears. Figure A.6 presents a map showing the year in which each state created a guarantee agency.
} 
Contraction: Accountability 1989-1993

The increase in the volume of the loan program, a dramatic increase in loan defaults, and reports of waste, fraud and abuse within the loan system prompted investigations from the Senate Committee on Governmental Affairs and ED's inspector general. For instance, investigations initiated by Secretary of Education William J. Bennett revealed a pattern of "exploitative and deceitful practices" by for-profit career programs, which Bennett summarized as "an outrage perpetrated not only on the American taxpayer, but, most tragically, upon some of the most disadvantaged, and most vulnerable members of society." The response of policymakers was swift and decisive, including legislation of substantial new accountability measures on institutions, limitations on the amounts of revenues forprofit institutions were able to derive from federal Title IV sources, and limits on other abusive practices.

These new accountability standards for schools and students impacted cohorts leaving school after 1988, limiting access to credit for high-default schools and strengthening collections from students. As is clear in figure 3, for-profit enrollment begins shrinking starting after 1989, just as these new eligibility criteria were being implemented.

Specifically, Congress enacted cohort default rate rules, which excluded schools whose students had systematically high default rates. Congress also passed the so-called 85/15 financing rule, which limited the share of revenue proprietary schools could obtain from Title IV federal aid to 85 percent, prohibited institutions from enrolling more than 50 percent of students in distance (or online) programs, and automatic wage garnishment for students with delinquent student loan debt. Those rules barred most of the worstperforming schools from participating in the program and led to an exodus from the program. The most significant of these rules was the cohort default rate (CDR) rule, which specifically barred schools with CDRs greater than 40 percent in one year or greater than 30 percent for the last three years from participation in Title IV, a sanction that typically resulted in the closure of institutions reliant on aid. ${ }^{17}$

\footnotetext{
${ }^{17}$ Initially the two-year cohort default rate threshold was set at 30 percent in 1989, raised to 35 percent in 1991 and then again lowered to 30 percent in 1993. See the Department of Education for further discussion.
} 
Figure 3 also illustrates the effect of a contemporaneous 1992 policy change, which created the unsubsidized loan program that allowed higher-income students without financial need access to federal loans. These higher-income borrowers were concentrated at four-year public and private institutions, and their numbers increased as enrollment grew over the subsequent two decades.

The impact of the entry and exit of new schools on the total number of defaults is shown in figure 6. We see similar patterns during the 1980s and 1990s in the aggregate number of new defaults annually as we did when looking at cohort default rates. There is a surge in defaults during the 1980s, and a sharp drop during the 1990s. The top left panel breaks the sample down between schools that were in the student loan program initially, and schools that entered later. While we do see defaults rise steadily for schools that were always in the federal student loan program, this rise is much more muted, and we do not see the clear temporal breaks observed in the aggregated series. The figure shows that these sharp breaks and the rise and fall in new defaults is almost entirely driven by schools that entered the sample after 1971.

Many of the schools that were established and entering federal loan programs during this time period still account for a sizable portion of student loan defaults. For example, the University of Phoenix was established in 1976 and accounted for the highest number of student loan defaults in 2014. This pattern is seen in other schools which saw high numbers of loan defaults in the early 2010s such as Walden University (established 1970 and acquired by Sylvan Learning Systems in 2002), Nova Southeastern (established 1974) and DeVry (established in 1931, but accredited in 1981 and which acquired and merged with the Keller Graduate School of Management in 1987.)

Many of the high default schools that entered the sample in the 1980s subsequently exit the sample once credit standards were tightened. The top right panel breaks new defaults by schools that are in the sample from their entry to 2014, and those that exit. The panel makes clear that many of the schools that drive the increase in defaults during the 1980s are also schools that exit federal loan programs following the imposition of sanctions. Many of these schools subsequently closed, which is discussed in section V.

Many of the schools that entered in the 1970s and 80s, and then survived the imposition of sanctions drive the increase in defaults during the 2000s. This is shown in the left panels 
of figure 6. The bottom left panel shows the number of new defaults, broken down by the date when a school entered the sample. We see that most of the schools driving the default increase during the 1980s enter the sample between 1975 and 1985. The right-hand panel shows that many of these schools exit, particularly during the early 1990s when the CDR rules are introduced. The number of defaults at these schools drops sharply during the 1990 s, but increases again during the 2000s.

\section{The Recent Crisis: Re-expansion of Credit starting in 1998}

Many of the accountability rules enacted in the wake of the first crisis were subsequently unwound. First, in 1998, the definition of default used in the CDR calculation was increased to 270 days, up from 180 days (lowering measured default rates within the twofiscal-year testing period) and the cohort default threshold was lowered to 25 percent. Additionally, the $85 / 15$ rule was revised to allow schools to receive $90 \%$ of their revenue from Title IV programs, up from $85 \%$, allowing institutions reliant on aid to expand. Increases in loan limits also allowed borrowers to finance more of their tuition. The expansion of income-driven plans loosened the relationship between formal default and repayment, and thus the efficacy of CDR rules. Credit availability at distance education programs was revised to facilitate the growth of online schools.

The Distance Education Demonstration Program began in 1999, which allowed a select number of online only schools to borrow for a trial program. Many of these schools involved in the trial program grew rapidly, such as the University of Phoenix, Capella University, American InterContinental University and Kaplan University. In 2006, the 50 percent distance rule was completely eliminated. The result was that a relatively small number of institutions developed programs that were exclusively online or partially online. Enrollment at these programs jumped, particularly after 2006. There are relatively few such online programs, and they account for only a small share of total enrollment - about 5\% in 2012. Average enrollment in these programs more than tripled in the period between 2006 and 2012. In 2010, borrowers at these institutions had an average two-year cohort default rate of 25 percent, far above the overall average. Figure 7 shows the share of defaults at predominantly online institutions. The share of defaults at online programs begins to rise 
after 1999 when the pilot program was introduced. The rise is especially sharp after 2006, when limitations on distance learning were removed from all institutions.

Finally, in 2008 Congress enacted the post-9/11 GI Bill offering tuition grants and living expense stipends to veterans. Since August, 2009, the Department of Veterans Affairs has paid almost $\$ 35$ billion in benefits, of which 39 percent was used at for-profit institutions. While not a loan program, and thus not a direct expansion in credit availability, veterans are also generally eligible for loans. In addition, GI Bill Benefits facilitate compliance with the 90/10 rule because they are not counted as federal Title IV aid, which limited the fraction of revenue coming from Title IV programs to $90 \%$ of a school's total revenue.

Over the 2000s and early 2010s, expansions in borrowing concentrated at for-profit and community colleges reshaped the composition of federal borrowers. Approximately half of the increase in default between 2000 and 2011 was driven by changes in the composition of borrowers and the types of institutions they attended (Looney and Yannelis 2015). Specifically, more borrowers from low-income families enrolled in for-profit institutions, and saw lower earnings and higher default rates when entering repayment.

Referring back to Figure 3, the recent experience is reminiscent of the surge in enrollment at for-profits that occurred in the 1980s. The difference, however, is that the increase in enrollment (and its reversal) was largely the product of the entry and expansion of new institutions. During the 2000s, there was little new entry of institutions. Instead, existing for-profit institutions, fueled by expanded access to federal aid for online programs, relieved of limits on the share of revenue they could derive from federal aid, and benefitting from regulatory changes in the 2000s expanded their size and scope. In short, the recent surge in for-profit borrowing was the result of rising enrollment at pre-existing institutions. Hence, over the long history of the loan program, as shown in figure 3 , most of the variation in default rates over time relates to entry and expansion (and exit or contraction) of highrisk institutions.

The paper thus far provides a narrative description of changes in federal policy and the subsequent changes in institutional behavior and student loan outcomes. This pattern is consistent with federal policy changes and the resultant incentives for institutions to enter and exit as causing these changes. To test this hypothesis more rigorously we examine 
several specific policy changes to measure their effect on educational institutions and student outcomes.

V. Effects of Federal Financial Aid Policy: The Role of Credit Policy in Contraction and Expansion of Borrowing

How much of a role did credit policy play in these changes? In this section we examine four specific policy changes: the establishment of state guarantee agencies, the introduction of the CDR rules which first affected the 1988 cohort, the relaxation the 90/10 rule in 2008 and the change in distance learning rules in 1999 and 2006.

\section{Expansion of State Guarantee Agencies}

Figure 8 provides suggestive evidence of the role of state guarantee agencies in driving school entry. Figure 8 shows the number of new schools entering in six selected states. ${ }^{19}$ The figure shows that we see sharp jumps in the number of schools entering in close correspondence with the establishment of state guarantee agencies and other national policy changes. For example, school entry in Minnesota and Indiana jumps in 1977 and 1978, which were the years in which these states created guarantee agencies. Colorado and Florida see jumps in 1980, and these states respectively established guarantee agencies in 1979 and 1980. Arizona and Texas see sharp jumps in 1981, the years they established their guarantee agencies, the Arizona Educational Loan Program and Texas Guaranteed Student Loan Corporation.

The fact that the establishment of a state guarantee agency leads to the entry of new schools is shown clearly in Figure 9. Figure 9 utilizes all states, and shows the number of schools entering before and after the establishment of a guarantee agency in each state. In periods prior to the creation of an agency, approximately 10 to 15 schools enter in a given year for the average state. This jumps to an average of 34.9 schools in the year that an agency enters, and increases to 68 schools two years later, before the flow of new schools entering slows.

\footnotetext{
${ }^{19}$ Appendix figure A.5 shows the entry of new schools for all states. For visual clarity due to the fact that some states like California have a larger number of schools, the y axis is normalized to 1 for each state in the year in which the maximum number of schools enters.
} 
Table 3 presents estimates of the effect of guarantee agencies on school entry between 1970 and 1990. The first four columns show estimates of variants of the following specification:

$$
E_{s t}=\alpha_{s}+\alpha_{t}+\beta_{1} \boldsymbol{G} \boldsymbol{A}_{s t}+\gamma X_{s t}+\varepsilon_{s t}
$$

$E_{s t}$ denotes the number of schools entering a state in a given year, while $\boldsymbol{G A}_{s t}$ denotes whether a state has a guarantee agency. The terms $\alpha_{s}$ and $\alpha_{t}$ are state and year fixed effects respectively. Standard errors are clustered at the state level. The state fixed effects absorb state specific factors that do not vary over time, such as certain states like California and New York being larger and having more schools. The time fixed effects absorb economy wide temporal shocks, for example national recessions. Controls $X_{s t}$ include the number of active borrowers, annual new borrowers, average and total balances in each state. The coefficient $\beta_{1}$ is the main object of interest, which captures the effect of a guarantee agency on school entry.

The key identifying assumption is that school entry followed similar trends prior to the introduction of guarantee agencies. Columns (5) through (8) provide supporting evidence for this assumption, and visually figure 9 suggests that there is a sharp jump in school entry in the year which a guarantee agency enters, and consistent with this assumption we do not see a jump in prior years.

The first column includes a year trend, while the second column includes state fixed effects $\alpha_{t}$. The results change very little, and a guarantee agency is associated with approximately 7 to 8 additional schools entering each year. The results are statistically significant, at the .01 level. Columns (3) to (4) respectively add state fixed effects and controls, absorbing time invariant state specific factors. The point estimates drop slightly when controls are added, which may be due to the fact that some controls, such as the number of students borrowing in a state, may also be affected by the entry of a guarantee agency. The results indicate that having a guarantee agency is associated with 4 to 7 additional schools entering annually. The effect is significant at the .01 level or higher.

While the estimates in columns (1) through (4) of Table 3 give the annual effect of a guarantee agency, the graphical evidence in Figure 9 suggests that effect may be much 
larger in the initial years following the creation of a guarantee agency to accommodate new demand for loans, and then slows considerably. This is explored in columns (5) through (8), which replaces the indicator of whether a state has a guarantee agency with indicators of the years before and after the establishment of a guarantee agency.

$$
E_{s t}=\alpha_{s}+\alpha_{t}+\sum_{t=-5}^{5} \beta_{t} \mathbf{1}\left[\text { Year }=\boldsymbol{G A}_{\mathbf{0}}+t\right]+\gamma X_{s t}+\varepsilon_{s t}
$$

Where $\boldsymbol{G}_{\mathbf{0}}$ is the year that a guarantee agency is established. The four columns add fixed effects and controls analogously to columns (1) through (4), and present a consistent pattern. We do not see statistically significant effects in the years prior to the establishment of a guarantee agency. This is consistent with the identifying assumption, that school entry followed similar trends prior to the introduction of a guarantee agency. In the year that a guarantee agency enters, there is a sharp jump in the number of schools entering with an additional 9 to 14 schools entering. The number of schools entering remains elevated for three years following the entry of the guarantee agency, before dropping. Appendix figure A.8 presents the same information graphically.

The estimates in column (7) suggest that approximately 12 additional schools entered annually for a three-year period, with an additional 4 schools entering the next three years. Twenty-six states and districts created guarantee agencies after 1976, and the estimates in table 3 suggest that an additional 1,248 schools entered due to the establishment of these agencies. Thus, the estimates suggest that the creation of state guarantee agencies accounts for approximately three in five of the 2,120 schools that entered between 1975 and 1980 .

\section{Sanctioning High-Default Schools}

We next turn to a policy that contracted the supply of credit to high default schools. One clue of the effect of the CDR rule can be illustrated by comparing the exit rates of institutions with ex-ante default rates that placed them at risk of disqualification. Figure 10 shows entry and exit from the student loan program - the fraction of schools that began and ceased participating each year-by CDR. ${ }^{20}$ The left panel shows the entry of institutions into the sample. Consistent with the evidence seen in section IV, the institutions

\footnotetext{
${ }^{20}$ Institutions are classified by their CDR two years after entry (left panel) or two years prior to exit (right panel).
} 
that entered following the expansion of credit tended to have high default rates. While the majority of schools that entered between 1980 and 1990 had average defaults in excess of 30 percent, many schools with lower average cohort default rates began having access to federal student loan programs.

The right panel of figure 10 shows that several hundred institutions (mostly for-profit schools) were forced out, including close to 15 percent of institutions in 1991 (more than 300 institutions). The chart shows, however, that they were almost exclusively high-CDR schools. In particular, nearly all of these exiting schools had average cohort default rates above 30 percent, the threshold for losing access to Title IV programs such as federal student loans. There is a sharp jump in the probability of exit by cohort default rates above the threshold in years following the introduction of the CDR rules. We see no such jump in earlier years, when there were no rules in effect limiting access to credit for high defaultrate institutions. Looking backwards (in the left panel of Figure 10), the schools eliminated from the program were almost exactly the same new entrants which had entered in 1980 or shortly thereafter during the major credit expansion in that period.

Table 4 examines the effect of the introduction of CDR thresholds on default rates. The table shows the results from a difference-in-difference specification, in which the treatment is an indicator of whether a school is above the CDR threshold. The table shows estimates of variants of the following equation:

$E_{s t}=\alpha_{s}+\alpha_{t}+\beta_{1} \mathbf{1}\left[C D R_{s t}>\bar{D}\right]+\beta_{2} \mathbf{1}\left[C D R_{s t}>\bar{D}\right] \times \mathbf{1}[$ Post 1988$]+\gamma X_{s t}+\varepsilon_{s t}$

Where the term $E_{s t}$ is an indicator of whether a school $s$ exits borrowing from federal student loan programs in a particular year $t$. Schools are dropped after they leave the sample. The term $\mathbf{1}\left[C D R_{s t}>\bar{D}\right]$ is an indicator of whether a school's cohort default rate is above $30 \%$, the threshold above which access to federal student loans is restricted. ${ }^{21}$ $\mathbf{1}$ [Post1988] is an indicator of whether the cohort year is after the introduction of CDR thresholds. The terms $\alpha_{s}$ and $\alpha_{t}$ are school and year fixed effects respectively. The school fixed effects allow us to difference out time invariant school specific factors that are correlated with default, for example the geographic location of a specific school or school quality to the extent that this is time invariant. The year fixed effects capture economy wide

${ }^{21}$ The threshold $\bar{D}$ was initially $25 \%$ when introduced, and then raised to $30 \%$. 
temporal shocks, such as overall national labor market conditions for graduates. Standard errors are clustered at the institution level.

The main coefficient of interest is the term $\beta_{2}$, which captures the effect of high cohort default rates following the introduction of the CDR thresholds. This coefficient captures the effect of being above the threshold. The key identifying assumption is that, conditional on observables, schools above and below the threshold would have followed similar trends in the absence of the introduction of the CDR threshold rules. Supporting evidence for this assumption is provided in figures 10 and 11, and is discussed in the remainder of this section.

Figure 11 breaks up the estimate in equation (5) and plots the treatment effect over time. The figure shows estimates of $\beta_{t}$ from the following specification:

$$
E_{s t}=\alpha_{s}+\alpha_{t}+\sum_{t=1971}^{2000} \beta_{t} \mathbf{1}\left[C D R_{s t}>\bar{D}\right] \times \mathbf{1}[\text { Year }=t]+\varepsilon_{s t}
$$

The solid line shows point estimates, while the dashed line shows a 95\% confidence interval. The figure shows that there are not strong pre-trends, and if anything, schools with higher default rates appear to be trending downwards and are less likely to exit than other schools in the years immediately prior to the imposition of CDR rules. Following the imposition of CDR rules, the coefficient estimates $\beta_{t}$ increase and become significant, which is consistent with schools exiting following the imposition of CDR rules.

Appendix Figure A.9 shows the correlation between exit, default and ownership over time. The left-hand panel of the figure shows the correlation between default and school exit between 1970 and 2010. There is a sharp spike in this relationship following the introduction of CDR rules post 1988. The correlation is estimated via an OLS regression, without the inclusion of any controls. The dashed lines show a 95\% confidence interval.

Figure 12 provides more direct evidence of how the application of the cohort default rate rules after 1990 lead to differential exit of educational institutions based on their ex-ante (pre-CDR legislation) default rates. The figures plot the exit rate of institutions in each specified year by their cohort default rate. The key CDR threshold over which an institution risked exclusion from Title IV funding is 30 percent (the red vertical line). Prior to the legislation establishing the CDR rules and other limitations on loan eligibility and enhanced accountability measures (1984-1988), there was no evidence of differential exit 
of institutions based on credit quality. During and after implementation of the new rules, exits are concentrated among those institutions who would be (or were) sanctioned. ${ }^{22}$

The results in Table 4 indicate that being above the threshold is associated with an increase in school exit following the introduction of CDR rules, which is consistent with the visual evidence. The table explores the effects of the introduction of CDR rules on school exit. The first column presents a simple difference-in-difference, with an indicator of default rates being above the threshold and an indicator of the year being post-1988 as opposed to including fixed effects. The coefficient on the interaction between being above the threshold and the CDR rules being in place is statistically significant at the .01 level. Columns (2) and (3) add in year and school type fixed effects respectively, and the coefficients remain highly statistically significant at the .01 level. The inclusion of year fixed effects doubles the magnitude of the coefficient on the interaction, which suggests that it is important to control for temporal trends. The coefficients are quite stable in later specifications which absorb temporal factors. The coefficients indicate that the introduction of the CDR rules are associated with an approximate 7 percentage point increase in school exit.

Column (4) adds in school fixed effects. The results remain significant and the magnitude of the coefficients increase, indicating that schools above the threshold are approximately 10 percentage points more likely to exit federal borrowing following the introduction of cohort default rules. Columns (5) reweighs schools by the number of active borrowers at schools. The results remain statistically indistinguishable from those in column (4). Column (6) adds in various controls for the number of active borrowers, annual new borrowers, average and total balances, and cohort default rates. The results remain highly statistically significant at the .01 level.

We next turn to school closure. Figure A.10 shows the raw number of schools closing each year, which closely tracks the number of schools exiting federal loan programs. Table 4 demonstrated that the CDR thresholds caused schools to exit the federal lending program,

\footnotetext{
${ }^{22}$ Note that schools above the threshold do not necessarily exit immediately, and that the break is fuzzy rather than sharp. This is due to three factors. The first is measurement error, as our cohort default rates are constructed from a $4 \%$ sample. The second is that schools could challenge CDR sanctions, both through administrative and legal channels, which would lead to schools exiting with a lag. Third, cohort default rates had to be above the threshold for three years.
} 
as was intended. Table 5 shows that this had real effects on school closure. Table 5 repeats the analysis in table 4, replacing the dependent variable with an indicator of whether a school closes, rather than an indicator of a school exiting the federal loan program. In all specifications the coefficient on the interaction is highly statistically significant, at the .01 level. When all controls and fixed effects are included, the coefficient on the interaction is .035 , which is smaller than the corresponding estimate for school closure. Unlike the school exit results, the school closure results are more sensitive to weighing. When we weigh the regressions by the number of borrowers, the coefficient jumps to approximately .08, which is much closer to the corresponding school exit coefficient. This suggests that some larger schools exited loans programs and closed, and that many smaller institutions exited federal loan programs but did not close.

\section{Expansion of Credit to Online Institutions}

Figure 13 shows online enrollment and new defaults over time, breaking schools down by the share of online enrollments in 2012. The top left panel shows the share of new defaults broken down by the share of online students in 2012. Schools that are more than $60 \%$ online in 2012 account for a very small portion of all defaults prior to 2006, and this share increases quickly following the relaxation of the $50 \%$ rules. The top right panel breaks schools down by whether more than $60 \%$ of students are enrolled in distance education in 2012, and for-profit status. The panel shows that most of these online schools, which drive much of the increase new defaults, are for-profit schools. The bottom panel repeats the analysis in the top left, restricting the sample to for-profit institutions. The panel demonstrates that much of the increase in for-profit defaults is indeed driven by the expansion of online institutions.

To formalize the role of policy changes expanding credit access to online institutions, Table 6 presents variants of equation (5), where the treatment is an indicator of whether a school is an online institution. The table shows estimates of the following equation:

$$
E_{s t}=\alpha_{s}+\alpha_{t}+\beta_{1} \mathbf{1}[\text { Online }]+\beta_{2} \mathbf{1}[\text { Online }] \times \mathbf{1}[\text { Post } 2006]+\zeta X_{s t}+\eta_{s t}
$$

Where the term $E_{s t}$ is now the log number of new federal student loan borrowers or new defaults at a school $s$ in a particular year $t$. The term $\mathbf{1}[$ Online] is an indicator of whether 
a school has more than $60 \%$ of their students online or in distance education in 2012 . $\mathbf{1}[$ Post2006] is an indicator of whether the year is after the relaxation of the $50 \%$ rule. The terms $\alpha_{s}$ and $\alpha_{t}$ are school and year fixed effects respectively, which capture time invariant school specific factors correlated with default and economy wide temporal macroeconomic shocks. Standard errors are clustered at the institution level.

The main coefficient of interest is the term $\beta_{2}$, which captures the effect of a school being an online institution following the relaxation of the $50 \%$ rule. This coefficient captures the effect of being an online institution and having increased access to credit. The key identifying assumption is that, conditional on observables, online and brick and mortar institutions would have followed similar trends without the relaxation of the $50 \%$ rule. Supporting evidence for this assumption is provided in appendix figure A.11, by showing that prior to the introduction of the rule schools trended similarly.

Appendix figure A.12 breaks up the estimate, and shows the online treatment effect over time. The figure shows estimates of $\beta_{t}$ from the following specification:

$$
E_{s t}=\alpha_{s}+\alpha_{t}+\sum_{t=1990}^{2015} \beta_{t} \mathbf{1}[\text { Online }] \times \mathbf{1}[\text { Year }=t]+\xi_{s t}
$$

The solid line shows point estimates, while the dashed line shows a 95\% confidence interval. The figure shows that there are not strong pre-trends prior to the introduction of the Distance Education Demonstration Program in 1998, and enrollment growth is similar in online and offline institutions prior to the relaxation of restrictions on credit for online institutions. The vertical line shows respectively the introduction of the Distance Education Demonstration Program and the elimination of the 50\% rule. Following the creation of the Distance Education Demonstration Program, the coefficient estimates $\beta_{t}$ increase and become significant, and there is a larger increase following the relation of the $50 \%$ rule. The fact that the coefficient is trending upwards slightly following the introduction of the Distance Education Demonstration Program, and that in our regression specification we denote the post-reform period as being after 2006 , when the $50 \%$ rule was eliminated, may cause us to underestimate the true effect of the policy on enrollment. ${ }^{23}$

\footnotetext{
${ }^{23}$ Appendix figures A.13 and A.14 provide further, more continuous evidence that growth in defaults is associated with online enrollment between 2000 and 2010. Figure A.13 shows new defaults and borrowers in 2000 and 2010, broken up by deciles of the share of students online in 2012. There is no relationship in 2000 , but a surge in defaults for borrowers at heavily online
} 
Table 6 presents estimates of the coefficient $\beta_{2}$ from variants of the estimating equation, which estimates the difference in enrollment between online and traditional brick and mortar institutions following the relaxation of the $50 \%$ rule. The main coefficient of interest is the interaction of this term with an indicator of the year being post 2006, when rules limiting access to credit for schools with more than $50 \%$ online enrollment were relaxed. In all specifications, there is an approximate $45 \%$ increase in new enrollment at online institutions, and this effect is significant at conventional levels. There is a similar effect on new defaults.

\section{Relaxing Credit Rules and the Post 9/11 GI Bill}

The Post-9/11 Veterans Educational Assistance Act of 2008, more commonly know as the Post 9/11 GI Bill became law on June 30, 2008, and provisions first took effect on August 1, 2009. The bill effectively relaxed the 90/10 rule, under which schools could obtain no more than $90 \%$ of their revenue from Title IV programs. Benefits for veterans count as non-federal funds under the 90/10 rule, such that increases in the use of veterans benefits at an institution reduces the share of revenues from Title IV programs. Between 2008 and 2018 , veterans have claimed $\$ 34.7$ billion in benefits and 39 percent of those benefits were used at for-profit schools. Because these benefits were large and concentrated at large forprofit institutions, they reduced 90/10 ratios substantially. For instance, in 2016, for purposes of the 90/10 rule, the 30 largest for-profit reported total revenues of $\$ 10.5$ billion of which $\$ 7.7$ billion was Title IV funds, resulting in a (dollar weighted) average 90/10 ratio of 73 percent. However, $\$ 1.0$ billion of those revenues were GI Bill benefits or other Department of Defense tuition benefits; excluding those benefits the aggregate 90/10 ratio would have been 81 percent. In the absence of GI Bill benefits, several large for-profit institutions would have failed the rule or come dangerously close, and would have had to reduce their reliance on Title IV programs including federal student loans.

We obtain data on the share of revenue from Title IV programs from the Department of Education. The Higher Education Act (section 487(d)4) requires the Department of

institutions. Figure A.14 shows a binned scatterplot of the change in defaults and the change in the number of borrowers between 2000 in 2010 , by the share of students online. 
Education to annually submit a report to Congress on the amount and percentage of each for-profit institution's revenues from Title IV sources. Figure 14 shows the share of all new defaults at for-profit schools coming from for-profits that receive more than $85 \%$ of revenue from Title IV programs. We restrict here to for-profit schools, for which we have data on Title IV revenue shares. There is a sharp increase in new defaults following the passage of the Post 9/11 GI Bill. Note that we see an almost immediate effect, as most forprofits offer one-year certificate or two-year Associates' Degree programs, and dropout rates are quite high. ${ }^{24}$

We again formalize the role of the effect of the introduction of the Post 9/11 GI Bill using a difference-in-difference framework. Table 7 presents variants of equation (1), where the treatment is an indicator of whether a school is near the 90/10 threshold. The sample is again restricted to for-profit schools, for which data on Title IV revenue shares is available. The table shows estimates of the following equation

$E_{s t}=\alpha_{s}+\alpha_{t}+\beta_{1} \mathbf{1}[$ HighTitleIV $]+\beta_{2} \mathbf{1}[$ HighTitleIV $] \times \mathbf{1}[$ Post 2008$]+\xi X_{s t}+\iota_{s t}$

Where the term $E_{s t}$ is the log number of new federal student loan borrowers or new defaults at a school $s$ in a particular year $t$. The term $\mathbf{1}[$ HighTitleIV] is an indicator of whether a school has more than $85 \%$ of revenue coming from Title IV programs. $\mathbf{1}$ [Post2008] is an indicator of whether the year is after the passage of the Post-9/11 GI Bill. The terms $\alpha_{s}$ and $\alpha_{t}$ are again school and year fixed effects. Standard errors are clustered at the institution level.

The main coefficient of interest is the term $\beta_{2}$, which captures the effect of a school being near the threshold following the introduction of the Post 9/11 GI Bill. The coefficient captures the difference in enrollments and defaults at schools with more than $85 \%$ of revenue coming from Title IV programs, relative to other for-profit schools.

The identifying assumption is a standard parallel trends assumption, that schools with more or less than $85 \%$ of revenue coming from Title IV programs would have trended similarly in the absence of the policy reform, the expansion of non-Title IV aid under the Post 9/11

\footnotetext{
${ }^{24}$ The appendix (figures A.15 and A.16) show that the share of borrowers and defaults increases for schools with a high fraction of revenue coming from Title IV programs. This increase is particularly large at for-profit institutions.
} 
GI Bill. Figure 15 provides supporting evidence for this assumption. The figure breaks up the difference-in-difference estimate, and plots the treatment effect over time. The figure shows estimates of $\beta_{t}$ from the following specification:

$$
E_{s t}=\alpha_{s}+\alpha_{t}+\sum_{t=2000}^{2015} \beta_{t} \mathbf{1}[\text { HighTitleIV }] \times \mathbf{1}[\text { Year }=t]+\xi_{s t}
$$

The solid line shows point estimates, while the dashed line shows a $95 \%$ confidence interval. The figure shows that there are not strong pre-trends for either enrollment and default, and that for-profit schools near the threshold appear to trend similarly prior to the introduction of the Post 9/11 GI Bill. ${ }^{25}$

Table 7 presents estimates of $\beta_{2}$, the difference in enrollment or new defaults for schools with more than $85 \%$ of revenue coming from Title IV programs following the passage of the Post 9/11 GI Bill. The top panel shows enrollment, while the bottom panel shows defaults. Each column gradually adds controls, which are denoted beneath the estimates. The first column presents a simple difference-in-difference, while the second column includes only year fixed effects, and the third and fourth columns respectively add in school type and institution fixed effects. The point estimates remain quite stable, with enrollment increasing by approximately $15 \%$ and defaults by $30 \%$ at institutions with more than $85 \%$ of revenue coming from Title IV programs. The remaining columns weight the results by the number of borrowers and add in school controls for the number of active borrowers, annual new borrowers, and average and total balances. All the estimates of $\beta_{2}$ are significant at the .05 level or higher.

\section{Decomposing Changes in Default Over Time}

The Effect of Entry and Exit

\footnotetext{
25 Appendix figures A.17 and A.18 provide more evidence that growth in borrowing and default is associated with the relaxation of the 90/10 rules between 2000 and 2010. Figure A.17 shows new defaults and borrowers in 2000 and 2010, broken up by the share of revenue coming from Title IV programs. There is no relationship in 2000, but a surge in defaults for borrowers at institutions that are heavily reliant on Title IV programs. Figure A.18 shows a binned scatterplot of the change in defaults and the change in the number of borrowers between 2000 in 2010, broken down by the share of Title IV revenue in 2012.
} 
How much of the change in default can be attributed to the institutional changes described above? In this section we quantify the effects of credit-induced school expansion on default. A simple decomposition reveals that the vast majority of variation in default rates between 1980 and 2000 is driven by the entry and exit of schools. The difference in defaults due to the entry in new schools can be decomposed as

$$
D_{1990}-D_{1980}=\underbrace{\left(D_{1990}^{\text {Enter }}-D_{1980}^{\text {Enter }}\right)}_{\text {Entering Share }}+\left(D_{1990}^{\text {In }}-D_{1980}^{I n}\right)
$$

Similarly, the difference in defaults due to school exit can be decomposed as

$$
D_{2000}-D_{1990}=\underbrace{\left(D_{2000}^{\text {Exit }}-D_{1990}^{\text {Exit }}\right)}_{\text {Exiting Share }}+\left(D_{2000}^{I n}-D_{1990}^{I n}\right)
$$

Where $D_{t}^{i}$ is the number of defaults in school type $i$ (entering, exiting, or in the sample consistently) in year $t$.

Table 8 presents the results of this simple decomposition. The top panel of table 8 decomposes enrolled borrowers, while the bottom panel decomposes new defaults. In 1990 there were 463,875 defaults, a nearly eighteen-fold increase from the 26,175 defaults in 1980. Schools that entered the federal loan program after 1970 accounted for 383,225 of the defaults in 1990, while schools that entered the federal loan program prior to 1970 accounted for 80,650 of these defaults. This compares to 16,775 defaults in 1980 from schools that entered the sample prior to 1970, and 9,400 from schools that entered the federal student loan program after 1970. In 1980 new schools accounted for $35.9 \%$ of all student loan defaults, while in 1990 they accounted for $82.6 \%$ of all student loan defaults. Moreover, these new schools account for $85.4 \%\left(\frac{D_{1990}^{E n t e r}-D_{1980}^{E n t e r}}{D_{1990}-D_{1980}}\right)$ of the increase in loan defaults between 1980 and 1990 .

Turning towards the exit of schools, we see a similar pattern. In 2000, the number of new defaults dropped to 177,425 , roughly a third of the number of defaults in 1990 . Of the new defaults in 2000, 72,900 new defaults are from schools that are consistently in the sample. Of the 463,875 new defaults in 1990, 302,450 new defaults are at schools that exit the federal student loan program. Schools that are consistently in the sample account for 161,425 new defaults in 1990. Schools exiting the sample thus account for $95.4 \%$ $\left(\frac{D_{2000}^{E x i t}-D_{1990}^{E x i t}}{D_{2000}-D_{1990}}\right)$ of the decrease in loan defaults between 1990 and 2000. 
A natural question that arises is whether these defaults are indeed due to the entry and exit of schools, or whether defaulting borrowers would have simply enrolled in other schools. To address this concern, we turn to our CDR threshold analysis, which captures the effect of the elimination of the thresholds on school exit. In table 4 we find that, following the introduction of CDR thresholds for access to credit, crossing the threshold leads to a 9percentage point annual increase in school exit for high default schools. The average number of annual defaults at these schools is 128 , compared to 43 at schools with CDRs below the threshold in $1990 .{ }^{26}$ Schools with CDRs above the threshold account for approximately one quarter of borrowers in the sample. There are 2,622 high default schools in the sample, so the estimates in table 4 over a span of ten years would lead us to estimate that the CDR thresholds led to a $128 \times .09 \times 10 \times 2622=302,054$ reduction in new defaults, which is extremely close to the 302,450 new defaults at schools that exit the federal student loan program.

\section{Quantifying the Effects of Online School Entry}

Table 9 shows borrowing and new defaults in 2000 and 2010, broken down by whether a school is an online or traditional brick and mortar institution. The top panel shows enrollments, while the bottom panel shows defaults. The first row shows the total number of enrolled borrowers and defaults respectively. The second and third rows show the number of borrowers and defaults in each group. Alternating columns show counts and shares. The difference in defaults due to the expansion of online schools can be decomposed as

$$
D_{2010}-D_{2000}=\underbrace{\left(D_{2010}^{O N}-D_{2000}^{O N}\right)}_{\text {Online Share }}+\left(D_{2010}^{O F F}-D_{2000}^{O F F}\right)
$$

Where $D_{t}^{i}$ is the number of defaults in school type $i$ (ON or OFF line) in year $t$. In 2010 the number of new defaults was 574,000, up from 177,425 in 2000 . Of the new defaults in 2010 , roughly a quarter or 163,025 were at schools where more than $60 \%$ of the instruction

\footnotetext{
${ }^{26}$ Note that there are a large number of very small schools. Weighted by the number of borrowers, there are 1,136 new defaults at schools above the threshold in 1990, and 124 new defaults at schools below the threshold.
} 
is online, compared to 30,500 new defaults at these schools in 2000. Online schools account for, approximately one third, or $33.4 \%\left(\frac{D_{2010}^{O N}-D_{2000}^{O N}}{D_{2010}-D_{2000}}\right)$ of the increase in loan defaults between 2000 and $2010 .{ }^{27}$

One potential concern with the decomposition above is that defaulting students would simply have enrolled in other schools had online programs been unavailable. To address this concern, we employ our estimates in table 6 of the effects of the repeal of the $50 \%$ rule for online and correspondence courses. The estimates imply very similar effects, namely that online schools increase enrollment by $46.5 \%$ after 2006 .

\section{Quantifying the Effects of the Post 9/11 GI Bill}

Table 10 quantifies the growth in enrollments and defaults by the share of a school's revenue coming from Title IV programs. The top panel shows enrolled borrowers, while the bottom panel shows new defaults. The first row shows the total number of enrolled borrowers and defaults respectively, the subsequent rows show the number of borrowers and defaults in each group. The difference in defaults due to the expansion of schools close to the $90 / 10$ threshold can be decomposed as

$$
D_{2010}-D_{2000}=\underbrace{\left(D_{2014}^{H T I V}-D_{2000}^{H T I V}\right)}_{\text {High Title IV Share }}+\left(D_{2014}^{L T I V}-D_{2000}^{L T I V}\right)
$$

Where $D_{t}^{i}$ is the number of defaults in school type $i$ (High or Low Title IV Share) in year $t$. In 2010 the number of new defaults was 574,000 up from 177,425 in 2000. Of the new defaults in 2010 , roughly one third, or 191,025 were at schools where more than $80 \%$ of revenue coming from Title IV programs. This compares to 23,700 new defaults at these schools in 2000 , which amounted to only $14 \%$ of all new defaults. Schools with more than

\footnotetext{
${ }^{27}$ This increase in the share of new defaults is larger at for-profit schools. In 2010 there were 279,300 new defaults at for-profit schools, or approximately $49 \%$ of all new defaults. Online schools accounted for 85,225 of these defaults. The corresponding numbers in 2000 was 40,275 new defaults at for-profits and just 3,475 defaults at online schools. Thus online for-profits account for $34.2 \%\left(\frac{D_{2010}^{O N}-D_{2000}^{O N}}{D_{2010}-D_{2000}}\right)$ of new defaults in the for-profit sector.
} 
$80 \%$ of revenue coming from Title IV programs account for, approximately two-fifths, or $42.2 \%\left(\frac{D_{2010}^{H T I V}-D_{2000}^{H T I V}}{D_{2010}-D_{2000}}\right)$ of the increase in loan defaults between 2000 and 2010. Additionally schools with more than $85 \%$ of revenue coming from Title IV programs account for, approximately one quarter, or $26.9 \%\left(\frac{D_{2010}^{H T I V}-D_{2000}^{H T I V}}{D_{2010}-D_{2000}}\right)$ of the increase in loan defaults between 2000 and 2010.

\section{Concluding Remarks}

We show that most of the variation over time in student loans default rates is the result of changes in the composition of borrowers. These changes in the composition of borrowers are in turn the result of policy changes expanding and limiting student loan credit to high default borrowers and schools. This cycle repeated between 1970 and 2010, and our findings suggest that most of the variation in the time series of default is driven by the expansion of credit to high-default institutions.

Policy makers face a trade-off between access and costs in designing a human capital investment system. Alleviating borrowing constraints by guaranteeing or subsidizing loans can be welfare improving (Stiglitz and Weiss 1981; Mankiw 1986). On the other hand, more recent work has also shown that credit expansions can have adverse consequences (Mian and Sufi 2009). This analysis highlights difficult tradeoffs in credit policies between providing access to students and minimizing costs to borrowers and taxpayers. Many federal policies aimed at alleviating the student loan repayment crisis have focused on borrowers, rather than providing credit to institutions. For example, borrowers can be insured by income driven repayment programs, which have expanded rapidly in the student loan market since 2007. However, this shifts risk from borrowers to taxpayers and may serve as a subsidy to institutions where students are unlikely to repay their loans.

While this study identifies the main driver of student loan default over time- changes in credit availability and the expansion and contraction of high-default schools- more work needs to be done to measure the returns of federal borrowing programs. The aggregate welfare effects of increasing credit access for human capital investment programs depends crucially on value added provided by the institutions where high-risk borrowers enroll, and the returns to investments in education. Future work should focus on designing policies 
which screen high-risk borrowers, while ensuring that constrained borrowers with high returns to education investments are able to access credit programs and make high-return investments in education and human capital. 


\section{References}

Adelino, M., Schoar, A., and Severino, F. (2017). "Loan originations and defaults in the mortgage crisis: The role of the middle class." Review of Financial Studies, 29(7), 16351670.

Amromin, G., and J. Eberly (2016). "Education financing and student loans." Annual Review of Financial Economics, 8(1) 289-315.

Amromin, G., J. Eberly, and J. Mondragon (2018). "The housing crisis and the rise in student loans." Unpublished Mimeo.

Armona, L., Chakrabarti, R., and Lovenheim M. (2018). "How does for-profit college attendance affect student loans, defaults, and earnings?" Federal Reserve Bank of New York Staff Report No. 811.

Avery, C., \& Turner, S. (2012). "Student loans: Do college students borrow too much-or not enough?" The Journal of Economic Perspectives, 26(1), 165-192.

Bachas, N. (2016). "Pricing, selection, and welfare in the student loan market: Evidence from borrower repayment decisions." Working Paper.

Bleemer, Z, and Brown, M. and Lee, D. and van der Klaauw, W., (2014). "Debt, jobs, or housing: What's keeping millennials at home?" (November 1, 2014). Federal Reserve Bank of New York Staff Report No. 700.

Bresnahan, T. and Reiss, P.C. (1991) "Entry and competition in concentrated markets." Journal of Political Economy 99(5), 997-1009.

Cellini, S. and Turner, N. (2018) "Gainfully employed? Assessing the employment and earnings of for-profit college students using administrative data." NBER Working Paper 22287.

Cellini, S. (2010) "Financial aid and for-profit colleges: Does aid did encourage entry?" Journal of Policy Analysis and Management 29(3), 526-552.

Cellini, S., Darolia, R. and Turner, L.J, (2018) "Where do students go when for-profit colleges lose aid?" NBER Working Paper 22697.

Darolia, R. (2013). "Integrity versus access? The effect of federal financial aid availability on postsecondary enrollment." Journal of Public Economics 106, 101-114.

Deming, D., C. Goldin, and L. Katz (2012). "The for-profit postsecondary school sector: Nimble critters or agile predators.” Journal of Economics Perspectives 26(1), 139-164.

Deming, D., C. Goldin, L. Katz, and N. Yuchtman (2015). "Can online learning bend the cost curve?" American Economic Review 5(105), 496-501.

DiMaggio, M. and Kermani, A (2017). "Credit induced booms and busts." Review of Financial Studies, 30(11), 3711-3758.

Eaton, C., Howell, S. and Yannelis, C. (2018) "When investor incentives and consumer interests diverge: Private equity in higher education.” NBER Working Paper 24967.

Gladieux, L. (1995). "Financing student aid policy: A history and assessment". Financing Postsecondary Education: The Federal Role, October. 
Favara, G. and J. Imbs (2015). "Credit supply and the price of housing." American Economic Review 105(3), 958-92.

Federal Reserve Bank of New York. (2018). "Quarterly report on household debt and credit." Federal Reserve Bank of New York.

Kargar, M. and Mann, W., (2018). "Student loans, marginal costs, and, markups: Estimates from the PLUS program." Working Paper.

Keys, B. J., Mukherjee, T., Seru, A., \& Vig, V. (2010). "Did securitization lead to lax screening? Evidence from subprime loans." The Quarterly Journal of Economics, 125(1), 307-362.

Kiyotaki, N. and J. Moore (1997). "Credit induced boom and bust." Journal of Political Economy 105(2), 211-248.

Lochner, L. J., \& Monge-Naranjo, A. (2011). "The nature of credit constraints and human capital." The American Economic Review 101(6), 2487-2529.

Looney, A., and Yannelis C. (2015). "A crisis in student loans? How changes in the characteristics of borrowers and in the institutions they attended contributed to rising loan defaults." Brookings Papers on Economic Activity 2015 2, 1-89.

Lucca, D., Nadauld, T., and Shen K. (2018). "Credit supply and the rise in college tuition: Evidence from the expansion in federal student aid programs." The Review of Financial Studies, 32(2),423-266.

Mankiw, N. G. (1986). "The allocation of credit and financial collapse." The Quarterly Journal of Economics 101, 455-70.

Mian, A., K. Rao, and A. Sufi (2013). "Household balance sheets, consumption and the economic slump." The Quarterly Journal of Economics 128(4), 1687-1726.

Mian, A., K. Rao, and E. Verner (2017). "Household debt and business cycles worldwide." The Quarterly Journal of Economics 128(4), 1755-1817.

Mian, A. and Sufi, A. (2009) "The consequences of mortgage credit expansion: Evidence from the US mortgage default crisis." The Quarterly Journal of Economics, 124 (4): 14491496.

Mian, A. and A. Sufi (2011). "House prices, home equity-based borrowing and the US household leverage crisis.” American Economic Review 101(5), 2132-56.

Mueller, H. and C. Yannelis (2019). "The rise in student loan defaults in the great recession." Journal of Financial Economics, 131(1), 1-19.

Palacios, M. (2014). "Human capital as an asset class: Implications from a general equilibrium model." The Review of Financial Studies, 28(4), 978-1023.

Rajan, R. and R. Ramcharan (2012). "The anatomy of a credit crisis: The boom and bust in farm land prices in the United States in the 1920s." American Economic Review 105(3), 1439-77.

Sallie Mae (1977). "Student Loan Marketing Association 1977 Annual Report."

Sallie Mae (1979). "Student Loan Marketing Association 1979 Annual Report." 
Sallie Mae (1981). "Student Loan Marketing Association 1981 Annual Report."

Solis, A. (2017). "Credit access and college enrollment." Journal of Political Economy 125(2), 562-622.

Stiglitz, J. and A. Weiss (1981). "Credit rationing in markets with imperfect information." American Economic Review, 393-410.

Sun, S. T., \& Yannelis, C. (2016). "Credit constraints and demand for higher education: Evidence from financial deregulation." Review of Economics and Statistics, 98(1), 12-24.

U.S. Senate (1991). "Abuses in federal student aid programs." Permanent Subcommittee of Investigations, Committee on Governmental Affairs. 
Figure 1: Default Rate and Share of New Borrowers at For-Profit Institutions

Notes: This figure shows the share of first-time borrowers at for-profit postsecondary institutions and the two-year cohort default rate of borrowers leaving school by fiscal year. Source: National Student Loan Data System (NSLDS).

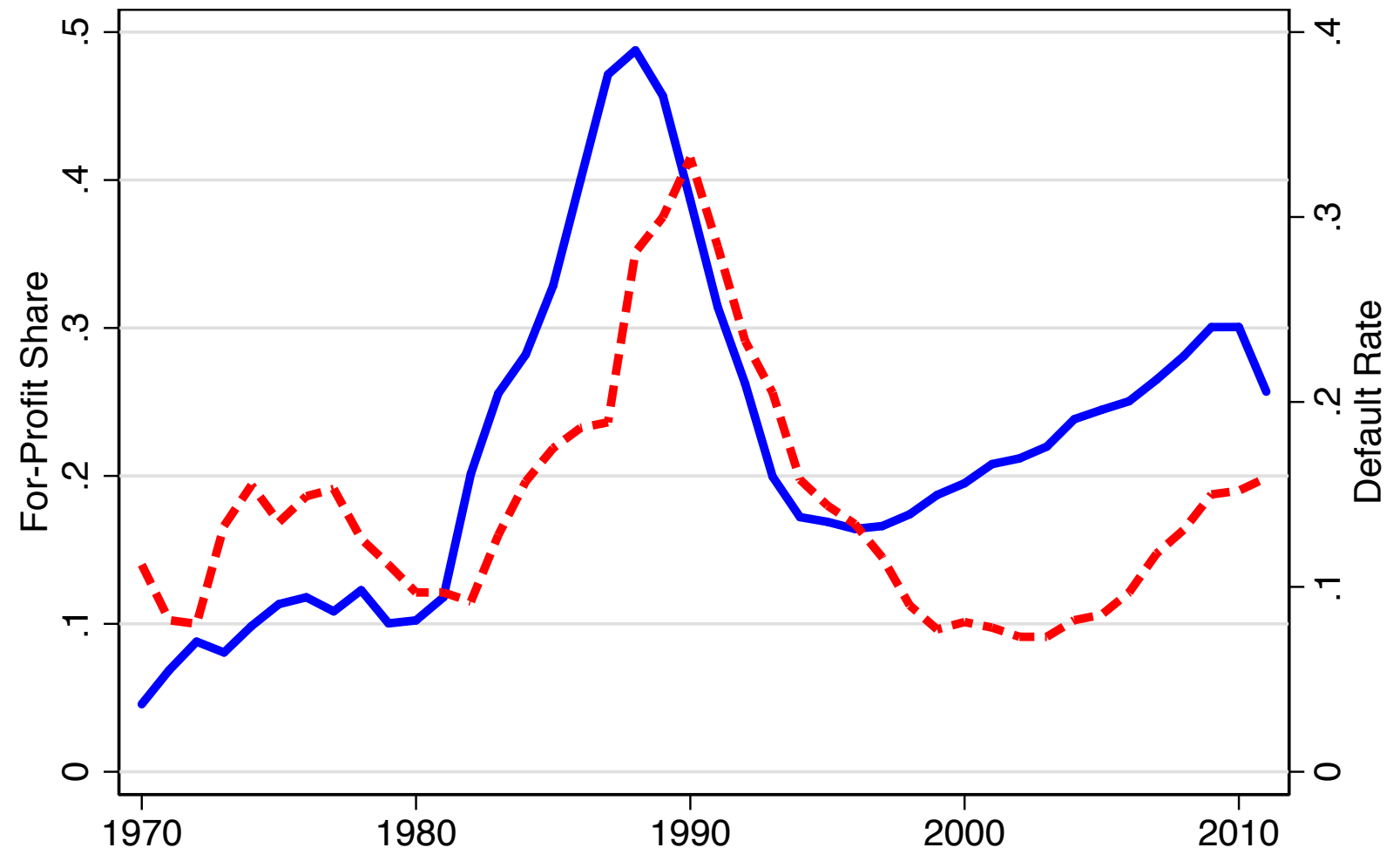

For-Profit Share $=\mathbf{n - n}$ - Default Rate 


\section{Figure 2: Default Rate by Permanent vs. Temporary Participants}

Notes: This figure shows the two-year cohort default rate, split by schools that are in the federal loan sample for the entire period from 1970-2015 and by schools that enter or leave the sample. Source: National Student Loan Data System (NSLDS).

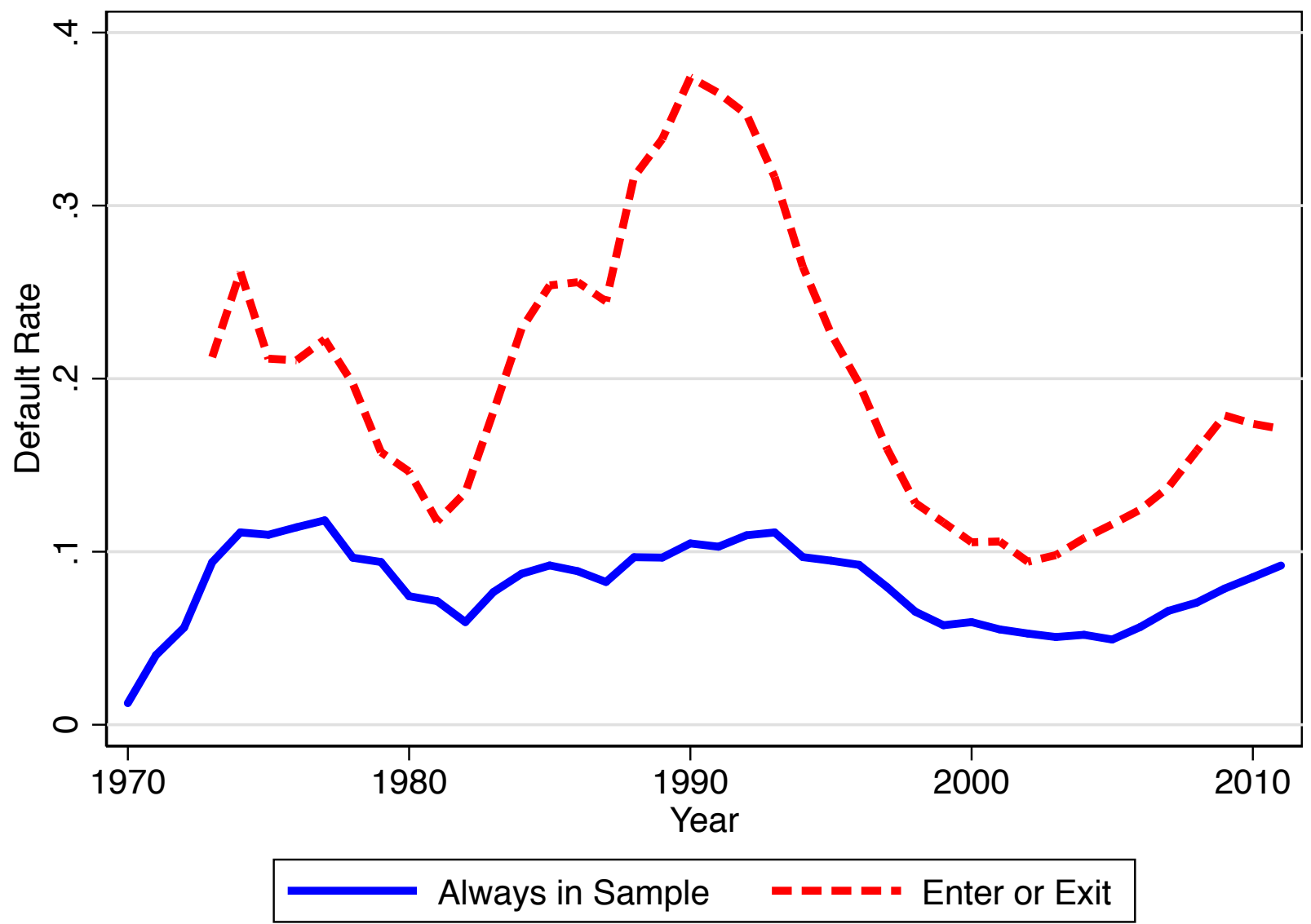


Figure 3: New Federal Borrowers by Type of Institution and Admissions Selectivity

Notes: The figure shows the number of new first-time federal student borrowers by the type of institution (for for-profit and community colleges) and admissions selectivity and level (for students at public and private institutions). New borrowers are measured in thousands. Less selective includes students at public and private institutions rated as non-competitive to competitive by Barron's Profiles of American Colleges; selective and graduate includes students at institutions rated very, highly, or most competitive, and graduate student borrowers. Source: NSLDS.

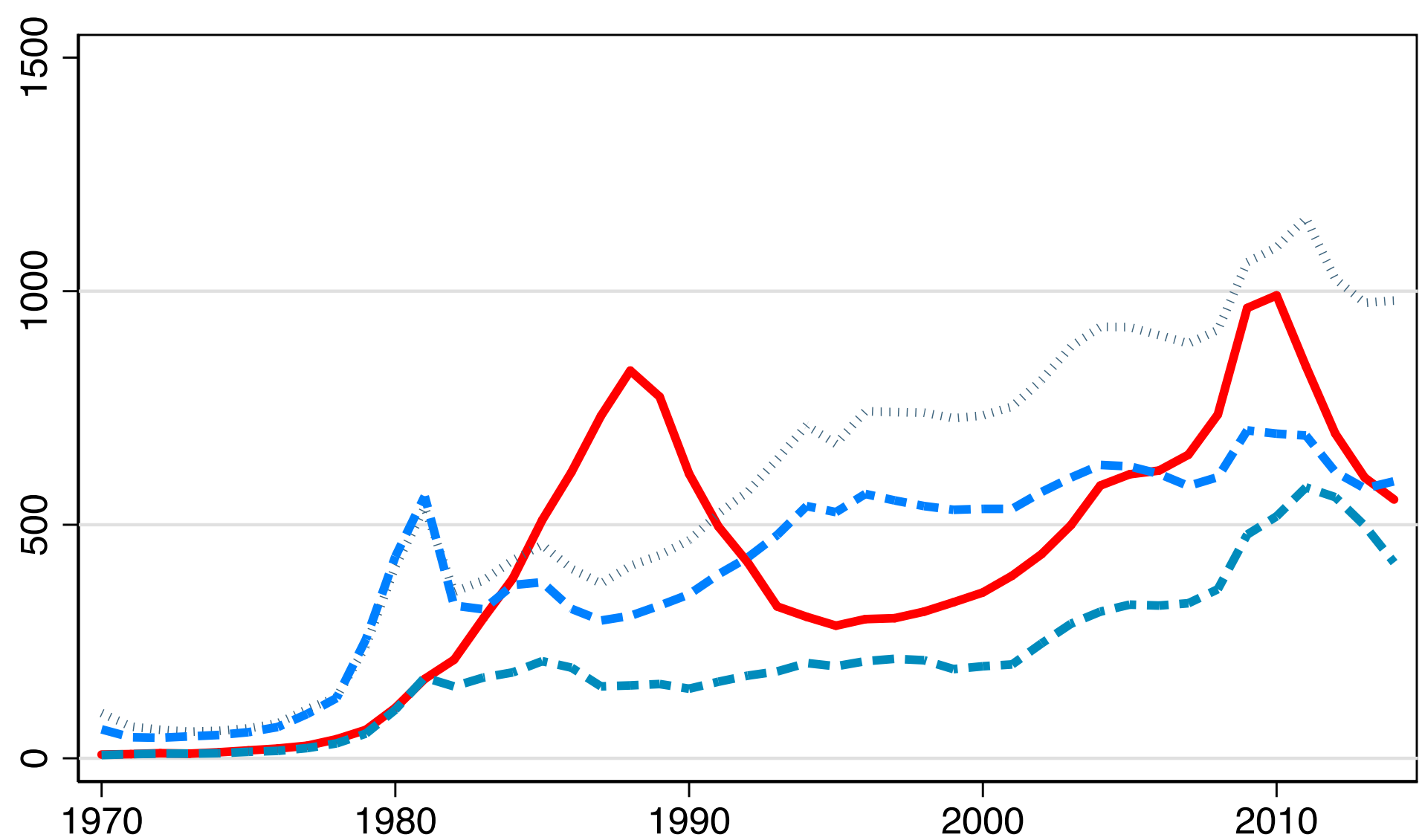

$$
\begin{array}{ll}
\text { For-Profit } & =-1=- \text { Community College } \\
\text { Less Selective } & -=-=- \text { Selective and Graduate Students }
\end{array}
$$




\section{Figure 4: Entry and Exit of Institutions by Cohort Default Rate}

Notes: The left panel shows the number of institutions entering or exiting federal student loan participation. The right panel decomposes the number of entering and exiting institutions between those whose lifetime average two-year cohort default rate was above or below the median. Source: NSLDS.
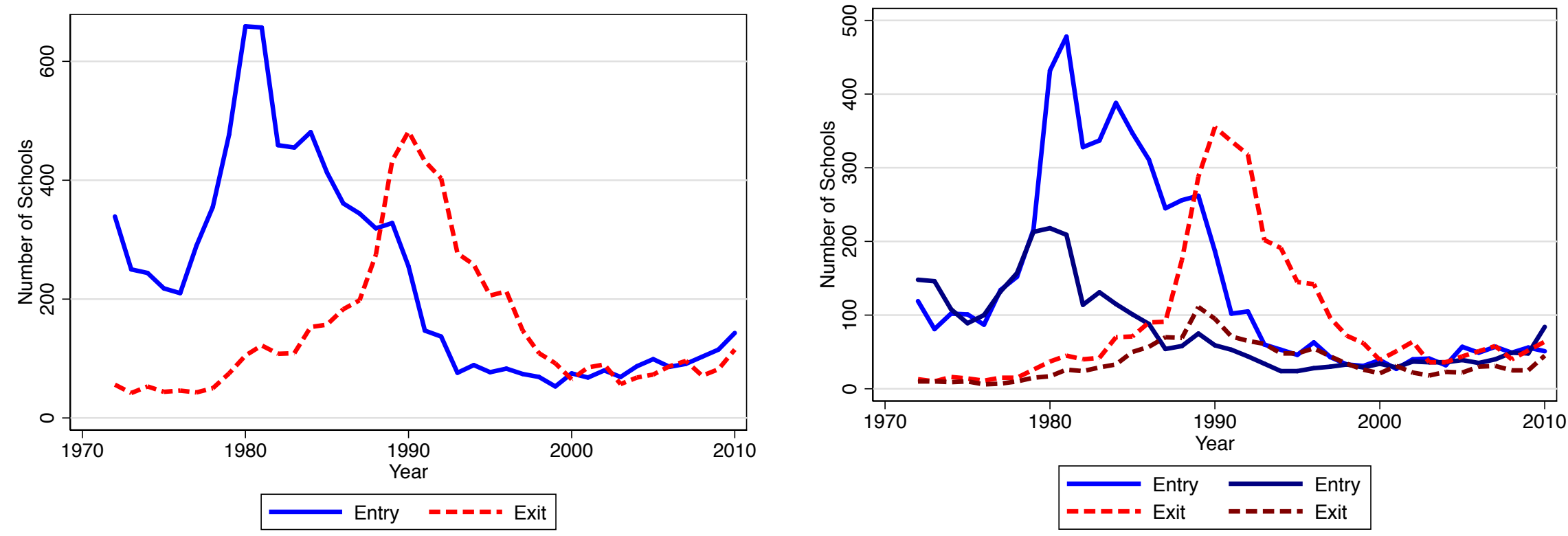
Figure 5: Entry of Schools by Guarantee Agency Establishment

Notes: This figure shows the number of schools entering each year between 1972 and 1982, broken down by states that had a guarantee agency before or after 1975. Source: National Student Loan Data System (NSLDS).

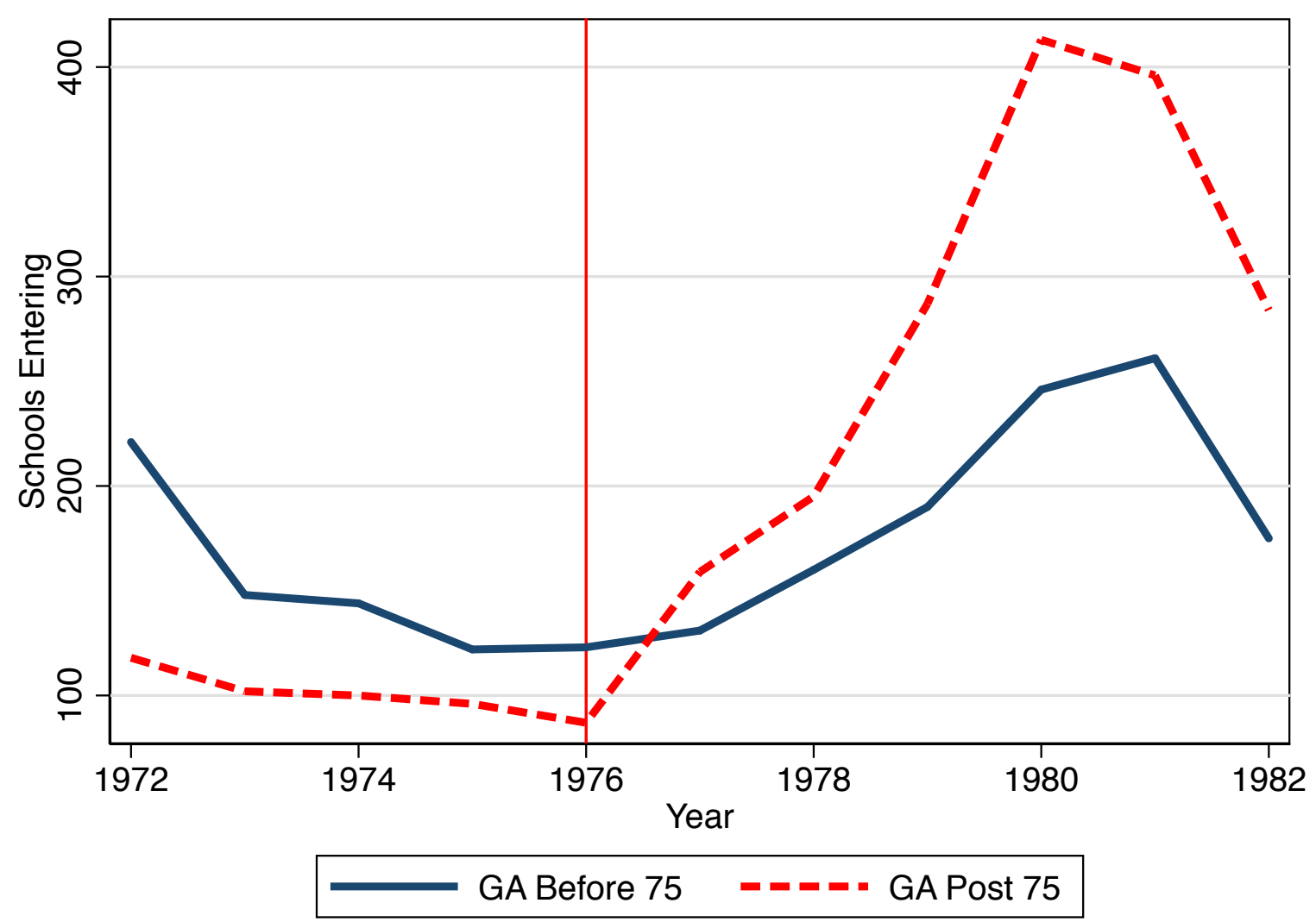




\section{Figure 6: New Defaults by Entry and Exit}

Notes: This figure shows the number of new defaults, broken down by the entry and exit of schools. Schools are broken into groups by the year of entry or exit of a school into the federal borrowing sample. Source: NSLDS.

School Entry
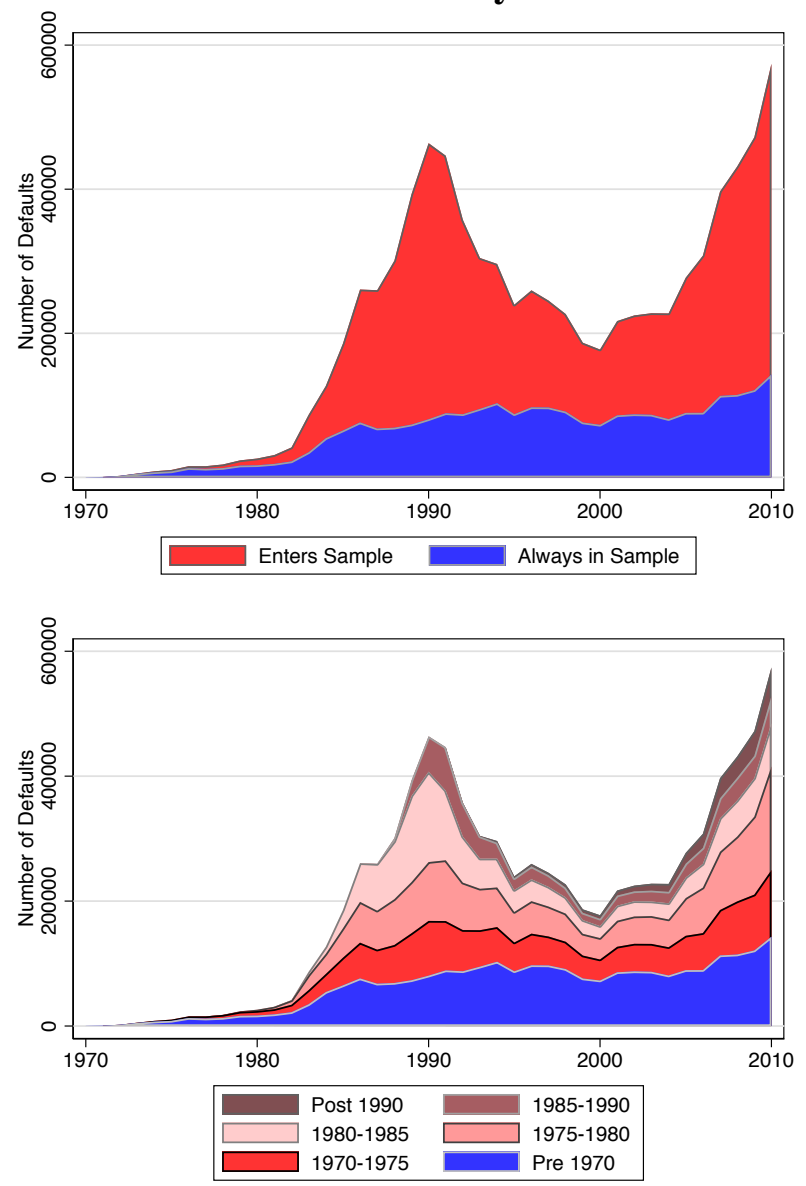

School Exit
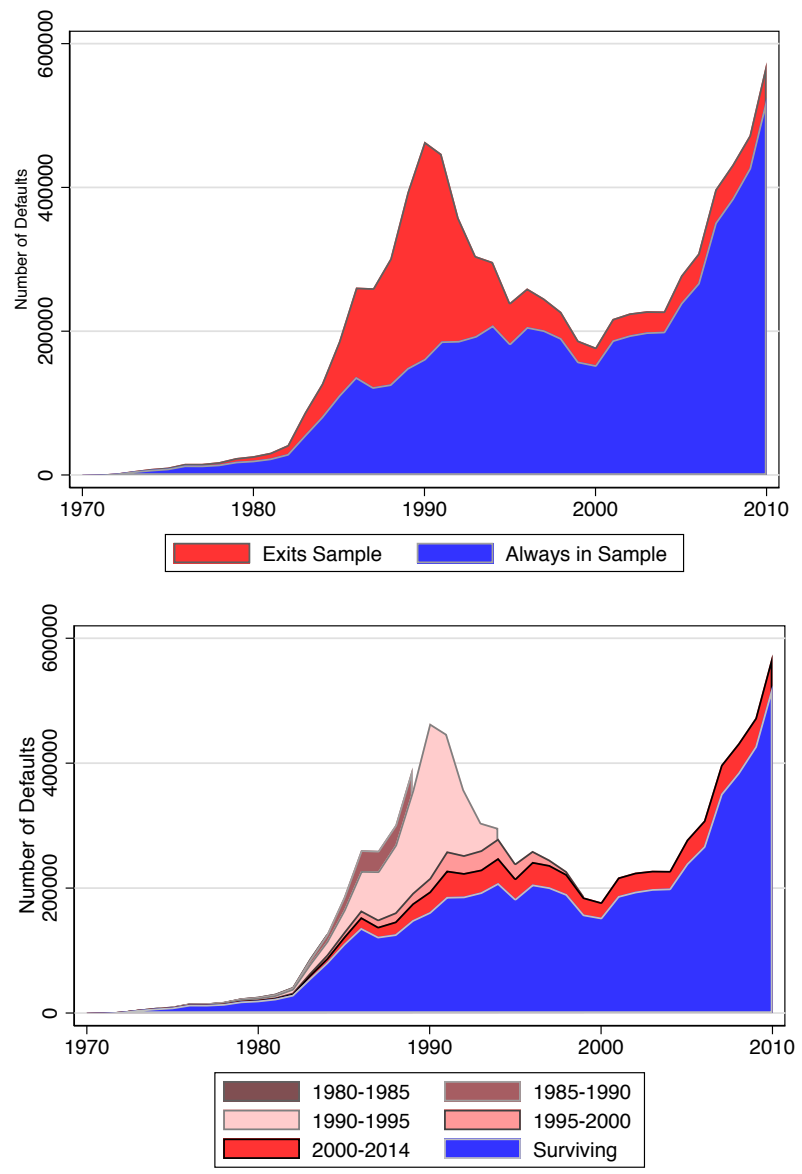


\section{Figure 7: Defaults at Predominantly Online Institutions}

Notes: This figure shows the share of all new defaults from majority online institutions. Online schools are defined as schools where more than $60 \%$ of students are enrolled in distance education in 2012. Source: National Student Loan Data System (NSLDS).

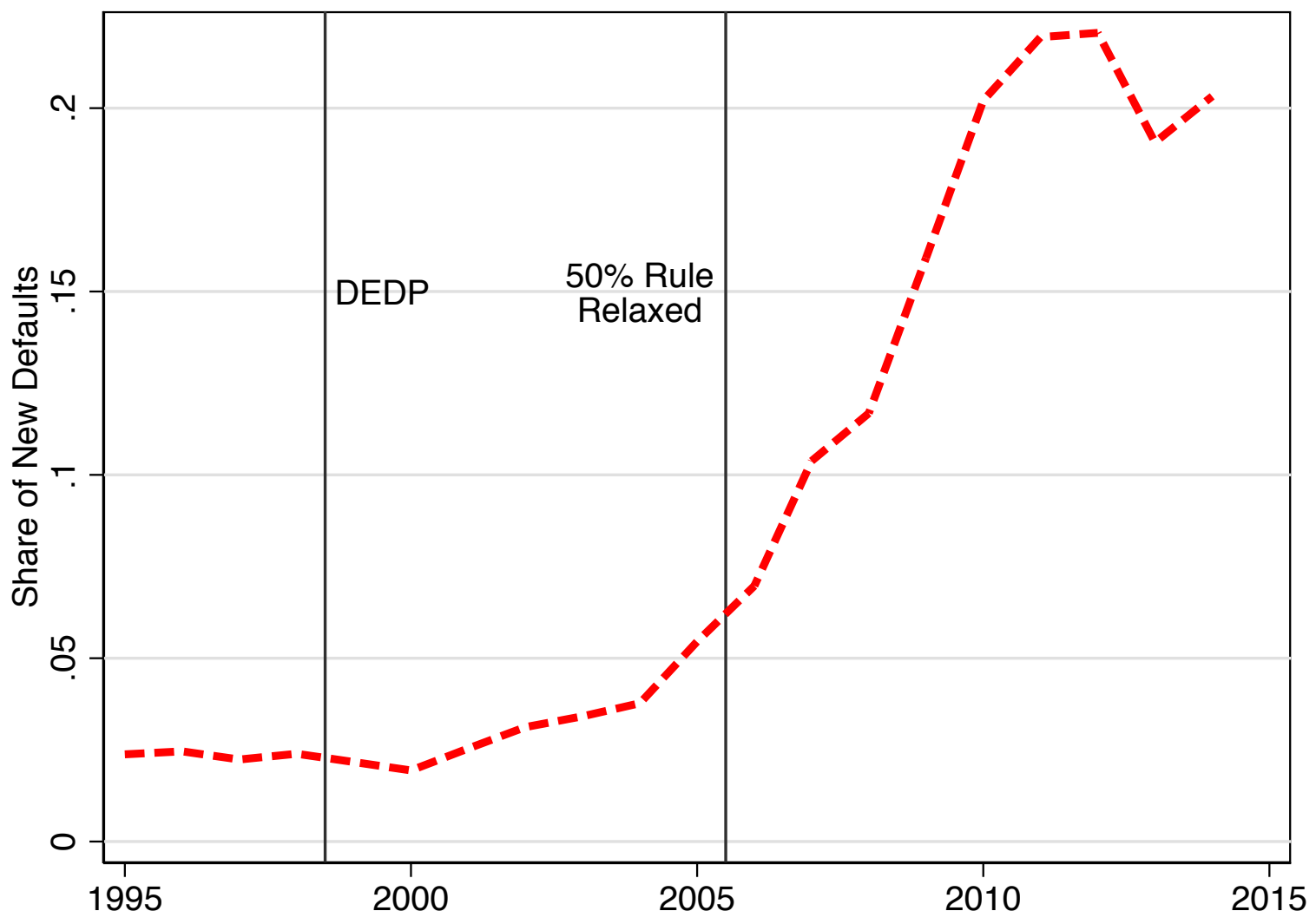




\section{Figure 8: Entry of Schools by State}

Notes: This figure shows the number of schools entering each year between 1972 and 1990, in Minnesota, Colorado, Arizona, Indiana, Florida and Texas. The remainder of states are shown in the appendix. Source: National Student Loan Data System (NSLDS).

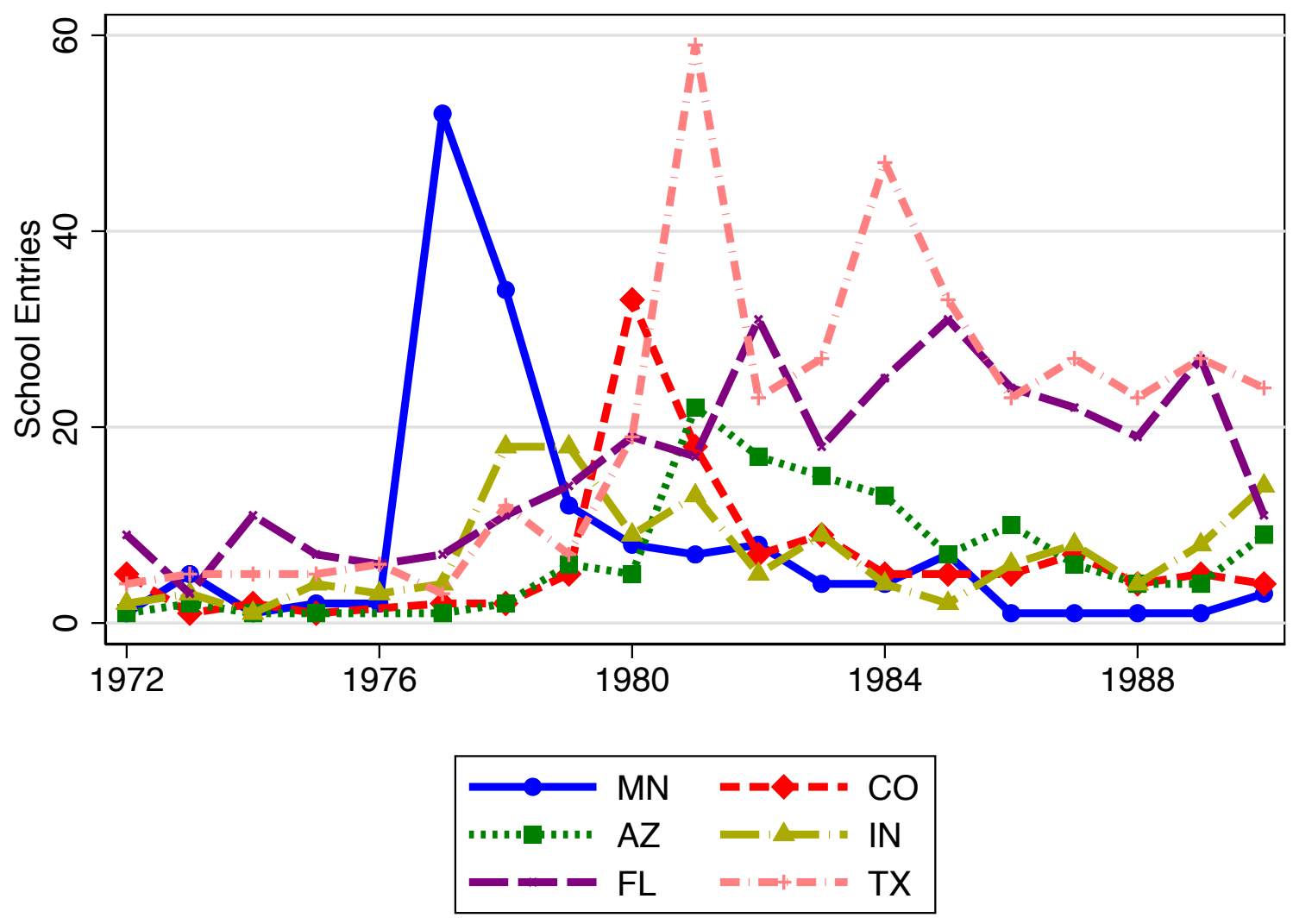




\section{Figure 9: Schools Entering Before and After Establishment of Guarantee Agencies}

Notes: This figure shows the number of schools entering in each state before and after the establishment of a state guarantee agency. The dark red lines around each point estimate depict a 95\% confidence interval. Time 0 denotes the first year in which a guarantee agency is established. Source: National Student Loan Data System (NSLDS).

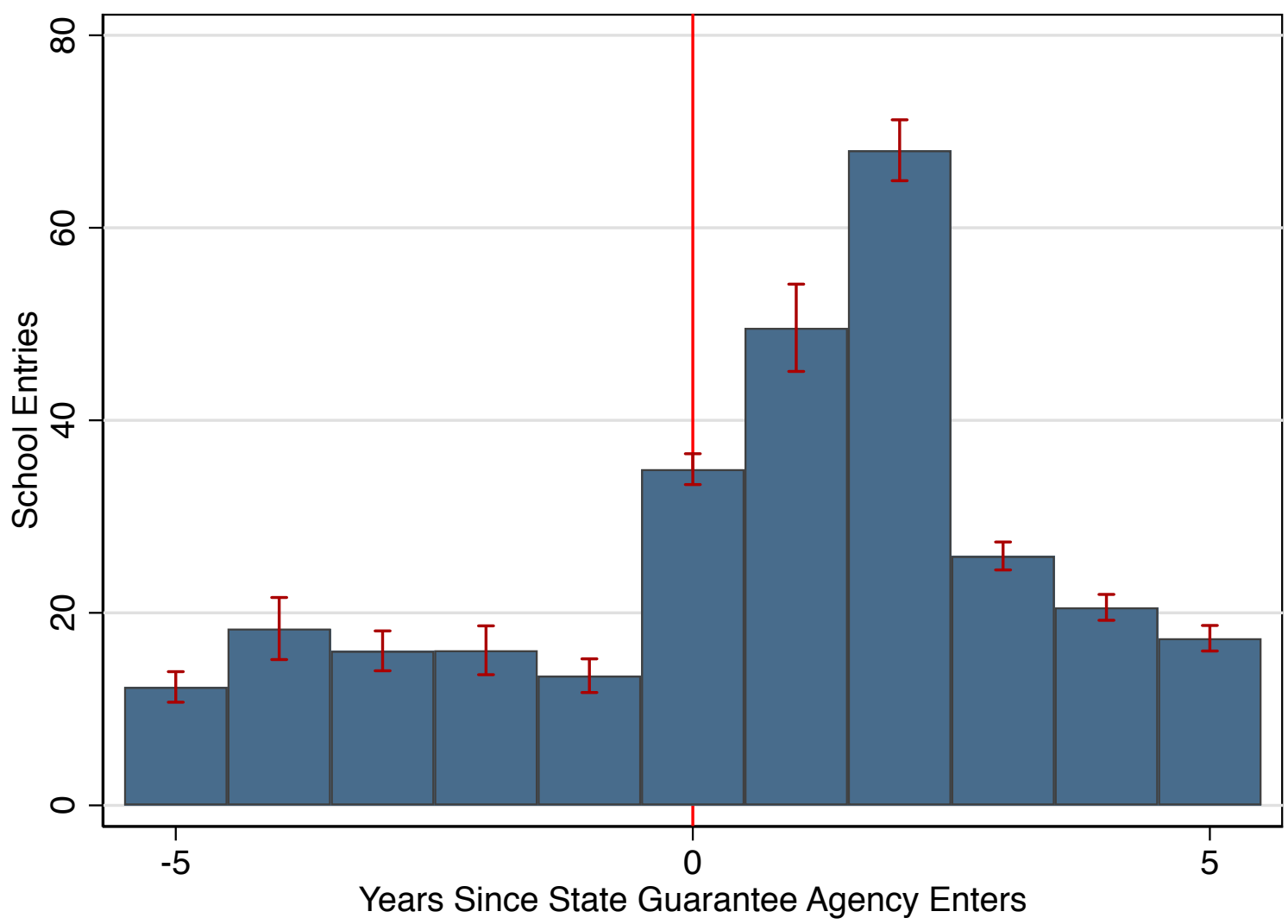




\section{Figure 10: School Entry and Exit by Default Rates}

Notes: The left panel shows the fraction of schools entering federal student loan participation by their two-year cohort default rate two years after entry. The right panel provides the corresponding fraction of schools exiting each year, by the default rate two years prior to exit. Source: NSLDS.
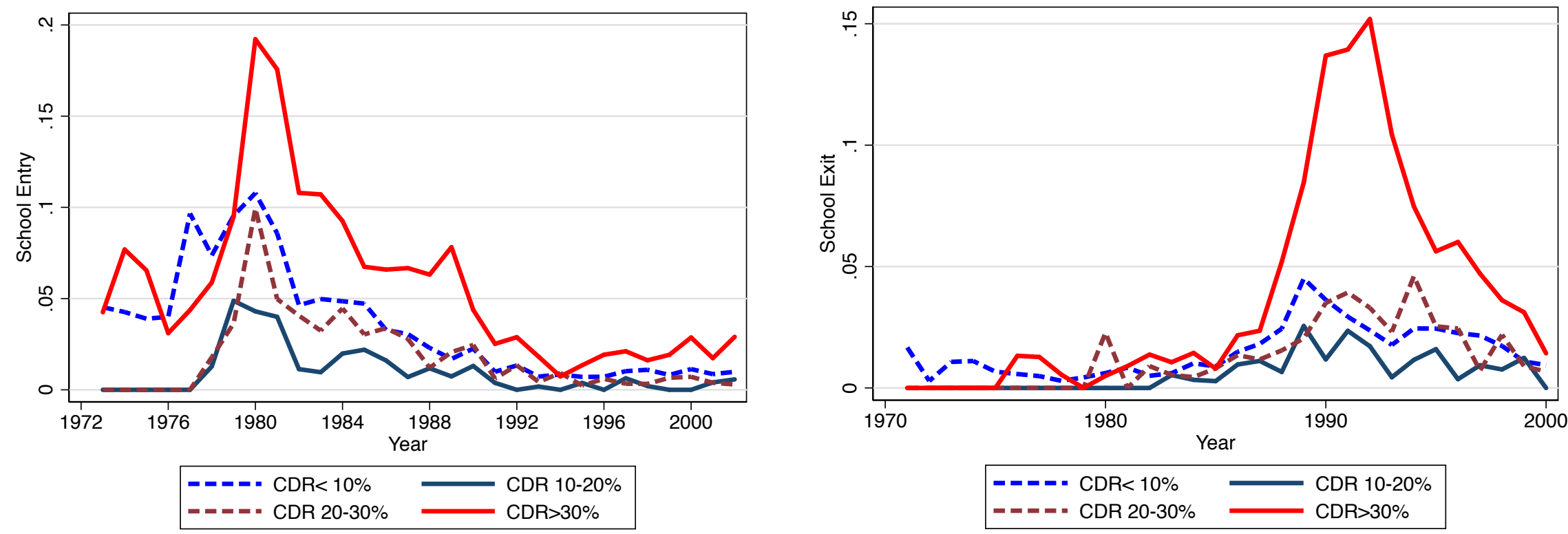


\section{Figure 11: CDR Threshold and School Exit and Closure Over Time}

Notes: This figure shows the coefficients $\beta_{t}$ from the specification $E_{s t}=\alpha_{s}+\alpha_{t}+\sum_{t=1971}^{2000} \beta_{t} \mathbb{1}\left[C D R_{s t}>\bar{D}\right] \times \mathbb{1}[Y e a r=t]+\varepsilon_{s t}$. The thick line shows point estimates, while the dashed lines show a $95 \%$ confidence interval. Standard errors are clustered at the institution level. The regression estimates the probability an institution exits the loan program each year as a function of whether the institution's two year lagged CDR is above the policy threshold, an indicator of the year, and the time-varying treatment effect: the interaction of the terms. The solid vertical line shows 1988, when CDR thresholds were introduced. Source: NSLDS.

School Exit

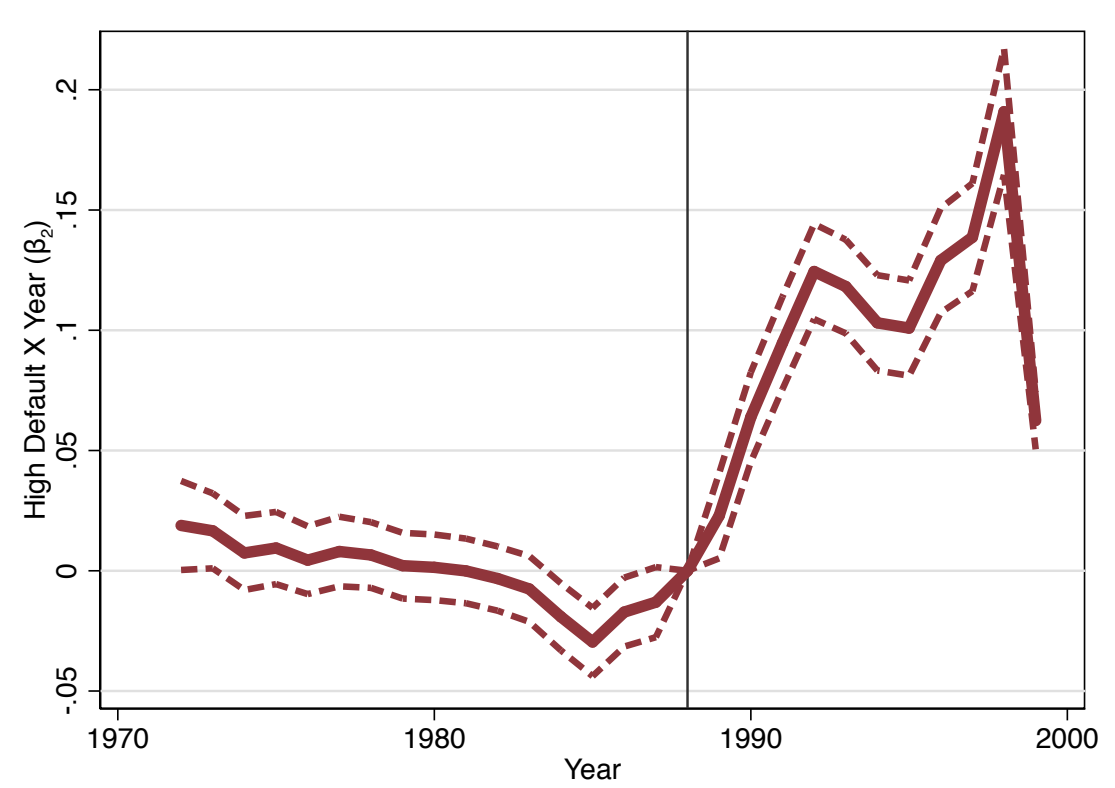

School Closure

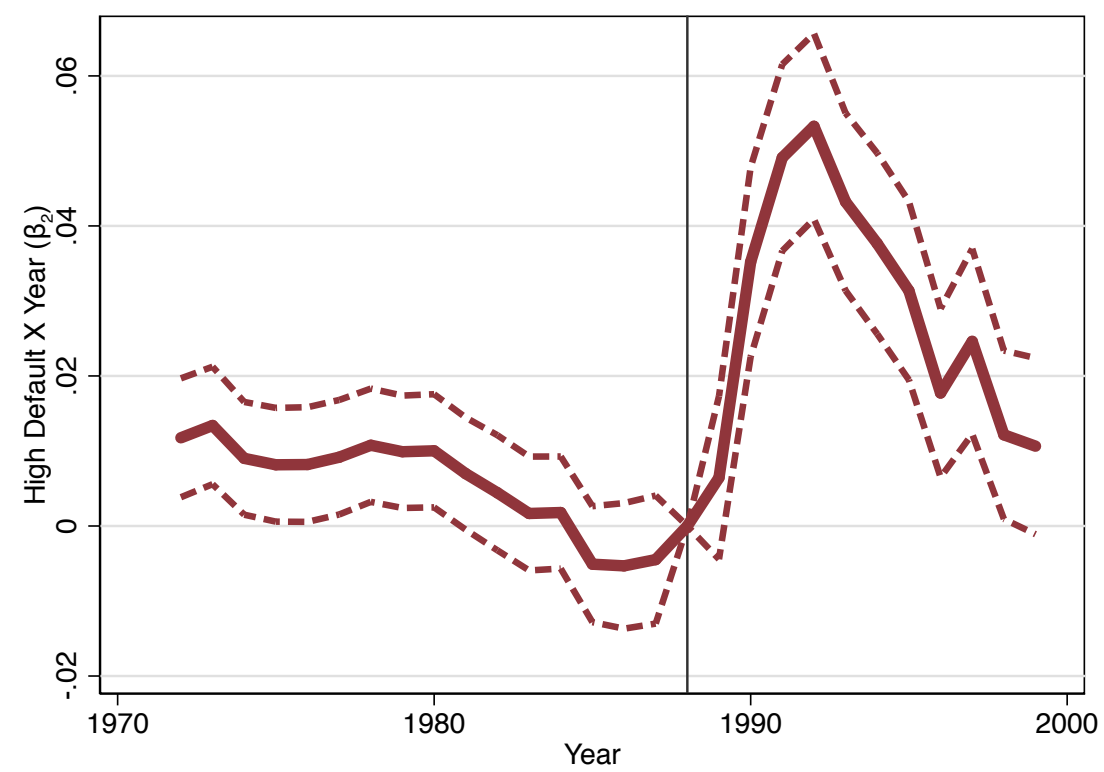


Figure 12: Fraction of Schools Exiting by Default Rate

Notes: This figure illustrates the probability of an institution exiting federal student loan participation by its two-year cohort default rate in the prior year. Years are listed above each panel. The figure illustrates that the probability an institution exits rises after the introduction of CDR rules specifically for institutions with CDRs in excess of the $30 \%$ statutory threshold. Source: NSLDS.

1984

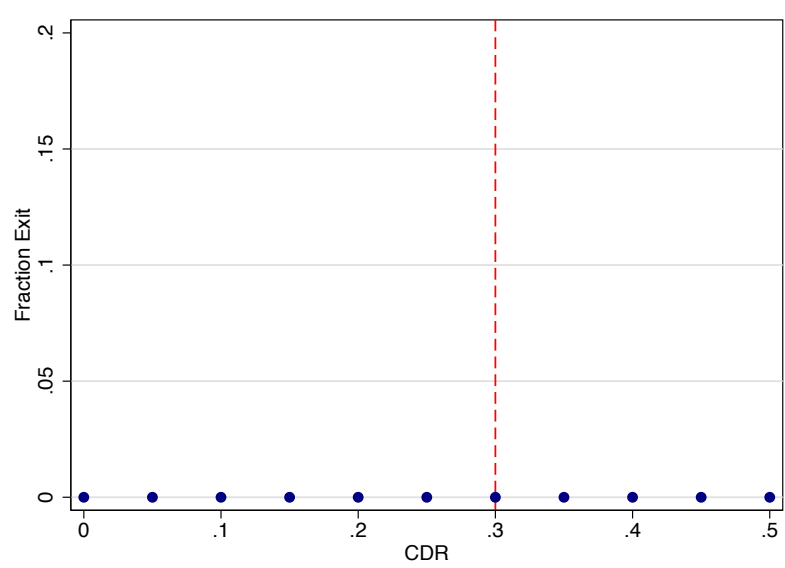

1988

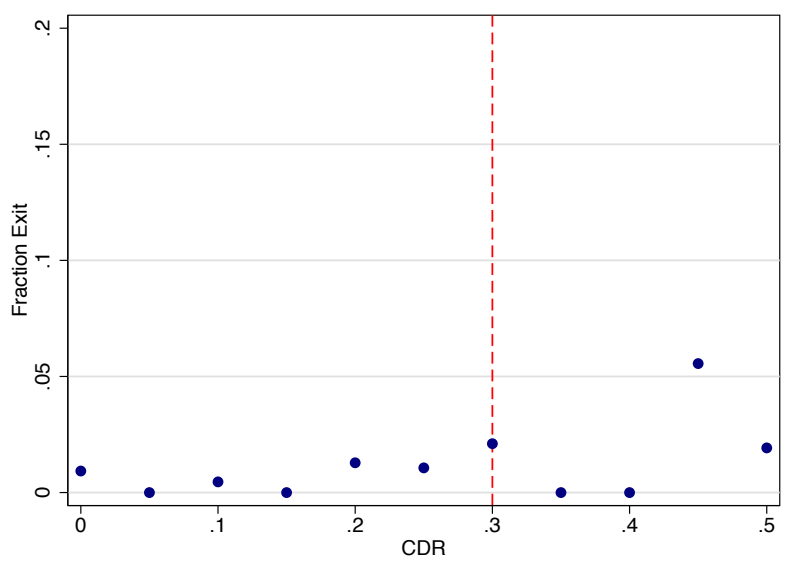

1992

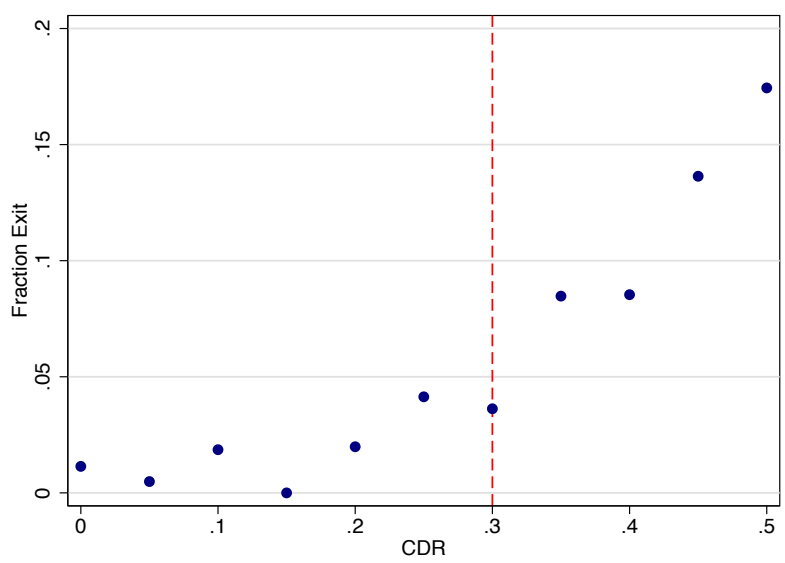

1986

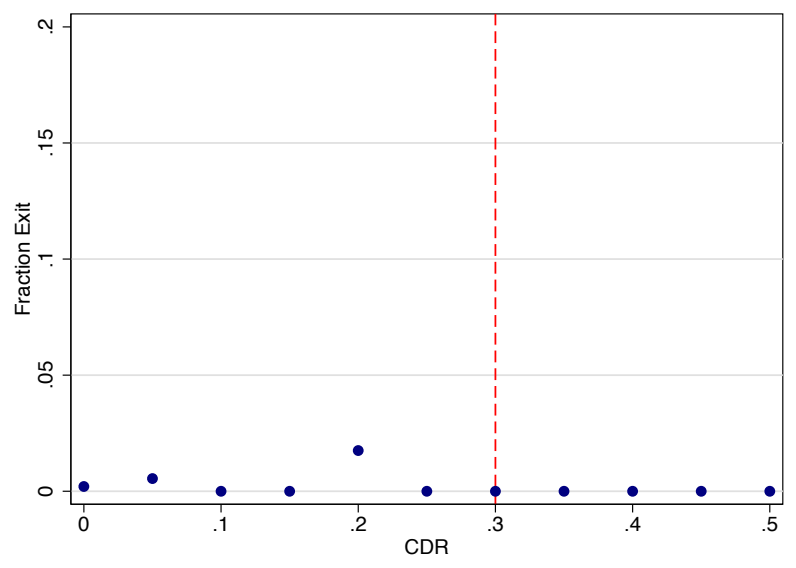

1990

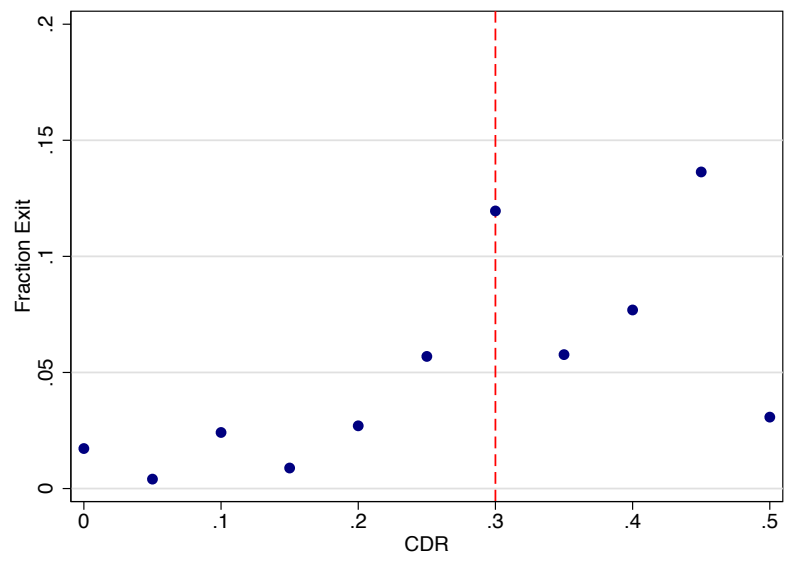

1994

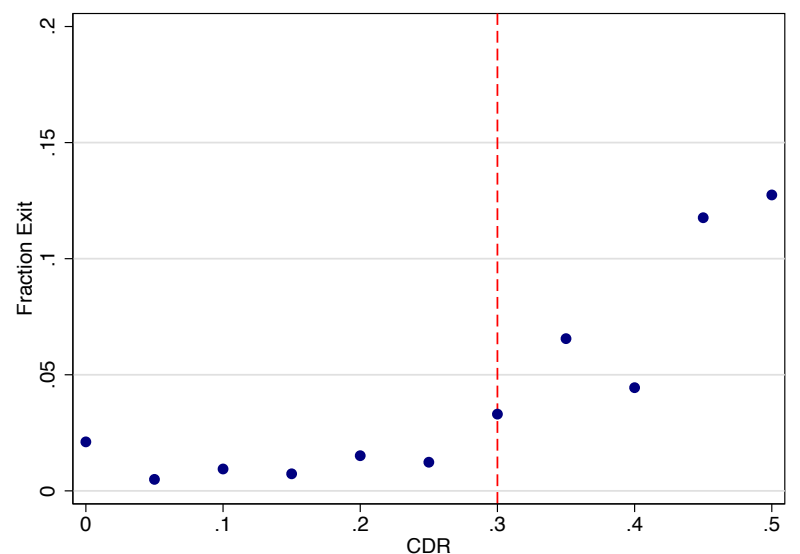




\section{Figure 13: New Defaults by Online and For-Profit Schools}

Notes: This figure shows new defaults by online and for-profit status. The top left panel shows new defaults by the share of students enrolled in online courses in 2012. The top right panel shows new defaults by online and for-profit institutions. The bottom panel shows new defaults by the share of students enrolled in online courses in 2012, restricting the sample to for-profit schools. Online schools are defined as schools where more than $60 \%$ of students are enrolled in distance education in 2012. Source: NSLDS. Defaults by Share Online

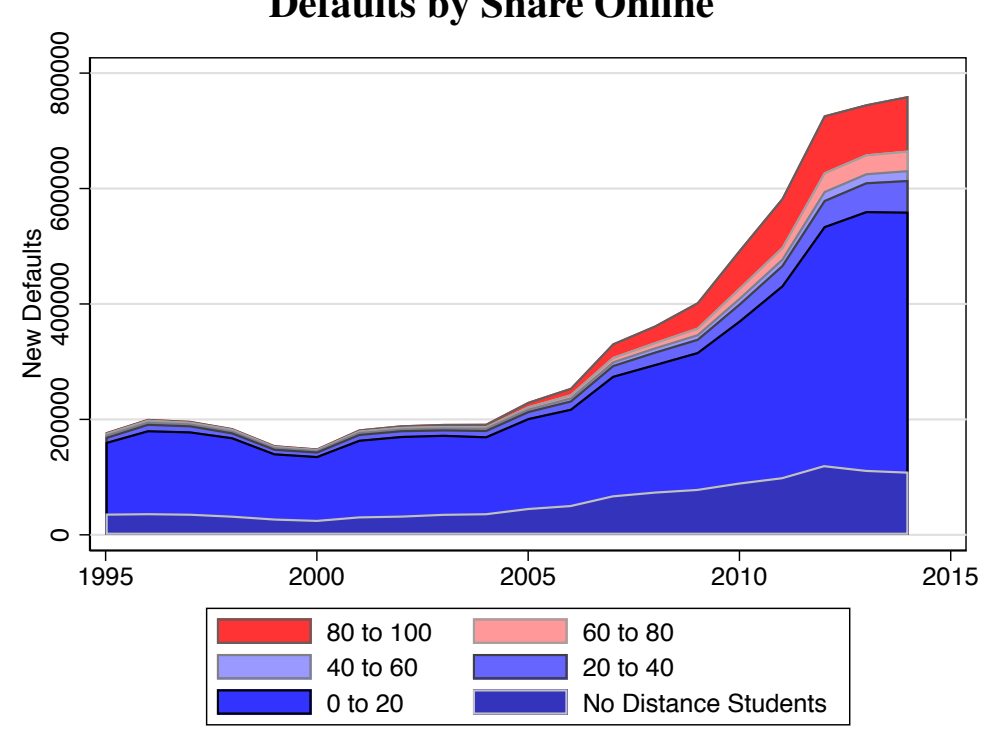

Defaults by For-Profit and Online

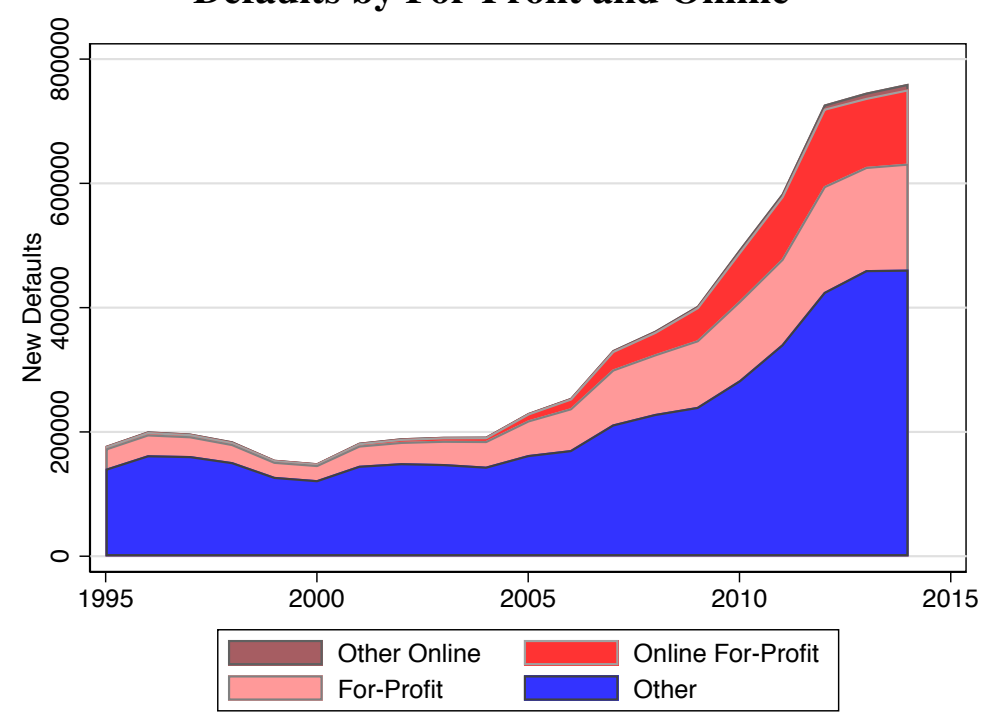

For-Profit Defaults by Share Online

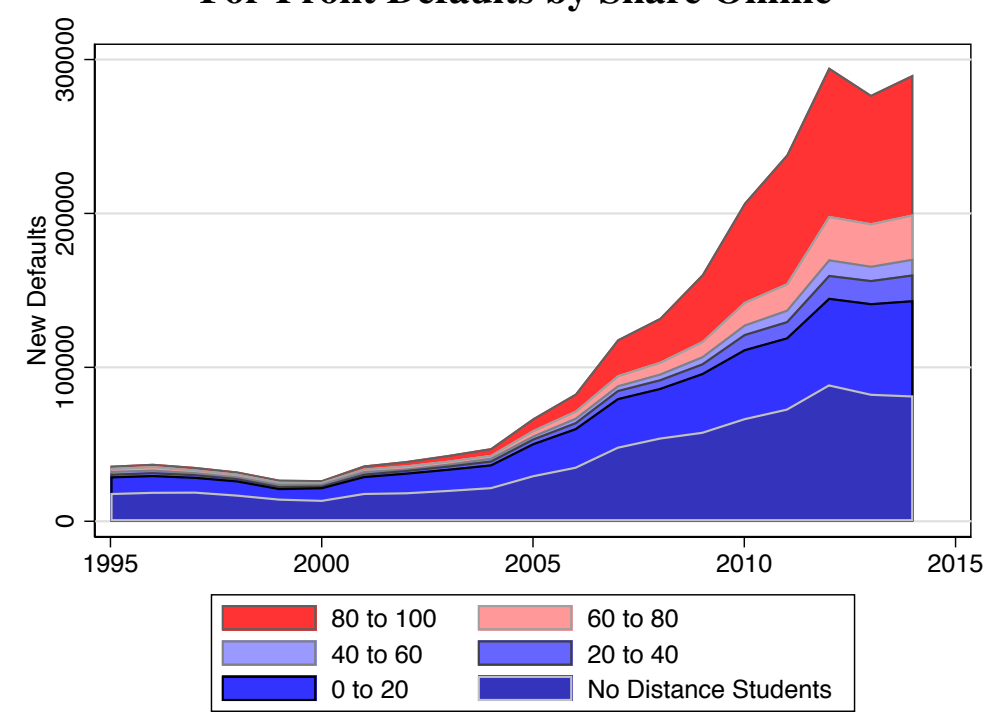


Figure 14: Defaults at Schools Near 90/10 Threshold

Notes: This figure shows the share of for-profit new defaults from schools receiving more than $85 \%$ of revenue from Title IV programs. Source: National Student Loan Data System (NSLDS) and Department of Education Proprietary School 90/10 Revenue Percentages..

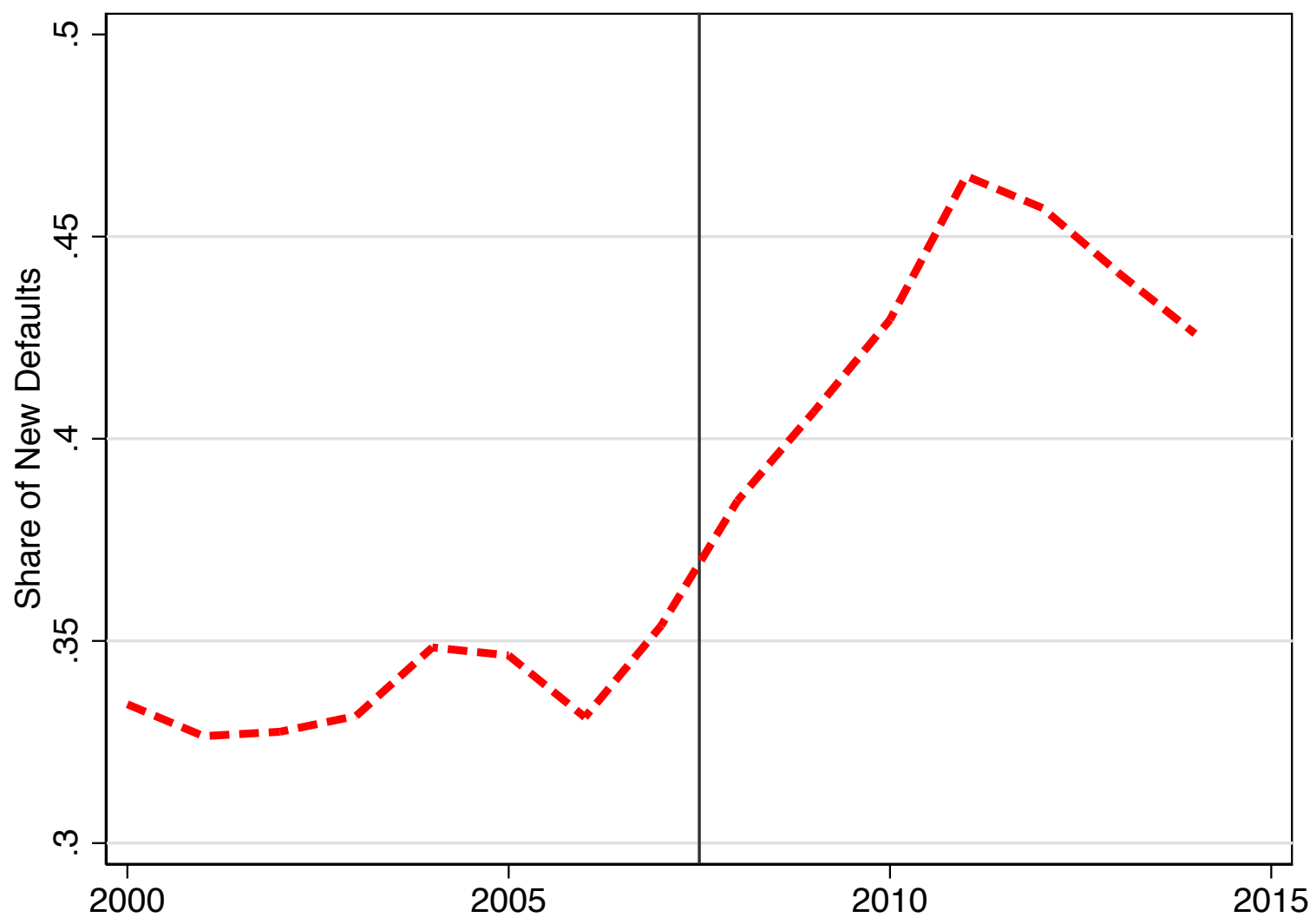




\section{Figure 15: High Title IV Share Enrollment and Default Over Time}

Notes: This figure shows the coefficients $\beta_{t}$ from the specification $E_{s t}=\alpha_{s}+\alpha_{t}+\sum_{t=2000}^{2014} \beta_{t} \mathbb{1}\left[\right.$ HighTitleIV] $\times \mathbb{1}[$ Year $=t]+\varepsilon_{s t}$. The outcome of interest is the log number of new federal borrowers and the log number of new defaults, and the treatment is an indicator of a school ever offering online education interacted with a year indicator. The thick line shows point estimates, while the dashed lines show a 95\% confidence interval. The vertical line shows the the year in between the previous year and the year of the introduction of the Post 9/11 GI Bill. Standard errors are clustered at the school level. Source: NSLDS and Department of Education Proprietary School 90/10 Revenue Percentages.

\section{Enrollment Share}

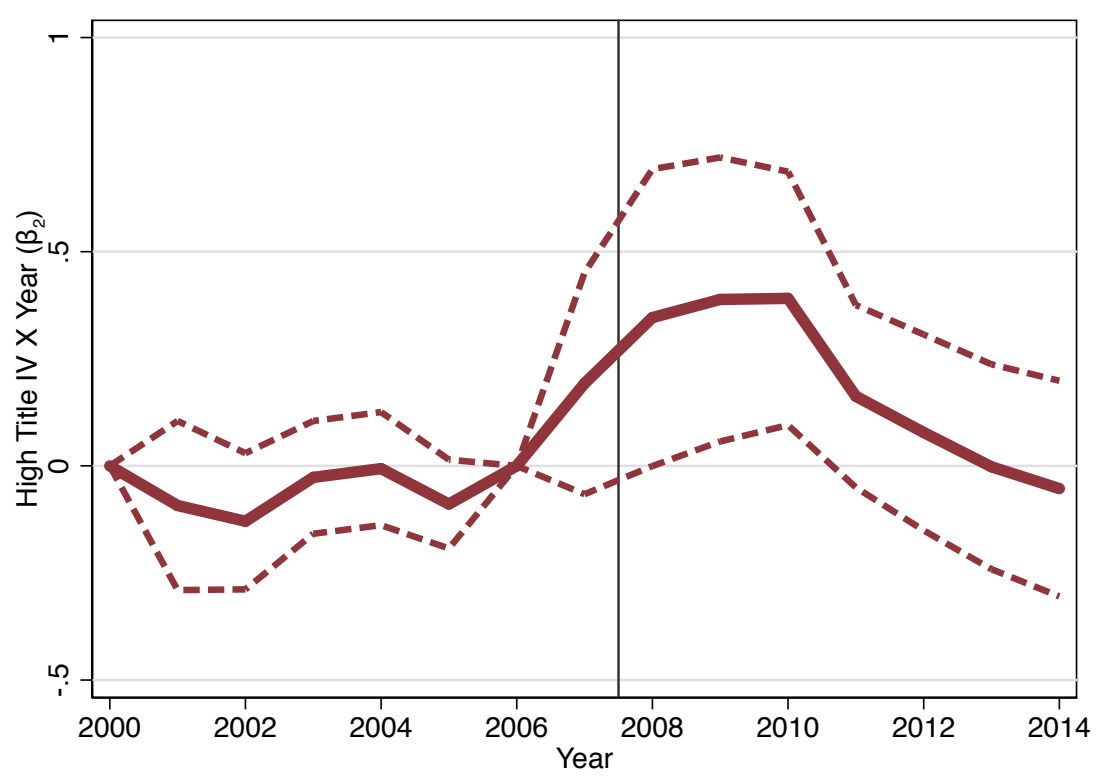

\section{New Default Share}

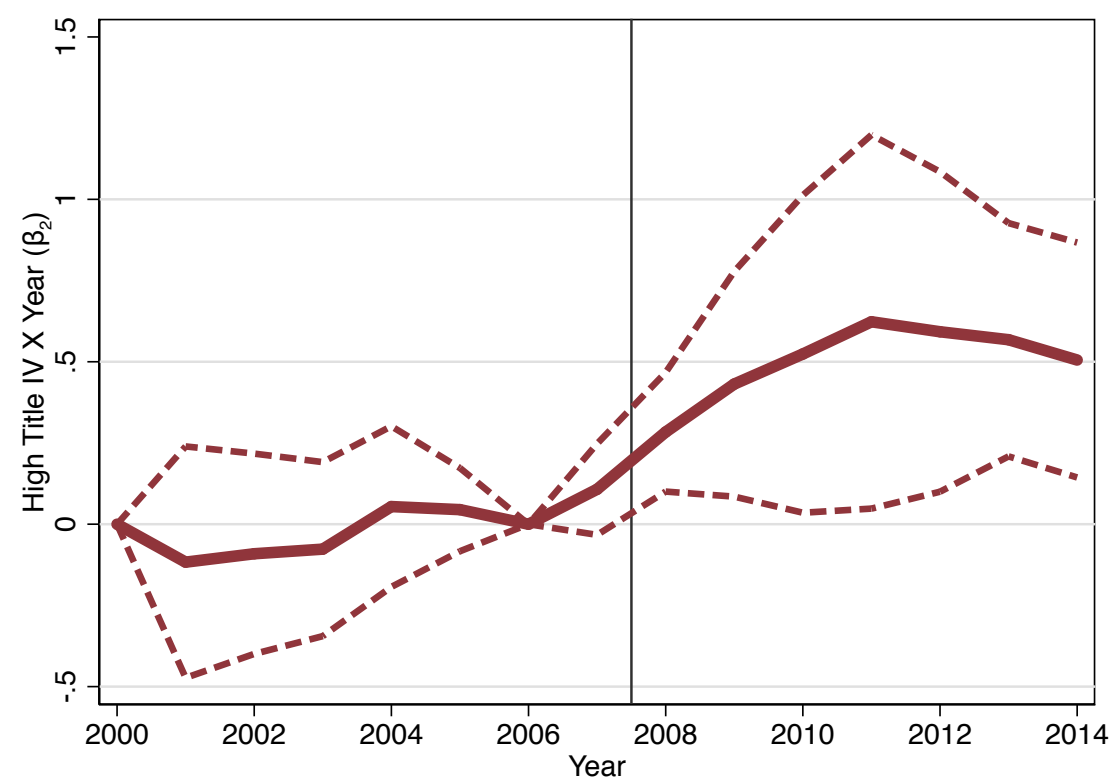


Table 1: Time Series Regressions of Cohort Default Rate and Lagged For-Profit Share

This table shows time series regressions between 1972 and 2012. The outcome in each specification is the two or three year cohort default rate, which is noted above each set of specifications. The $R^{2}$ is denoted beneath each specification. Note that including the lagged share of for-profit borrowers explains the majority of the variation in the time series. Source: NSLDS. ${ }^{*} p<.1, * * p<.05, * * * p<.01$.

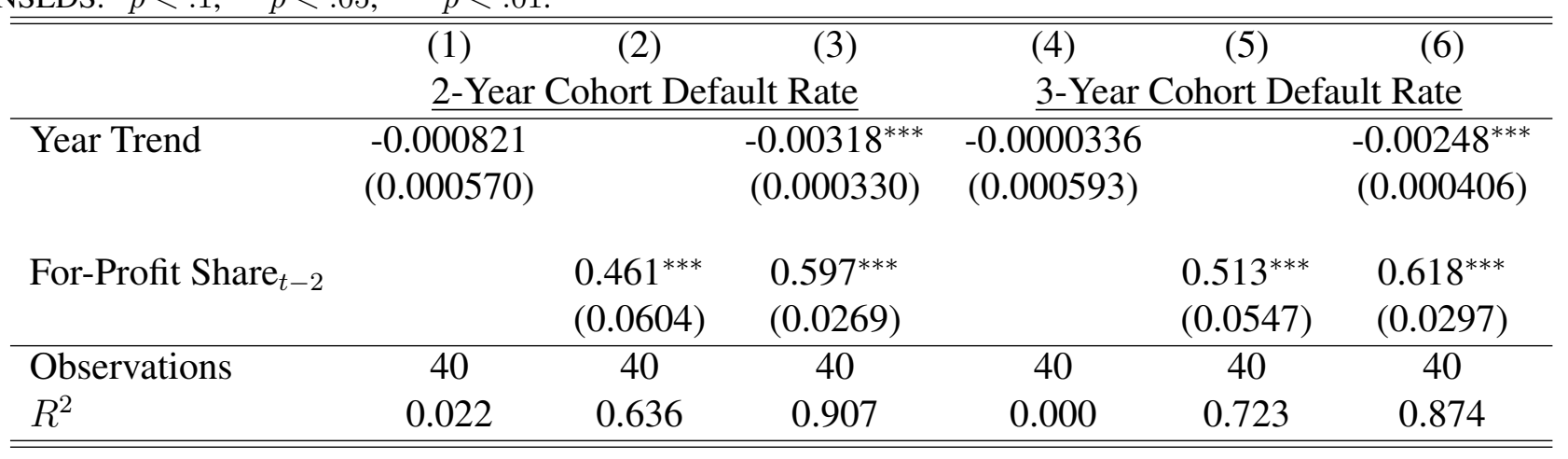




\section{Table 2: Timeline of Student Loan Credit Expansion and Contraction}

This table describes key events related to the supply of credit. The first column lists the event, the second column lists the date, and the third column describes the event. Sources : Gladieux (1995), US Senate (1991) and Deming et al. (2015).

\begin{tabular}{|c|c|c|}
\hline Event & Date & Description \\
\hline National Defense Education Act & 1958 & $\begin{array}{l}\text { Establishes targeted Federal Student Loan Programs in response to So- } \\
\text { viet launch of Sputnik. }\end{array}$ \\
\hline Higher Education Act & 1965 & Establishes modern federal student loan programs. \\
\hline $\begin{array}{l}\text { Reauthorization of } \\
\text { Higher Education Act }\end{array}$ & 1972 & $\begin{array}{l}\text { Loan programs expanded and formulas adopted. For-profit schools gain } \\
\text { eligibility to participate. }\end{array}$ \\
\hline
\end{tabular}

\begin{tabular}{|c|c|c|}
\hline $\begin{array}{l}\text { Reauthorization of } \\
\text { Higher Education Act }\end{array}$ & 1976 & $\begin{array}{l}\text { States provided with incentives to guarantee loans. Students without } \\
\text { high school degrees made eligible for loans. Loan limits increased. }\end{array}$ \\
\hline
\end{tabular}

\begin{tabular}{|c|c|c|}
\hline $\begin{array}{l}\text { Middle Income Student } \\
\text { Assistance Act }\end{array}$ & 1978 & $\begin{array}{l}\text { Eliminated income restrictions on student loans, expanding eligibility to } \\
\text { higher-income students. }\end{array}$ \\
\hline $\begin{array}{l}\text { Higher Education Act } \\
\text { Amendments }\end{array}$ & 1979 & $\begin{array}{l}\text { Banks guaranteed favorable rate of return by tying subsidies to Treasury } \\
\text { bill rates, increases bank participation in student lending. }\end{array}$ \\
\hline $\begin{array}{l}\text { Reauthorization of } \\
\text { Higher Education Act }\end{array}$ & 1980 & $\begin{array}{l}\text { Rules regarding need-based aid liberalized, supplemental borrowing op- } \\
\text { portunities for graduate students expanded. Parent loans for undergrad- } \\
\text { uate students (PLUS) program established. }\end{array}$ \\
\hline
\end{tabular}

Higher Education Act 1986

Amendments

Loan limits increased (amounts vary by class status). Created Supplemental Loan to Students (SLS) to provide loans to graduate students and independent undergraduate students. Gave institutional financial aid officers broader authority over eligibility determination.

\author{
Budget Reconciliation \\ Act, Higher Education \\ Act Amendments \\ Higher Education Act \\ Reauthorization
}

1989-93 Introduction of sanctions on schools with cohort default rates above $30 \%$, in 1992 raised to $35 \%$ and then lowered to $30 \%$.

1992 Schools required to offer more than $50 \%$ of their courses in traditional classrooms. Eliminated PLUS loan limits. Added unsubsidized loans. Simplified aid application.

Higher Education Act
Amendments

Amendments

\author{
Higher Education Recon- \\ ciliation Act
}

Higher Education Act Amendments

Post - 9/11 Veterans Educational Assistance Act

1998
Lowered cohort default rate cutoff to $25 \%$, interest rate reductions, expanded eligibility through income protection allowances. Distance Education Demonstration Program allowed trial schools exemption from $50 \%$ rules, which allowed them to offer online only education. Changed $85 / 15$ rule to $90 / 10$. Established loan forgiveness program for teachers. Changed default definition to 270 days delinquent.

$50 \%$ rules repealed, allowing online-only schools to access federal loans. Loan Limits increased. Expands PLUS loans to graduate students. Makes private student loans non-dischargable in bankruptcy.

2008 Loan limits increased (amounts vary by class status.)

2008 Provided four academic years of educational tuition benefits and a monthly living stipend for members of the Armed Forces on active duty on or after September 11, 2001. 
Table 3: Effect of Guarantee Agencies on School Entry

This table shows the effect of the introduction of state guarantee on school entry agencies between 1970 and 1990 . The first four columns show regression estimates of the number of entering schools on an indicator of whether a state has a guarantee agency. The second four columns show regression estimates of indicators of the years before and after a guarantee agency enters a state. Standard errors are clustered at the state level. Washington DC is included as a separate state. Source: NSLDS. $* p \leq .1, * * p<.05, * * * p<.01$.

\begin{tabular}{|c|c|c|c|c|c|c|c|c|}
\hline & (1) & (2) & (3) & (4) & (5) & (6) & (7) & (8) \\
\hline Has GA & $\begin{array}{c}7.842^{* * *} \\
(1.531)\end{array}$ & $\begin{array}{c}6.971^{* * *} \\
(1.497)\end{array}$ & $\begin{array}{c}6.380^{* * *} \\
(2.155)\end{array}$ & $\begin{array}{c}3.885^{* * *} \\
(1.431)\end{array}$ & & & & \\
\hline Year & $\begin{array}{c}-0.436^{* * *} \\
(0.114)\end{array}$ & & & & $\begin{array}{c}-0.0582 \\
(0.102)\end{array}$ & & & \\
\hline $\mathrm{T}-5$ & & & & & $\begin{array}{c}-0.657 \\
(1.495)\end{array}$ & $\begin{array}{c}0.868 \\
(1.495)\end{array}$ & $\begin{array}{l}-1.877 \\
(1.464)\end{array}$ & $\begin{array}{c}-1.318 \\
(1.026)\end{array}$ \\
\hline $\mathrm{T}-4$ & & & & & $\begin{array}{l}-1.325 \\
(1.767)\end{array}$ & $\begin{array}{c}0.940 \\
(2.071)\end{array}$ & $\begin{array}{l}-1.762 \\
(1.523)\end{array}$ & $\begin{array}{c}-1.744^{*} \\
(0.992)\end{array}$ \\
\hline $\mathrm{T}-3$ & & & & & $\begin{array}{l}-0.635 \\
(1.590)\end{array}$ & $\begin{array}{c}-0.385 \\
(1.730)\end{array}$ & $\begin{array}{l}-1.658 \\
(1.310)\end{array}$ & $\begin{array}{c}-1.161 \\
(0.791)\end{array}$ \\
\hline $\mathrm{T}-2$ & & & & & $\begin{array}{l}-0.644 \\
(1.432)\end{array}$ & $\begin{array}{c}0.431 \\
(1.749)\end{array}$ & $\begin{array}{l}-1.105 \\
(1.323)\end{array}$ & $\begin{array}{c}-1.130 \\
(0.778)\end{array}$ \\
\hline $\mathrm{T}-1$ & & & & & $\begin{array}{c}0.316 \\
(1.288)\end{array}$ & $\begin{array}{c}0.747 \\
(1.555)\end{array}$ & $\begin{array}{l}-0.209 \\
(1.395)\end{array}$ & $\begin{array}{c}-0.340 \\
(0.889)\end{array}$ \\
\hline GA Enters & & & & & $\begin{array}{c}13.35^{* * *} \\
(3.638)\end{array}$ & $\begin{array}{c}13.48^{* * *} \\
(3.641)\end{array}$ & $\begin{array}{c}13.07^{* * *} \\
(3.364)\end{array}$ & $\begin{array}{c}9.059^{* * *} \\
(2.421)\end{array}$ \\
\hline $\mathrm{T}+1$ & & & & & $\begin{array}{l}13.83^{* *} \\
(5.493)\end{array}$ & $\begin{array}{l}12.75^{* *} \\
(5.211)\end{array}$ & $\begin{array}{c}11.53^{* * *} \\
(4.263)\end{array}$ & $\begin{array}{c}8.203^{* * *} \\
(2.828)\end{array}$ \\
\hline $\mathrm{T}+2$ & & & & & $\begin{array}{c}21.58^{* * *} \\
(4.610)\end{array}$ & $\begin{array}{c}13.97^{* * *} \\
(3.906)\end{array}$ & $\begin{array}{c}12.67^{* * *} \\
(3.958)\end{array}$ & $\begin{array}{l}4.389^{* *} \\
(1.923)\end{array}$ \\
\hline $\mathrm{T}+3$ & & & & & $\begin{array}{c}6.532^{* * *} \\
(1.720)\end{array}$ & $\begin{array}{c}6.850^{* * *} \\
(1.894)\end{array}$ & $\begin{array}{c}5.104^{* * *} \\
(1.745)\end{array}$ & $\begin{array}{c}4.119^{* * *} \\
(1.377)\end{array}$ \\
\hline $\mathrm{T}+4$ & & & & & $\begin{array}{l}3.431^{* *} \\
(1.358)\end{array}$ & $\begin{array}{c}4.572^{* * *} \\
(1.472)\end{array}$ & $\begin{array}{l}3.057^{* *} \\
(1.325)\end{array}$ & $\begin{array}{l}2.393^{* *} \\
(1.038)\end{array}$ \\
\hline $\mathrm{T}+5$ & & & & & $\begin{array}{c}2.669^{* *} \\
(1.259)\end{array}$ & $\begin{array}{c}4.328^{* * *} \\
(1.260)\end{array}$ & $\begin{array}{l}2.024^{*} \\
(1.021)\end{array}$ & $\begin{array}{c}1.512^{*} \\
(0.843)\end{array}$ \\
\hline Year Effects & & $\checkmark$ & $\checkmark$ & $\checkmark$ & & $\checkmark$ & $\checkmark$ & $\checkmark$ \\
\hline State Effects & & & $\checkmark$ & $\checkmark$ & & & $\checkmark$ & $\checkmark$ \\
\hline Controls & & & & $\checkmark$ & & & & $\checkmark$ \\
\hline Observations & 1,071 & 1,071 & 1,071 & 1,071 & 1,071 & 1,071 & 1,071 & 1,071 \\
\hline
\end{tabular}




\section{Table 4: Effect of CDR Threshold on School Exit}

This table shows the effect of the application of the cohort default rate (CDR) rule taking effect in 1988, which prohibited institutions with CDRs in excess of 30 percent for three years from receiving federal loans. The regression estimates the probability an institution exits the loan program each year as a function of whether the institution's two year lagged CDR is above the 30 percent threshold, an indicator of the year being post 1988 when CDR rules are in effect, and the treatment effect: the interaction of the two terms. The sample is restricted to years prior to 2000. Standard errors are clustered at the school level. Source: NSLDS. $* p<.1, * * p<.05, * * * p<.01$.

\begin{tabular}{lcccccc}
\hline \hline & $(1)$ & $(2)$ & $(3)$ & $(4)$ & $(5)$ & $(6)$ \\
\hline Above Threshold X Post 1988 & $0.0342^{* * *}$ & $0.0721^{* * *}$ & $0.0700^{* * *}$ & $0.0976^{* * *}$ & $0.112^{* * *}$ & $0.0927^{* * *}$ \\
& $(0.00311)$ & $(0.00277)$ & $(0.00276)$ & $(0.00296)$ & $(0.00742)$ & $(0.00301)$
\end{tabular}

\section{Post 1988}

$$
\begin{gathered}
0.108^{* * *} \\
(0.00119)
\end{gathered}
$$

\begin{tabular}{lcccccc} 
Above Threshold & $0.0231^{* * *}$ & $0.0278^{* * *}$ & $0.0197^{* * *}$ & $-0.0447^{* * *}$ & $-0.0680^{* * *}$ & $-0.0428^{* * *}$ \\
& $(0.00118)$ & $(0.00128)$ & $(0.00136)$ & $(0.00156)$ & $(0.00597)$ & $(0.00160)$ \\
\hline Year Fixed Effects & & $\checkmark$ & $\checkmark$ & $\checkmark$ & $\checkmark$ & $\checkmark$ \\
School Type & & & $\checkmark$ & & & \\
School Fixed Effects & & & & $\checkmark$ & $\checkmark$ & $\checkmark$ \\
$\begin{array}{l}\text { Weighted } \\
\text { Controls }\end{array}$ & & & & & $\checkmark$ & $\checkmark$ \\
\hline Observations & 111,606 & 111,606 & 111,606 & 111,606 & 111,606 & 111,606 \\
\hline \hline
\end{tabular}




\section{Table 5: Effect of CDR Threshold on School Closure}

The top panel of this table examines the application of the cohort default rate (CDR) rule taking effect in 1988, which prohibited institutions with CDRs in excess of 30 percent for three years from receiving federal loans. The regression estimates the probability an institution closes each year as a function of whether the institution's two year lagged CDR is above the 30 percent threshold, an indicator of the year being post 1988 when CDR rules are in effect, and the treatment effect: the interaction of the two terms. The sample is restricted to years prior to 2000. Standard errors are clustered at the school level. Source: NSLDS. ${ }^{*} p<.1,{ }^{* *} p<.05, * * * p<.01$.

\begin{tabular}{ccccccc}
\hline & $(1)$ & $(2)$ & $(3)$ & $(4)$ & $(5)$ & $(6)$ \\
\hline Above Threshold X Post 1988 & $0.0223^{* * *}$ & $0.0196^{* * *}$ & $0.0185^{* * *}$ & $0.0265^{* * *}$ & $0.0868^{* * *}$ & $0.0346^{* * *}$ \\
& $(0.00171)$ & $(0.00163)$ & $(0.00161)$ & $(0.00189)$ & $(0.0127)$ & $(0.00240)$
\end{tabular}

Post 1988

$0.0143^{* * *}$

$(0.000957)$

\begin{tabular}{lcccccc} 
Above Threshold & 0.000368 & $0.00190^{* * *}$ & $-0.00374^{* * *}$ & $-0.0111^{* * *}$ & $-0.0509^{* * *}$ & $-0.0167^{* * *}$ \\
& $(0.000434)$ & $(0.000485)$ & $(0.000561)$ & $(0.000941)$ & $(0.00883)$ & $(0.00121)$ \\
\hline Year Fixed Effects & & $\checkmark$ & $\checkmark$ & $\checkmark$ & $\checkmark$ & $\checkmark$ \\
$\begin{array}{l}\text { School Type } \\
\text { School Fixed Effects }\end{array}$ & & $\checkmark$ & & & \\
$\begin{array}{l}\text { Weighted } \\
\text { Controls }\end{array}$ & & & & $\checkmark$ & $\checkmark$ \\
\hline Observations & & & & & $\checkmark$ & $\checkmark$ \\
\hline \hline
\end{tabular}




\section{Table 6: Effect of Online Credit Expansion on Borrowing and Default}

The tables shows the effect of the elimination of the requirement that no more than 50 percent of students be distance or online students after 2006. The outcome of interest is the log number of new federal borrowers or the log number of new defaults, and the treatment is an indicator of a school ever offering online education interacted with a post-2006 indicator. Standard errors are clustered at the school level. Source: NSLDS. ${ }^{*} p<.1, * * p<.05, * * * p<.01$.

\begin{tabular}{lccc}
\hline \hline & $(1)$ & $(2)$ & $(3)$ \\
\hline \multirow{2}{*}{ Panel A: } & & & \multicolumn{1}{c}{$\operatorname{Ln}($ Enro } \\
Online X Post 2006 & $0.425^{* * *}$ & $0.480^{* * *}$ & $0.457^{* * *}$ \\
& $(0.134)$ & $(0.134)$ & $(0.137)$ \\
& & & \\
Post 2006 & $0.360^{* * *}$ & & \\
& $(0.0119)$ & & \\
Online & & & \\
& -0.0735 & -0.126 & -0.0245 \\
& $(0.133)$ & $(0.136)$ & $(0.153)$
\end{tabular}

Panel B:

Ln(Default)

$\begin{array}{ccccccc}\text { Online X Post } 2006 & 0.419^{* * *} & 0.446^{* * *} & 0.443^{* * *} & 0.623^{* * *} & 0.977^{* * *} & 0.658^{* * *} \\ & (0.121) & (0.122) & (0.122) & (0.135) & (0.151) & (0.133)\end{array}$

Post 2006

$0.526^{* * *}$

(0.00961)

\begin{tabular}{lcccccc} 
Online & 0.00732 & -0.0253 & -0.0145 & & & \\
& $(0.0697)$ & $(0.0719)$ & $(0.0733)$ & & & \\
\hline Year Fixed Effects & & $\checkmark$ & $\checkmark$ & $\checkmark$ & $\checkmark$ & $\checkmark$ \\
School Type & & $\checkmark$ & & & \\
School Fixed Effects & & & & $\checkmark$ & $\checkmark$ \\
Weighted & & & & $\checkmark$ & \\
Controls & & & & & & $\checkmark$ \\
\hline Observations & 137,103 & 137,103 & 137,103 & 137,103 & 137,103 & 137,103 \\
\hline \hline
\end{tabular}




\section{Table 7: Effect of Post 9/11 G.I. Bill on Borrowing and Default}

The tables shows the effect of the Post-9/11 GI bill on enrollment and default. The outcome of interest is the log number of new federal borrowers or the log number of new defaults, and the treatment is an indicator of whether a school receives more than $85 \%$ of revenue from Title IV programs interacted with a post-2008 indicator. The sample is restricted to forprofit schools, for which 90/10 Revenue Percentages are available. Standard errors are clustered at the school level. Source: NSLDS and Department of Education Proprietary School 90/10 Revenue Percentages. ${ }^{*} p<.1, * * p<.05$, *** $p<.01$.

(1)

(2)
(4)

(5)

(6)

\section{Panel A:}

Title IV > 85\% X Post 2008

Title IV $>85 \%$

\section{Ln(Enrollment $)$}

$-0.0432^{*}$

(0.0227)

$0.364^{* * *}$

$0.364^{* * *} \quad 0.362^{* * *}$
$0.149^{* * *}$
$0.142^{* * *}$
$0.107^{* *}$
$0.190^{*}$
$0.0890^{* *}$
(0.0482)
(0.0483) (0.0482)
$(0.0461)$
$(0.0916)$
(0.0439)

Panel B:

Above Threshold X Post 2008

$\begin{array}{lll}(0.0722) & (0.0723) & (0.0720)\end{array}$ 
Table 8: Entry and Exit Decomposition

This table shows total enrolled borrowers and new defaults in 1980, 1990 and 2000, broken down by schools that enter and exit the sample. The top panel shows the total number of enrolled borrowers. The bottom panel shows the total number of new defaults. In each panel, the top rows break down the sample by whether a school enters the sample prior to 2014 . The bottom rows break down the sample between schools that exit the sample prior to 2014 and those that survive conditional on entry. The first row shows the total number of enrolled borrowers and defaults, respectively. The second and third rows show the number of borrowers and defaults in each group, the subsequent rows break down the sample into time periods of school entry and exit. Alternating columns show counts and shares. Source: National Student Loan Data System (NSLDS).

\begin{tabular}{|c|c|c|c|c|c|c|}
\hline & \multicolumn{2}{|c|}{1980} & \multicolumn{2}{|c|}{1990} & \multicolumn{2}{|c|}{2000} \\
\hline & Level & Share & Level & Share & Level & Share \\
\hline Panel A & \multicolumn{6}{|c|}{ Enrolled Borrowers } \\
\hline Total & $2,280,650$ & & $6,219,950$ & & $11,133,275$ & \\
\hline Schools in Sample & $1,722,775$ & 0.76 & $3,269,100$ & 0.53 & $6,550,275$ & 0.59 \\
\hline Schools that Enter & 557,875 & 0.24 & $2,950,850$ & 0.47 & $4,583,000$ & 0.41 \\
\hline $1970-75$ & 357,725 & 0.16 & $1,103,175$ & 0.18 & $2,058,050$ & 0.18 \\
\hline $1975-80$ & 200,150 & 0.09 & 931,050 & 0.15 & $1,536,300$ & 0.14 \\
\hline $1980-85$ & & & 627,975 & 0.10 & 555,000 & 0.05 \\
\hline $1985-90$ & & & 288,650 & 0.05 & 282,075 & 0.03 \\
\hline Post 1990 & & & & & 151,575 & 0.01 \\
\hline Total & $2,280,650$ & & $6,219,950$ & & $11,133,275$ & \\
\hline Schools that Survive & $2,026,525$ & 0.89 & $4,811,950$ & 0.77 & $10,350,450$ & 0.93 \\
\hline Schools that Exit & 254,125 & 0.11 & $1,408,000$ & 0.23 & 782,825 & 0.07 \\
\hline $1980-85$ & 20,625 & 0.01 & & & & \\
\hline $1985-90$ & 48,350 & 0.02 & & & & \\
\hline $1990-95$ & 77,850 & 0.03 & 806,425 & 0.13 & & \\
\hline $1995-2000$ & 34,950 & 0.02 & 203,575 & 0.03 & & \\
\hline $2000-2014$ & 72,350 & 0.03 & 398,000 & 0.06 & 782,825 & 0.07 \\
\hline Panel B & & & New De & aults & & \\
\hline Total & 26,175 & & 463,875 & & 177,425 & \\
\hline Schools in Sample & 16,775 & 0.64 & 80,650 & 0.17 & 72,900 & 0.41 \\
\hline Schools that Enter & 9,400 & 0.36 & 383,225 & 0.83 & 104,525 & 0.59 \\
\hline $1970-75$ & 7,275 & 0.28 & 87,625 & 0.19 & 33,625 & 0.19 \\
\hline $1975-80$ & 2,125 & 0.08 & 94,200 & 0.20 & 34,300 & 0.19 \\
\hline $1980-85$ & & & 144,725 & 0.31 & 19,150 & 0.11 \\
\hline $1985-90$ & & & 56,675 & 0.12 & 11,800 & 0.07 \\
\hline Post 1990 & & & & & 5,650 & 0.03 \\
\hline Total & 26,175 & & 463,875 & & 177,425 & \\
\hline Schools that Survive & 19,975 & 0.76 & 161,425 & 0.35 & 152,825 & 0.86 \\
\hline Schools that Exit & 6,200 & 0.24 & 302,450 & 0.65 & 24,600 & 0.14 \\
\hline $1980-85$ & 525 & 0.02 & & & & \\
\hline $1985-90$ & 1,200 & 0.05 & & & & \\
\hline $1990-95$ & 2,775 & 0.11 & 247,975 & 0.53 & & \\
\hline $1995-2000$ & 725 & 0.03 & 21,525 & 0.05 & & \\
\hline 2000-2014 & 975 & 0.04 & 32,950 & 0.07 & 24,600 & 0.14 \\
\hline
\end{tabular}




\section{Table 9: Online Decomposition}

This table shows total enrolled borrowers and new defaults in 2000 and 2010, broken down by online and traditional offline schools. Online schools are defined as schools where more than $60 \%$ of students are enrolled in distance education in 2012. The top panel shows the total number of enrolled borrowers. The bottom panel shows the total number of new defaults. The first row shows the total number of enrolled borrowers and defaults, respectively. The second and third rows show the number of borrowers and defaults in each group. Alternating columns show counts and shares. Source: National Student Loan Data System (NSLDS).

\begin{tabular}{cccc}
\hline \hline 2000 & \multicolumn{2}{c}{2010} \\
\hline Level & Share & Level & Share \\
\hline
\end{tabular}

\section{Enrolled Borrowers}

\begin{tabular}{lcccc}
\hline Total & $11,132,700$ & & $18,515,450$ & \\
Offline Schools & $9,990,500$ & .90 & $15,707,800$ & 0.85 \\
Online Schols & $1,142,200$ & .10 & $2,807,650$ & 0.15
\end{tabular}

New Defaults

\begin{tabular}{lcccc}
\hline Total & 177,425 & & 574,000 & \\
Offline Schools & 146,925 & .83 & 410,975 & 0.72 \\
Online Schols & 30,500 & .17 & 163,025 & 0.28 \\
\hline \hline
\end{tabular}


Table 10: Title IV Revenue Share Decomposition

This table shows total enrolled borrowers and new defaults in 2000 and 2010, broken down by for-profit status and the share of all revenue coming from Title IV programs. The top panel shows the total number of enrolled borrowers. The bottom panel shows the total number of new defaults. The first row shows the total number of enrolled borrowers and defaults, respectively. The subsequent rows show the number of borrowers and defaults in each group. Alternating columns show counts and shares. Source: National Student Loan Data System (NSLDS) and Department of Education Proprietary School 90/10 Revenue Percentages.

\begin{tabular}{|c|c|c|c|c|}
\hline & \multicolumn{2}{|c|}{$\overline{2000}$} & \multicolumn{2}{|c|}{$\overline{2010}$} \\
\hline & Level & Share & Level & Share \\
\hline \multicolumn{5}{|c|}{ Enrolled Borrowers } \\
\hline Total & $11,132,700$ & & $18,515,450$ & \\
\hline Non-Profit & $9,826,725$ & .88 & $14,441,475$ & 0.77 \\
\hline$<55 \%$ Title IV & 9,325 & .00 & 160,25 & 0.00 \\
\hline 55-60\% Title IV & 30,675 & .00 & 80,250 & 0.00 \\
\hline 60-65\% Title IV & 62,100 & .00 & 124,600 & 0.01 \\
\hline 65-70\% Title IV & 111,350 & .01 & 226,775 & 0.01 \\
\hline 70-75\% Title IV & 231,100 & .02 & 516,025 & 0.03 \\
\hline 75-80\% Title IV & 203,875 & .02 & 650,575 & 0.04 \\
\hline 80-85\% Title IV & 317,075 & .03 & 922,100 & 0.05 \\
\hline$>85 \%$ Title IV & 340,475 & .03 & $1,537,625$ & 0.08 \\
\hline \multicolumn{5}{|l|}{ New Defaults } \\
\hline Total & 177,425 & & 574,000 & \\
\hline Non-Profit & 137,150 & .77 & 294,700 & 0.51 \\
\hline$<55 \%$ Title IV & 325 & .00 & 1,950 & 0.00 \\
\hline 55-60\% Title IV & 425 & .00 & 3,900 & 0.01 \\
\hline 60-65\% Title IV & 1,600 & .00 & 5,750 & 0.01 \\
\hline $65-70 \%$ Title IV & 2,675 & .01 & 11,000 & 0.02 \\
\hline 70-75\% Title IV & 6,400 & .04 & 27,925 & 0.05 \\
\hline 75-80\% Title IV & 5,150 & .03 & 38,650 & 0.07 \\
\hline $80-85 \%$ Title IV & 10,050 & .06 & 70,550 & 0.12 \\
\hline$>85 \%$ Title IV & 13,650 & .08 & 120,575 & 0.21 \\
\hline
\end{tabular}




\section{Figure A.1: Annual Change in Default Rates}

Notes: This figure shows the average change in the annual default rate. The dashed line shows the change in default for schools that ever enter the sample, and the solid line shows the change in default for schools that are consistently in the sample. Source: NSLDS and BLS.

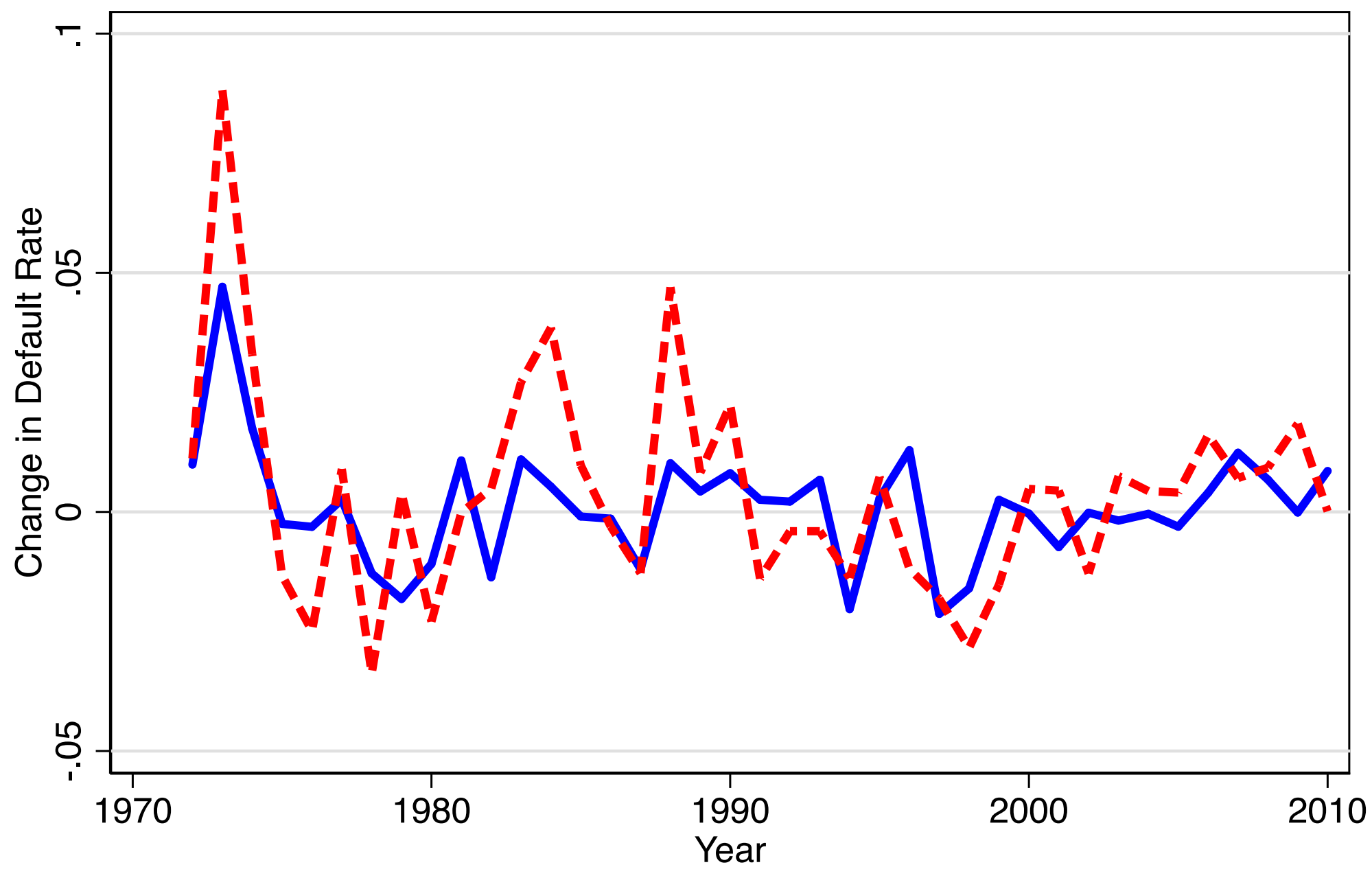

$$
\text { Schools in Sample } \quad-=-=- \text { Schools that Enter }
$$


Figure A.2: Unemployment and Cohort Default Rates

Notes: This figure shows the unemployment rate and the two-year cohort default rate. Source: NSLDS and BLS.

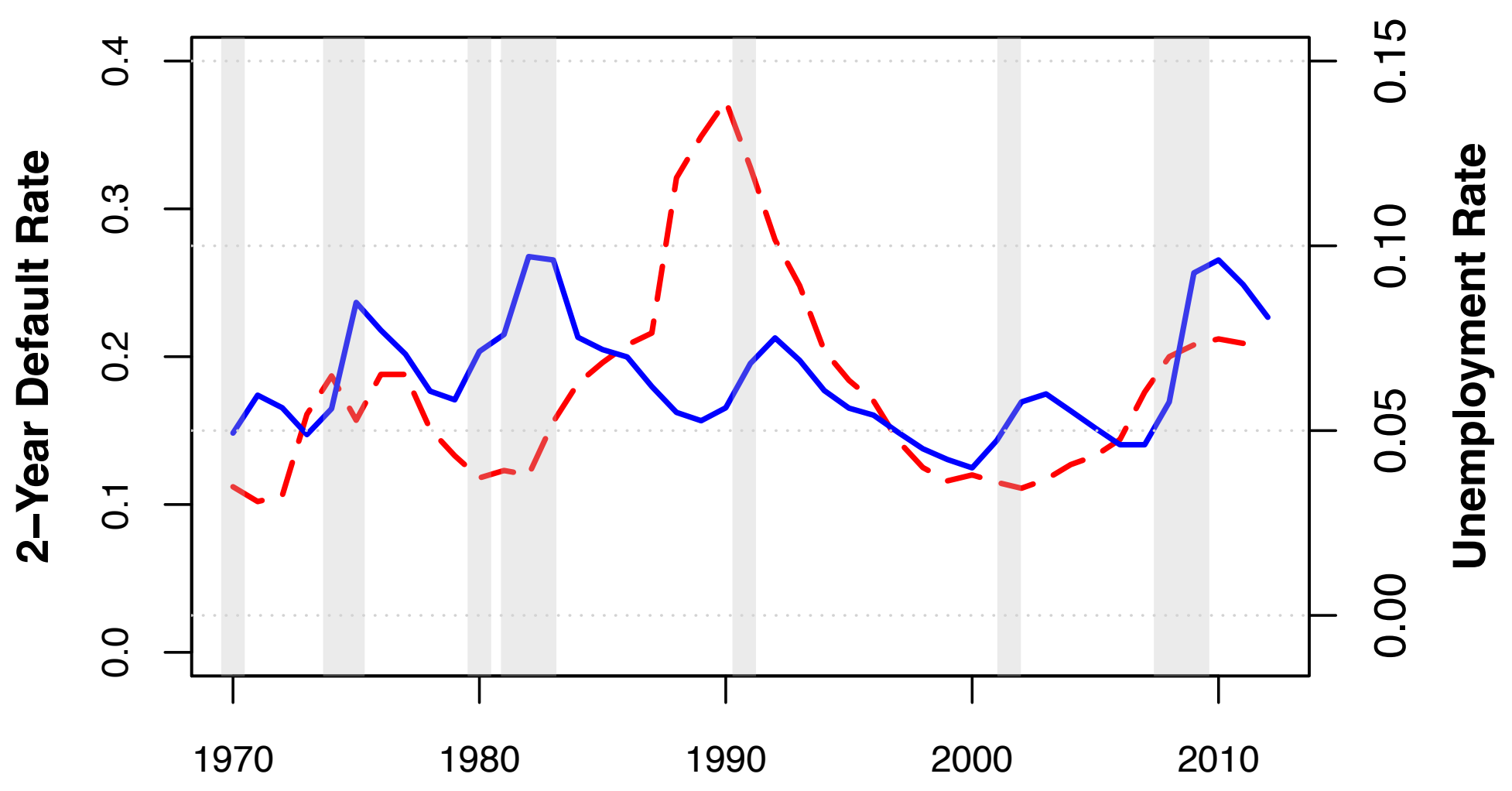

$$
\text { - - 2-Year Default Rate _ Unemployment Rate }
$$


Figure A.3: Unemployed and Cohort Default Rates by Education Levels

Notes: This figure shows the unemployment rate and the two-year cohort default rate, broken down by education level and school type. Source: NSLDS and BLS.

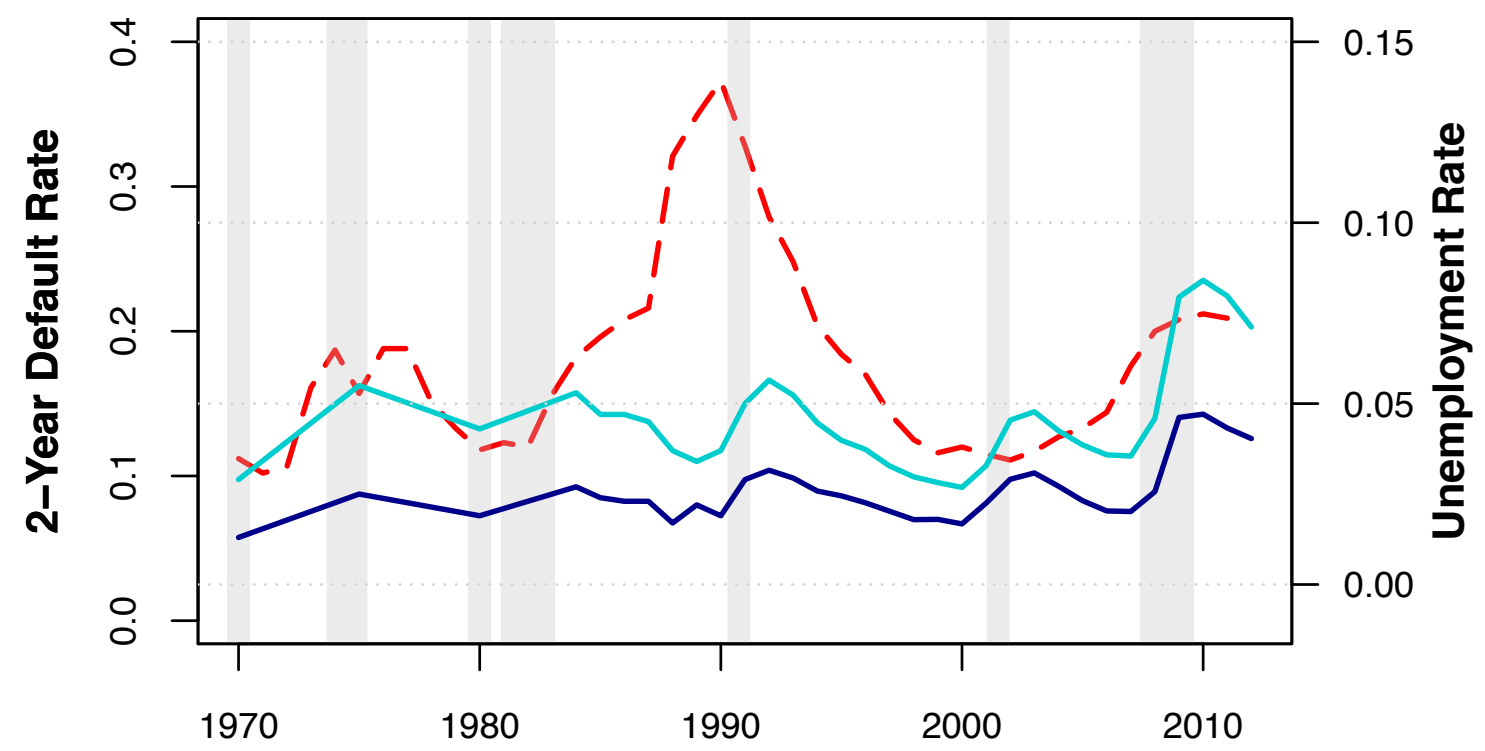

- 2-Year Default Rate _ _ College Grad Unemployment — $\quad$ Some College Unemployment

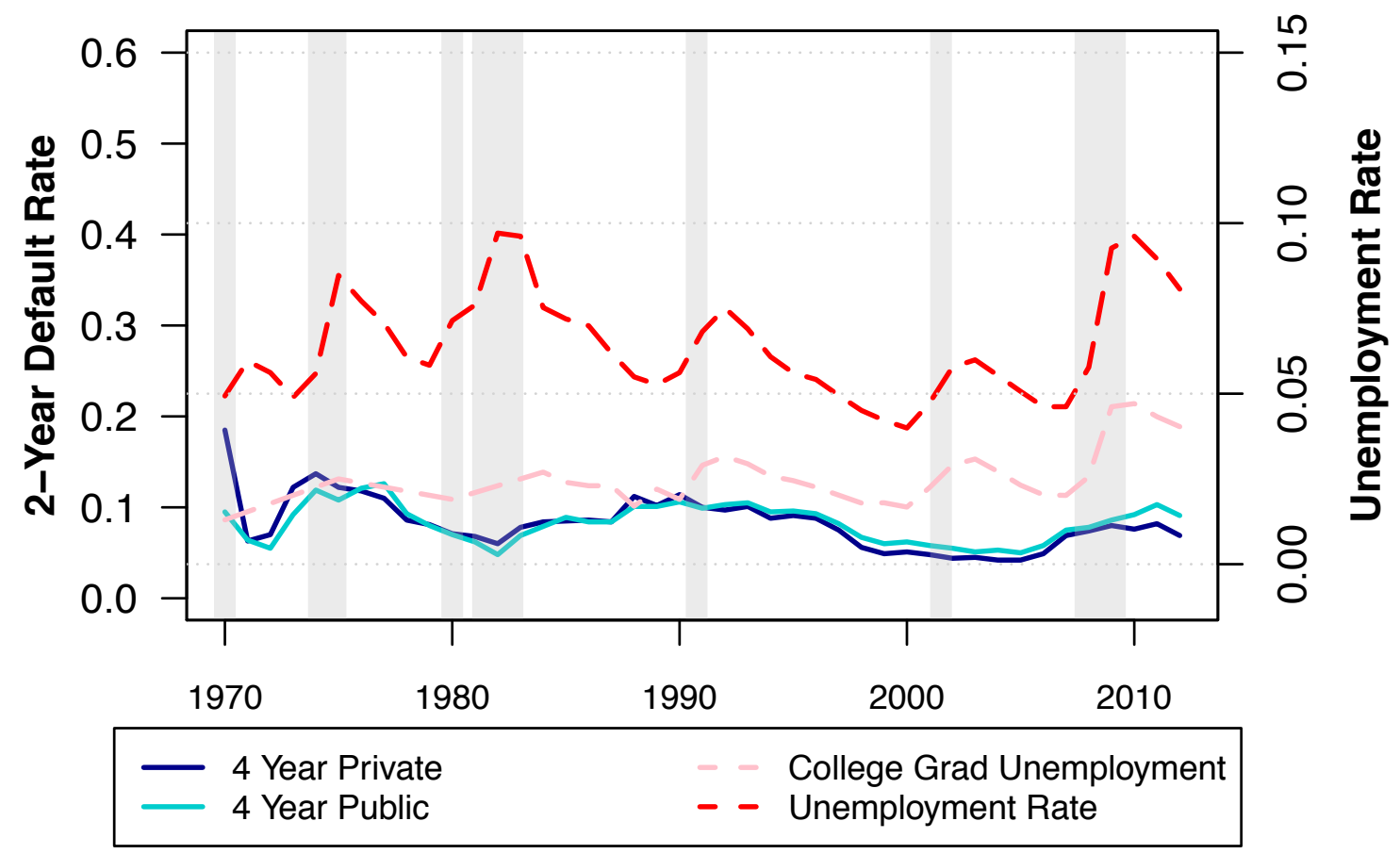




\section{Figure A.4: Assessing Alternative Explanations}

Notes: This figure shows the two-year cohort default rate, median annual borrowing, the number of repayment plans and net tuition and fees. Source: NSLDS, Brookings, Lumina Foundation and College Board.
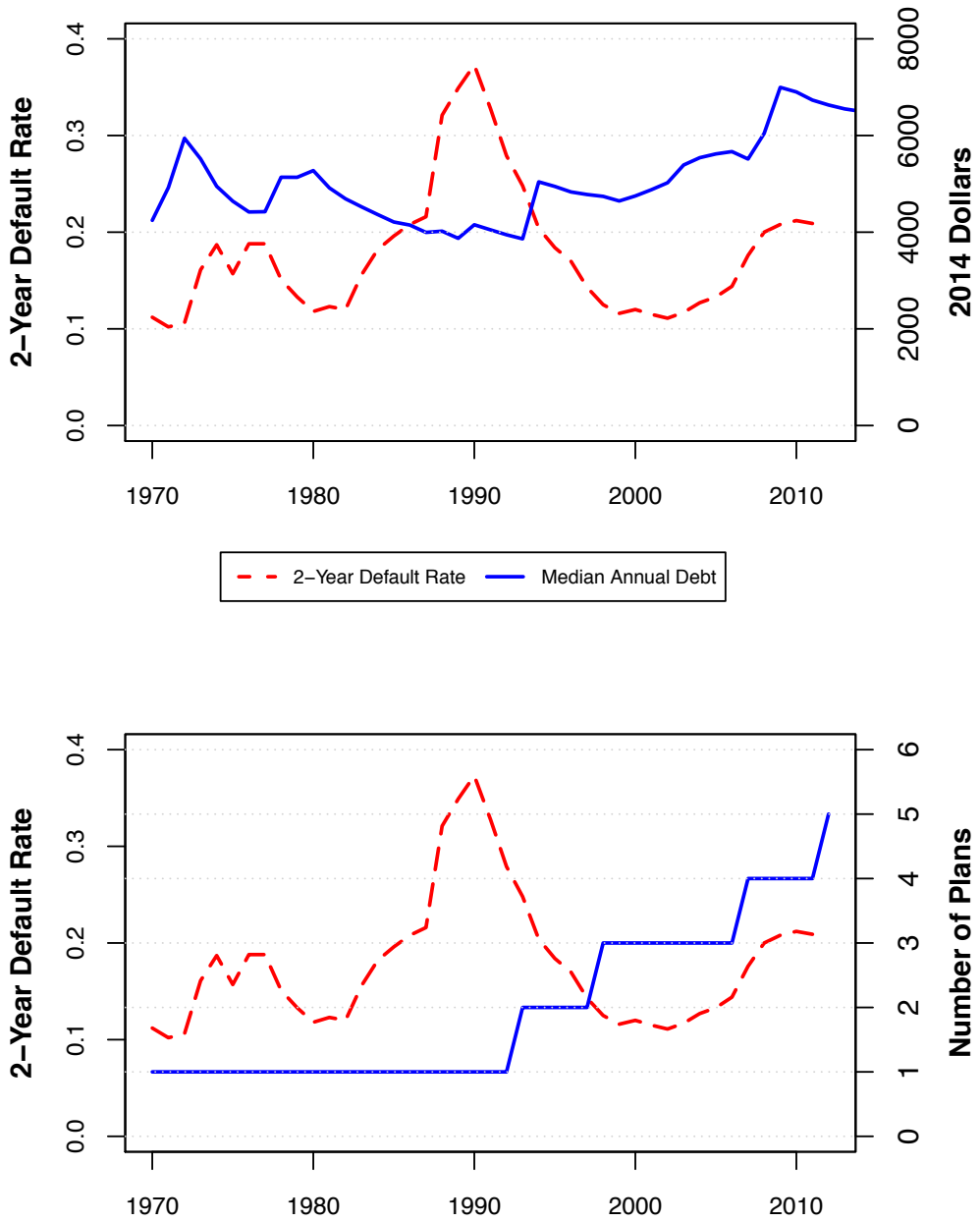

- - 2-Year Default Rate _ Number of Available Repayment Plans

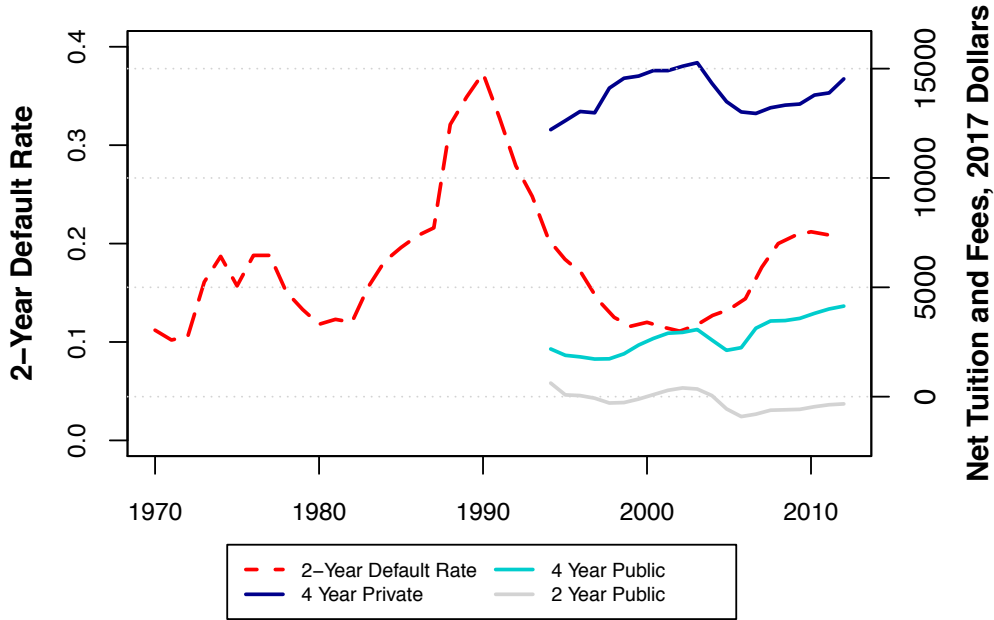


Figure A.5: Entry of Schools by State

Notes: This figure shows the fraction of states with a guarantee agency between 1970 and 1985. Source: National Student Loan Data System (NSLDS).

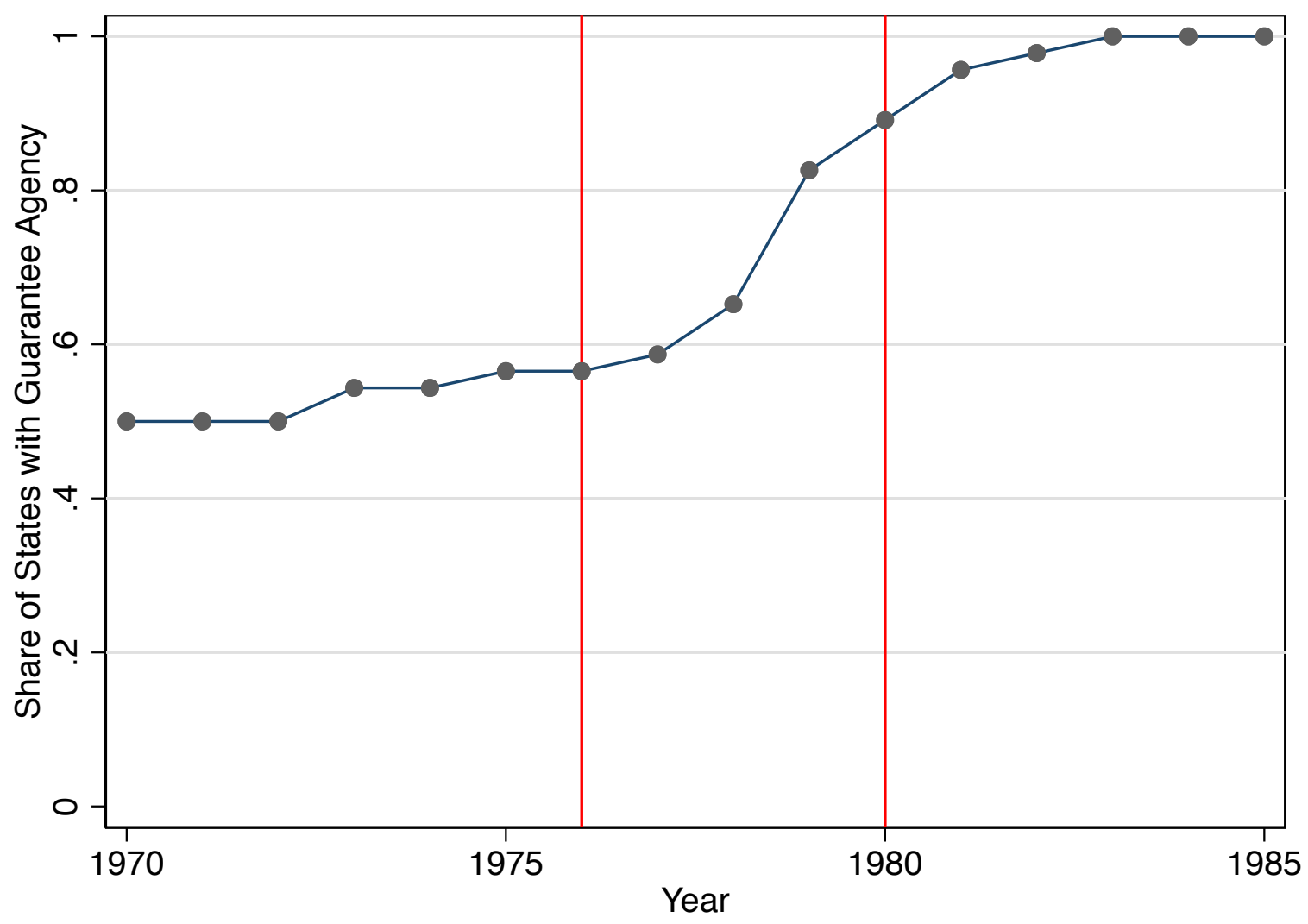




\section{Figure A.6: Entry of Schools by State}

Notes: This map shows the year which a state guarantee agency first began guaranteeing federal student loans. Source: National Student Loan Data System (NSLDS).

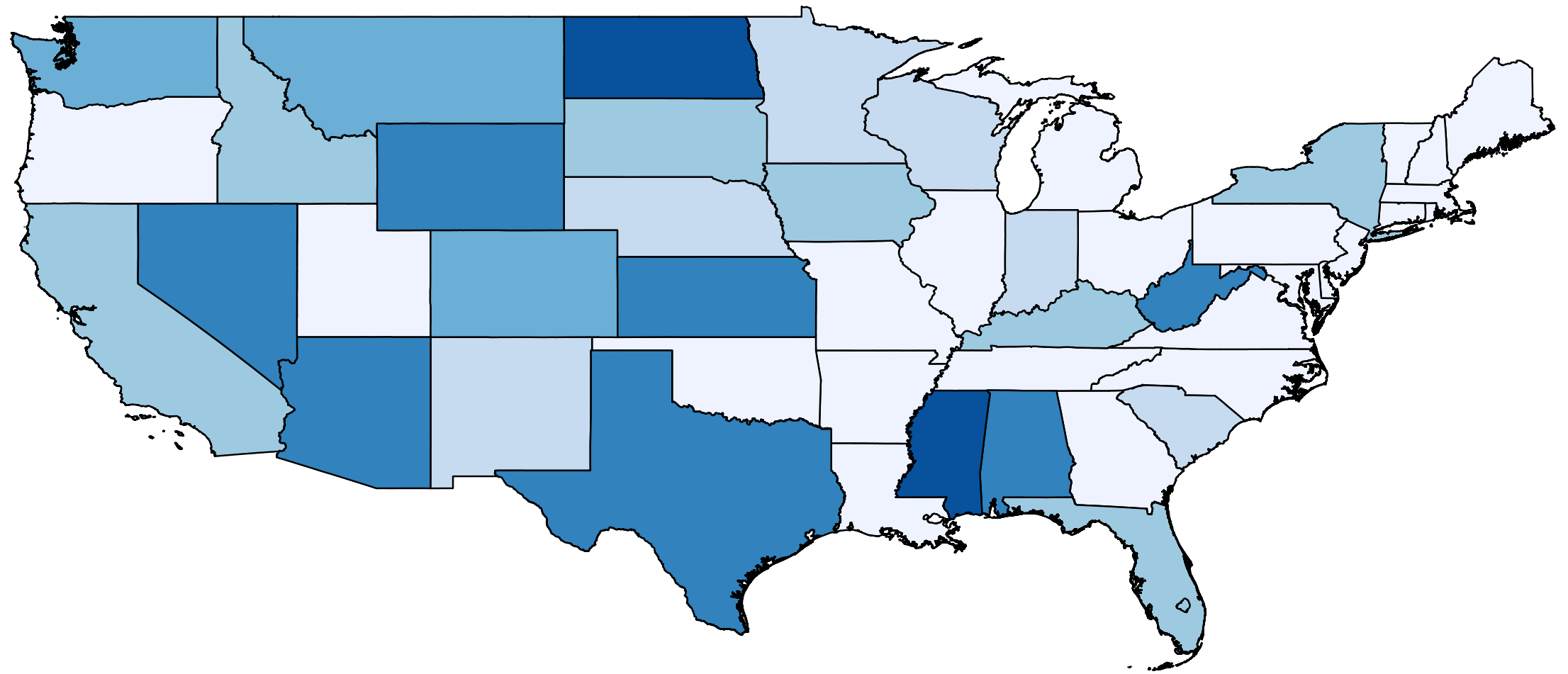

$$
\begin{aligned}
& (1981,1983] \\
& (1980,1981] \\
& (1979,1980] \\
& (1978,1979] \\
& (1968,1978] \\
& {[1968,1968]}
\end{aligned}
$$




\section{Figure A.7: Entry of Schools by State}

Notes: This figure shows, for each state, the number of schools entering in each year as a fraction of the maximum number of schools ever entering in a state. Source: National Student Loan Data System (NSLDS).
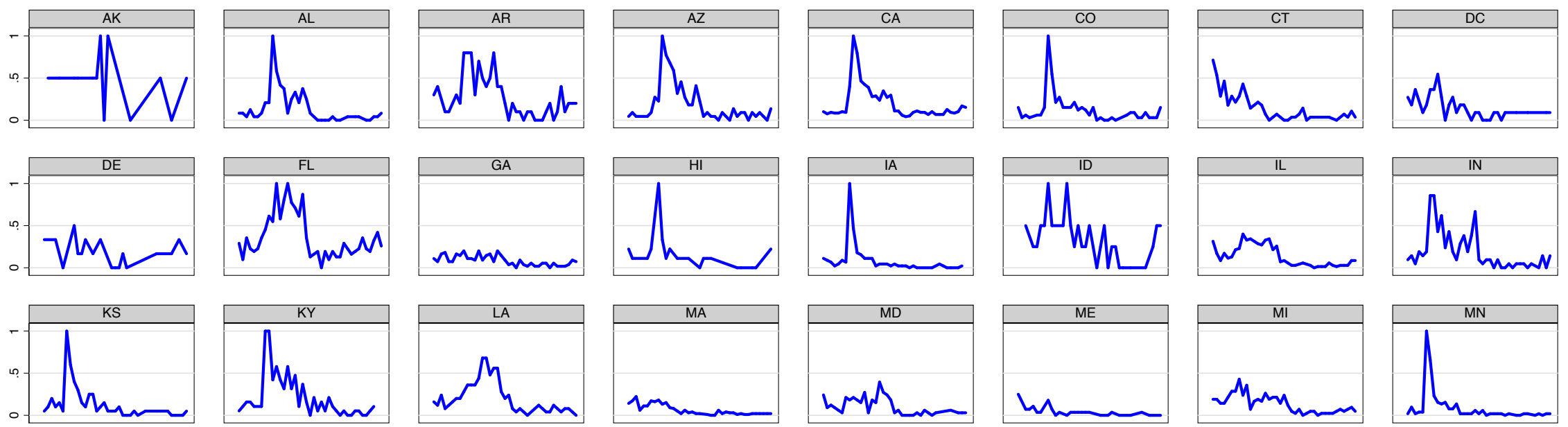

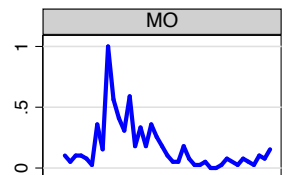
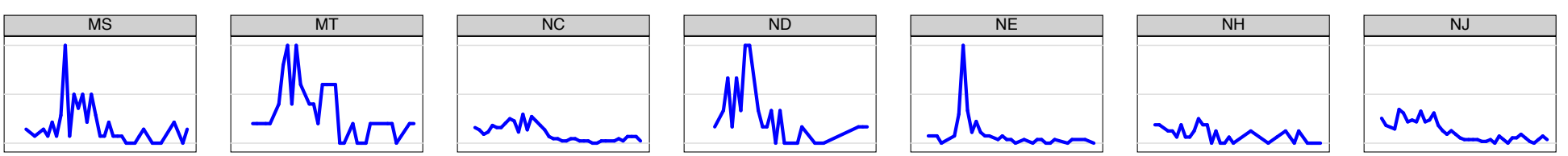

hunLN
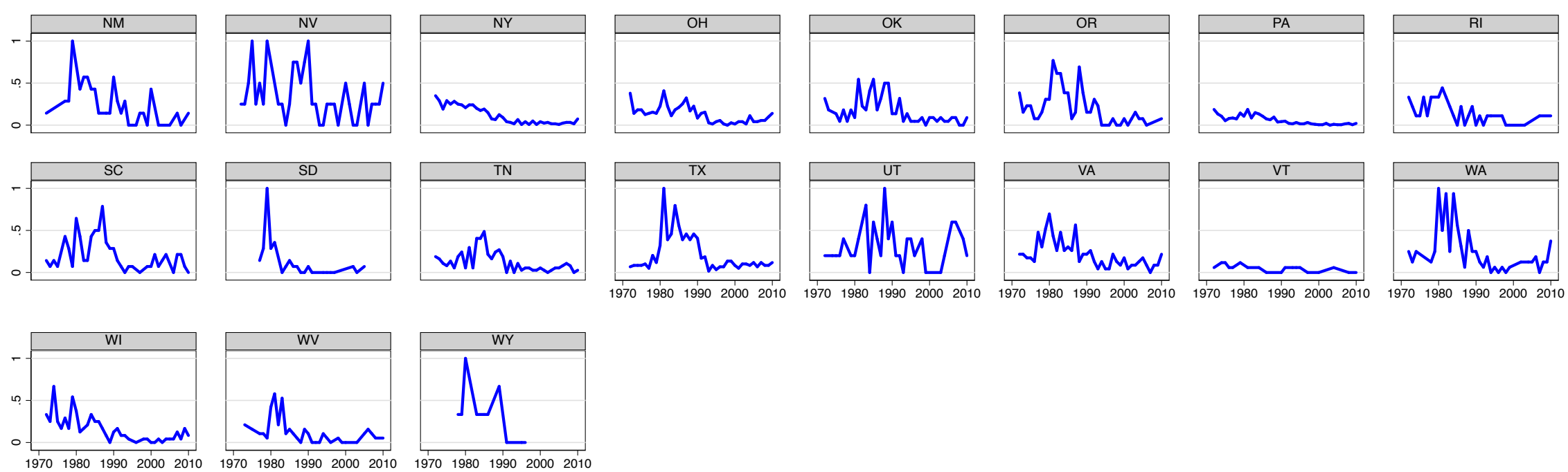
Figure A.8: Entry of Schools by State

Notes: This figure shows the coefficients $\beta_{t}$ from the specification $E_{s t}=\alpha_{s}+\alpha_{t}+\sum_{t=-5}^{5} \beta_{t} \mathbb{1}[$ HasGA] $\times \mathbb{1}[Y$ ear $=$ $t]+\varepsilon_{s t}$, where $\alpha_{s}$ and $\alpha_{t}$ denote state and year fixed effects and $E_{s t}$ denotes the number of schools entering in a state. The thick line shows point estimates, while the dashed lines show a 95\% confidence interval. Standard errors are clustered at the state level. The vertical line shows the year in which a guarantee agency was established. Source: National Student Loan Data System (NSLDS).

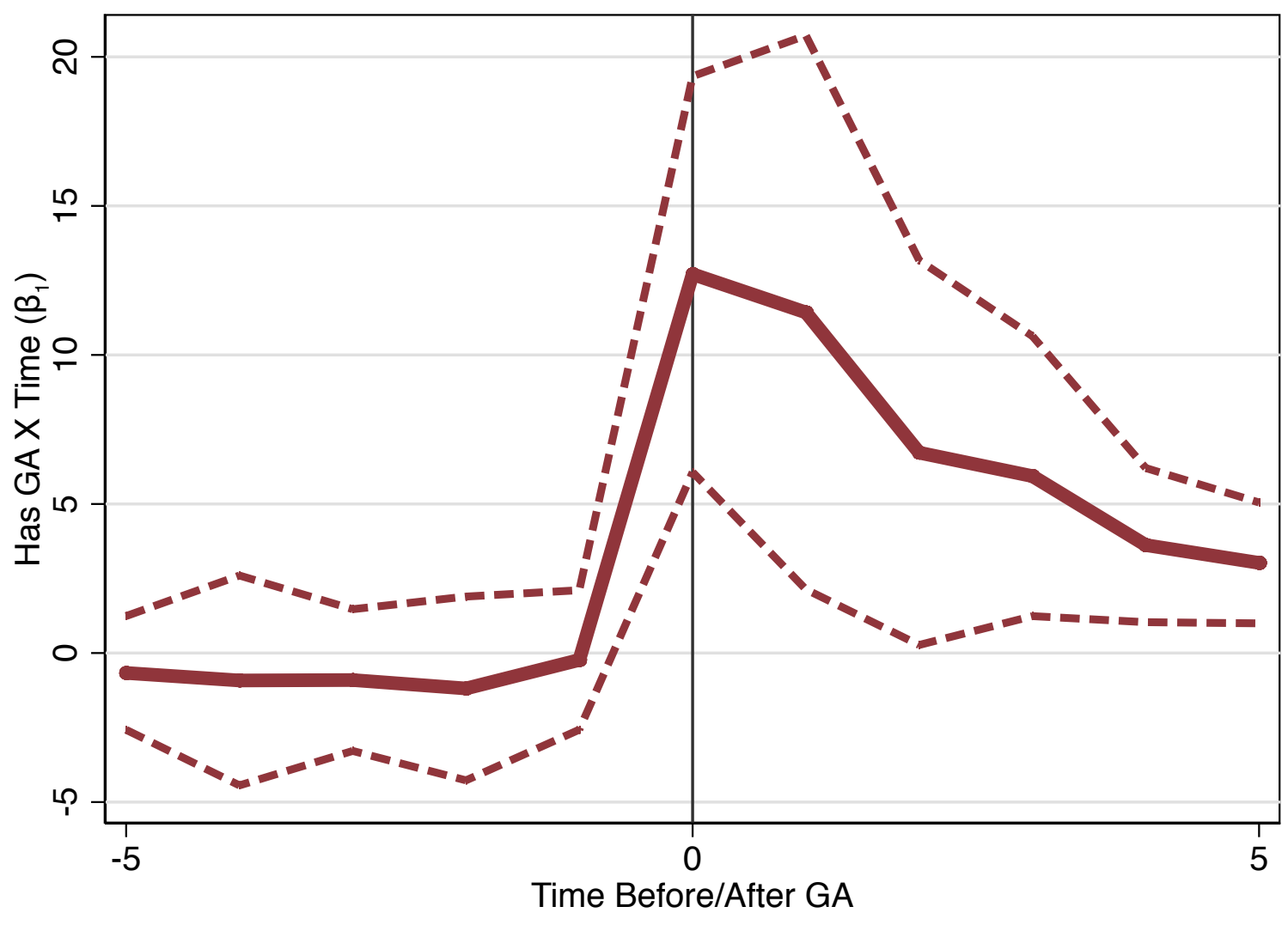




\section{Figure A.9: Correlation Between School Exit, Defaults and Ownership}

Notes: The left panel shows the correlation between an institution's exit from the federal loan program and its two-year cohort default rate. The right panel shows the correlation between an institution's exit and whether the institution was for-profit. The figure illustrates that the correlation between exiting, default rate, and for-profit control spikes soon after CDR and other accountability measures were enacted starting in 1988. The dashed lines show a 95\% confidence interval. Source: NSLDS.
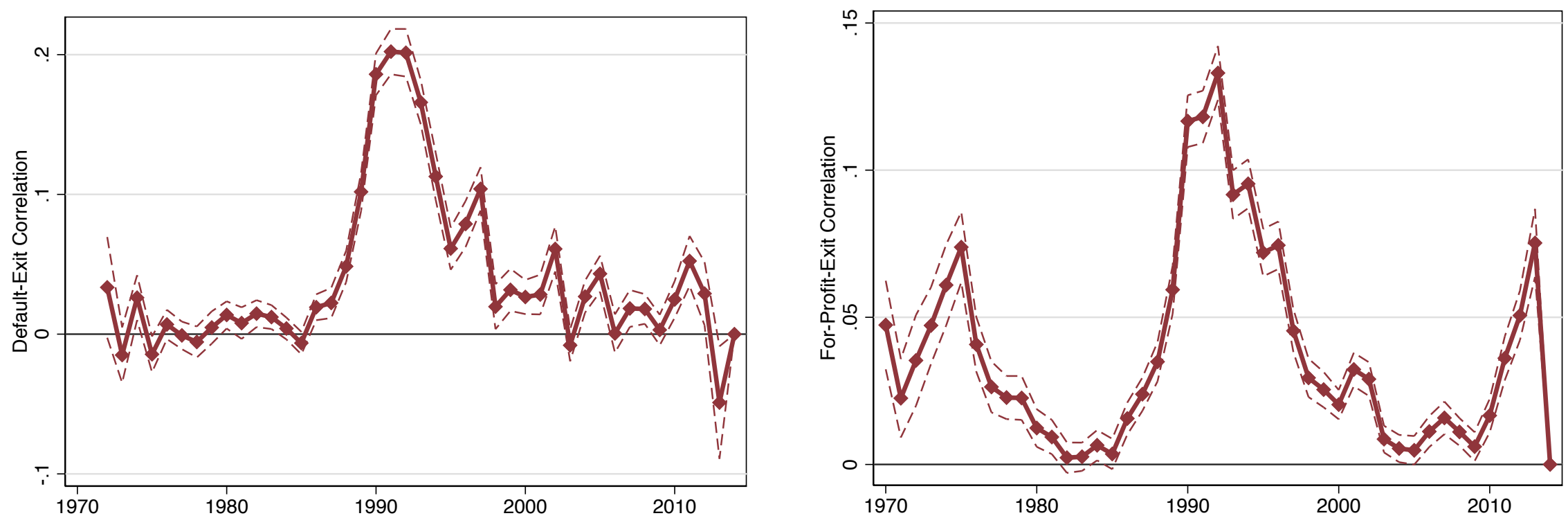
Figure A.10: School Closure and Exiting Federal Borrowing

Notes: This figure shows the number of school closures reported by the Department of Education and the number of schools we measure exiting the loan program. Institutions may exit the loan program but remain open and continue to receive other Title IV aid (e.g., Pell Grants). Source: NSLDS and Department of Education FSA Closed Schools Database.

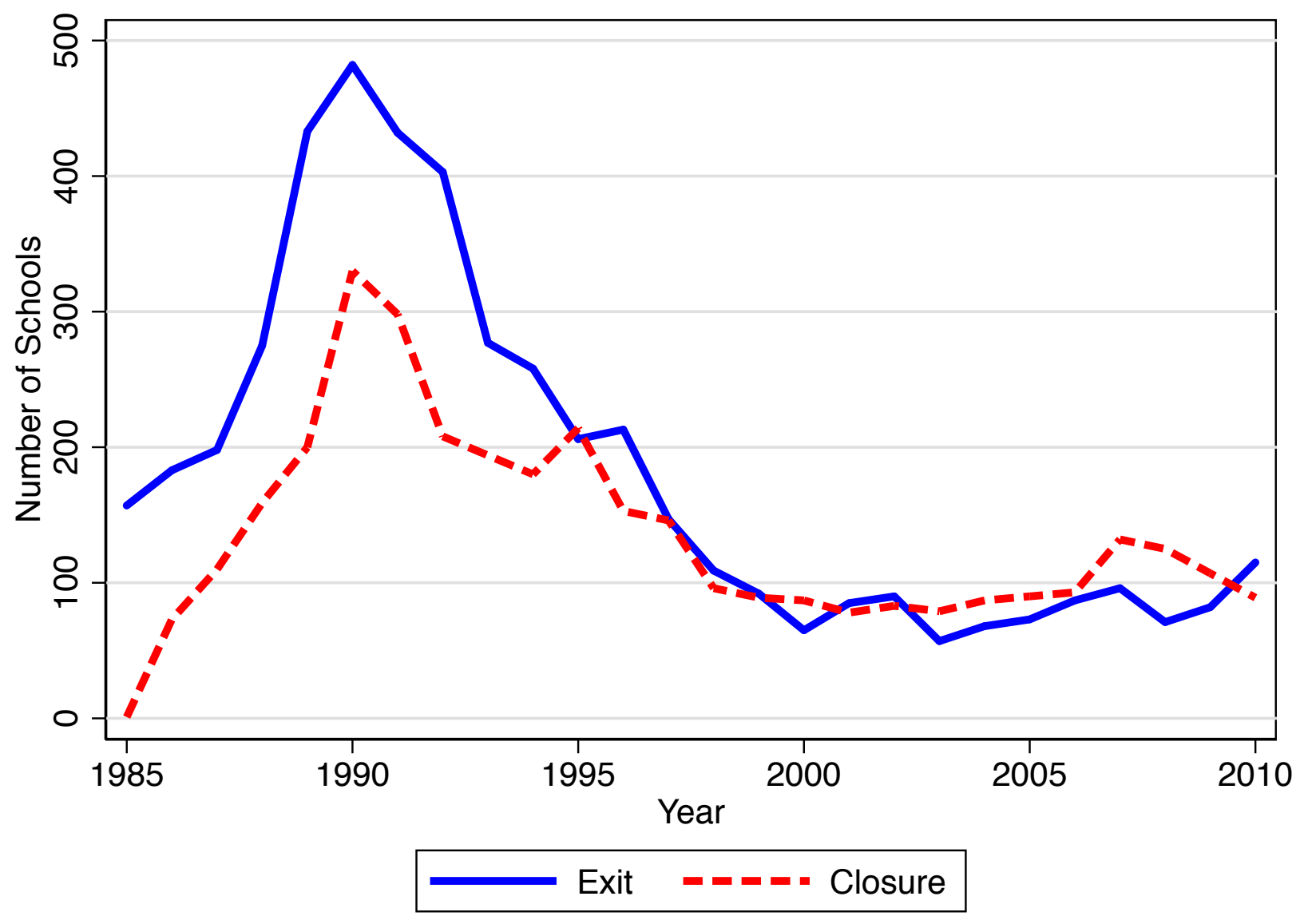




\section{Figure A.11: Relaxation of Online and 90/10 Rules}

Notes: This figure examines the role of two changes in institutional accountability that expanded the number of student loan borrowers starting in the late 1990s. In 1998, Congress revised from 85 percent to 90 percent the amount of revenue for-profit institutions were allowed to derive from Title IV student aid (the $90 / 10$ rule). The left panel shows the total number of new borrowers each year at for-profit schools by the maximum 90/10 ratio that applied in 2009 or 2010 . The graph shows that new borrowing increased most at institutions which would have been limited by the prior 85 percent limit. The right panel shows the average number of new borrowers per institution by the fraction of enrollment in 2012-2016 that was distance or online. After 2000, a pilot program allowed some institutions to expand online enrollment in excess of the 50 percent limit. In 2006, the limit was repealed entirely. Average enrollment of new borrowers increased by more at institutions that are predominately online. Source: NSLDS, IPEDS, and FSA Proprietary School 90/10 Revenue Percentages.

\section{Fraction of Revenue from Title IV Programs}

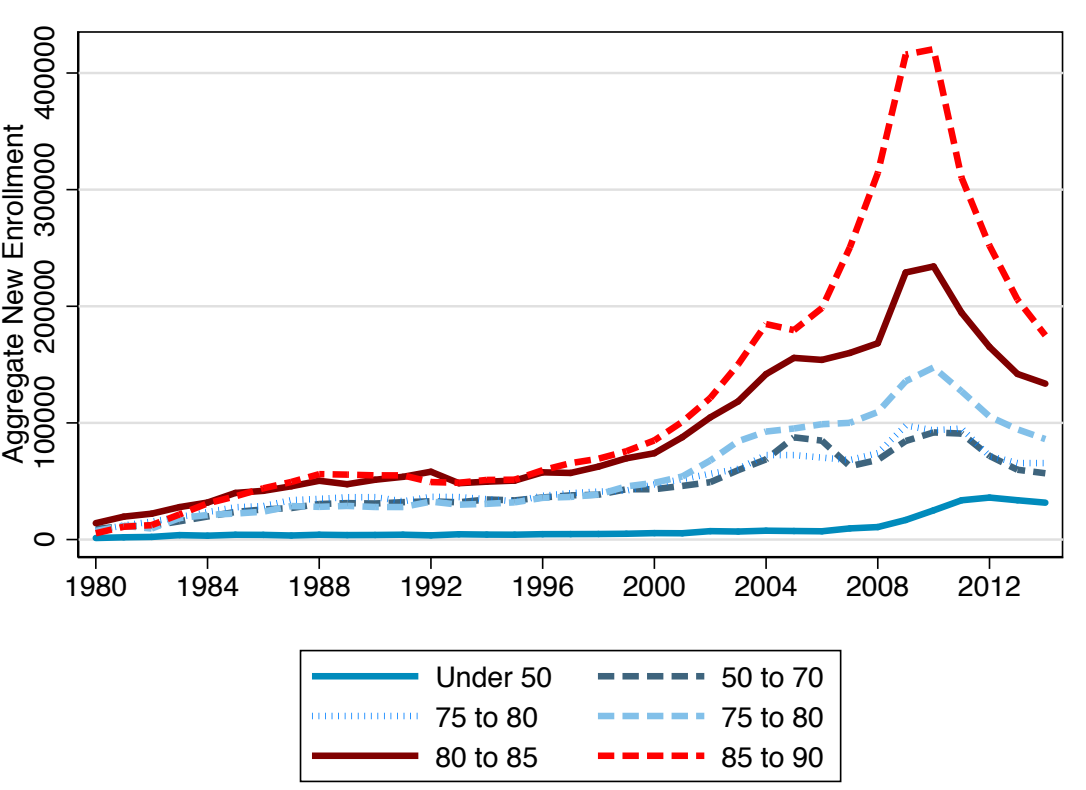

Distance/Online Education

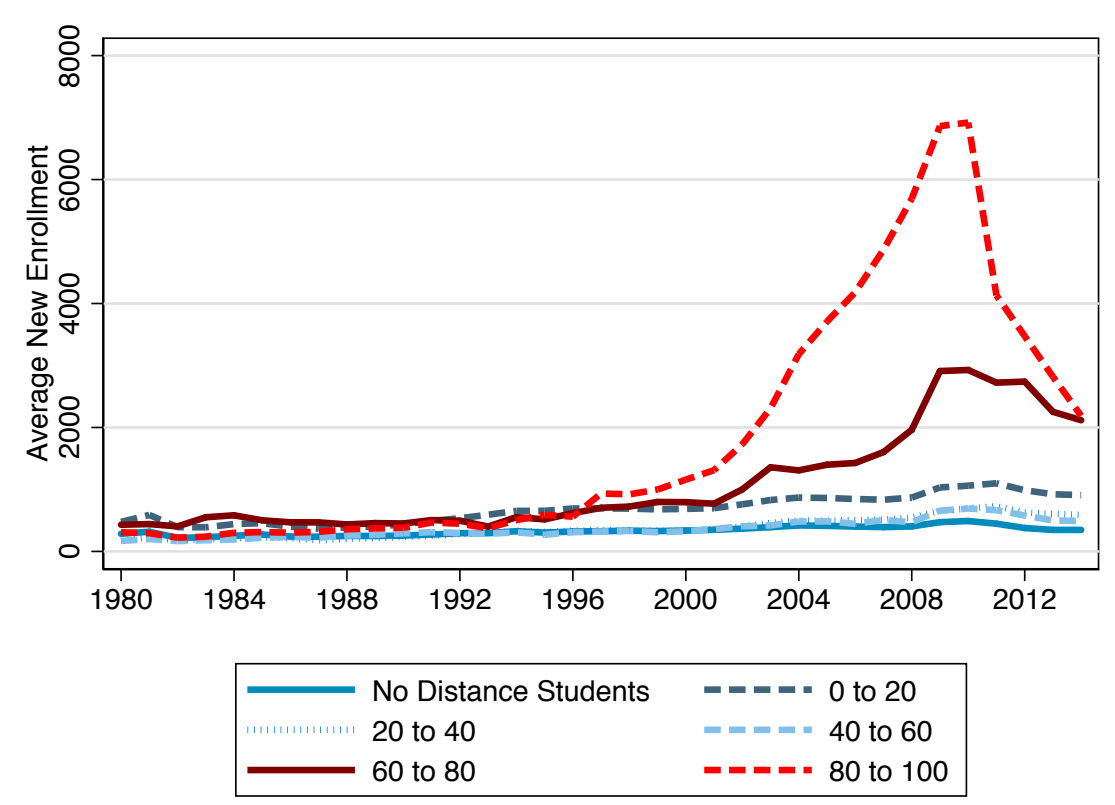




\section{Figure A.12: Online School Enrollment and Default Over Time}

Notes: This figure shows the coefficients $\beta_{t}$ from the specification $E_{s t}=\alpha_{s}+\alpha_{t}+\sum_{t=1990}^{2015} \beta_{t} \mathbb{1}[$ Online $] \times \mathbb{1}[$ Year $=t]+\varepsilon_{\text {st }}$. The outcome of interest is the log number of new federal borrowers and the log number of new defaults, and the treatment is an indicator of a school ever offering online education interacted with a year indicator. The thick line shows point estimates, while the dashed lines show a 95\% confidence interval. The first vertical line shows the introduction of the Distance Education Demonstration Program. The second vertical line shows the elimination of the requirement that no more than 50 percent of students be distance or online students after 2006. Standard errors are clustered at the school level. Source: NSLDS.

\section{Enrollment Share}

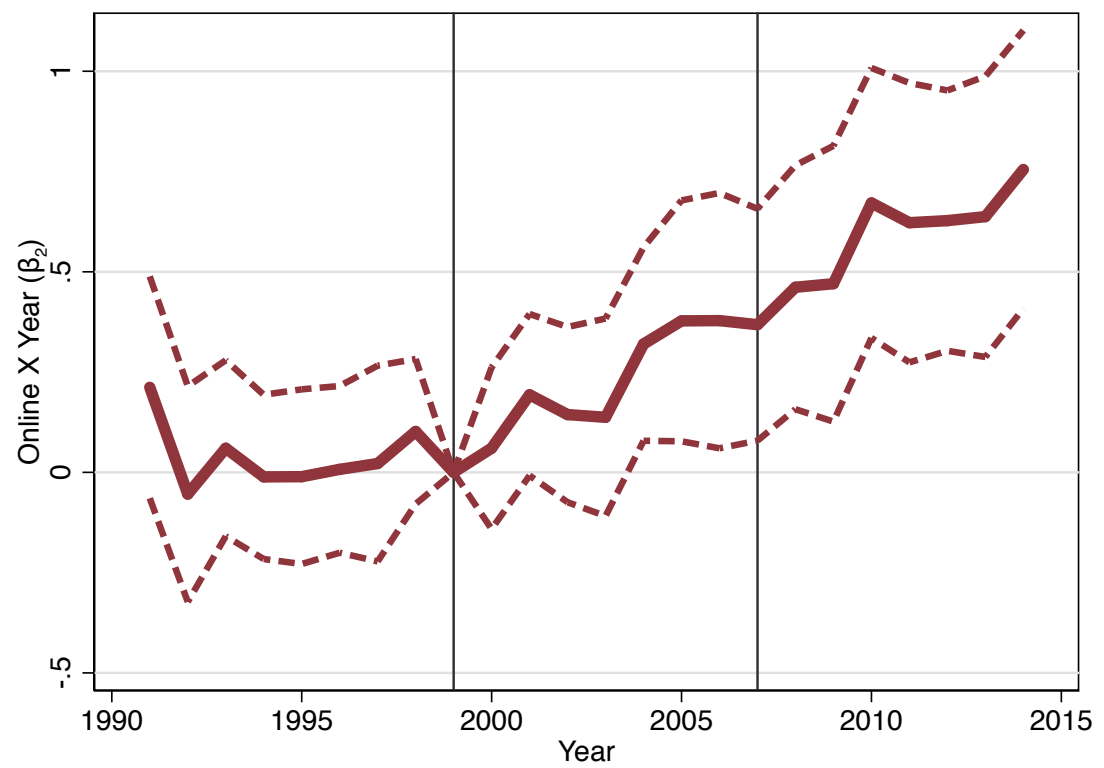

New Default Share

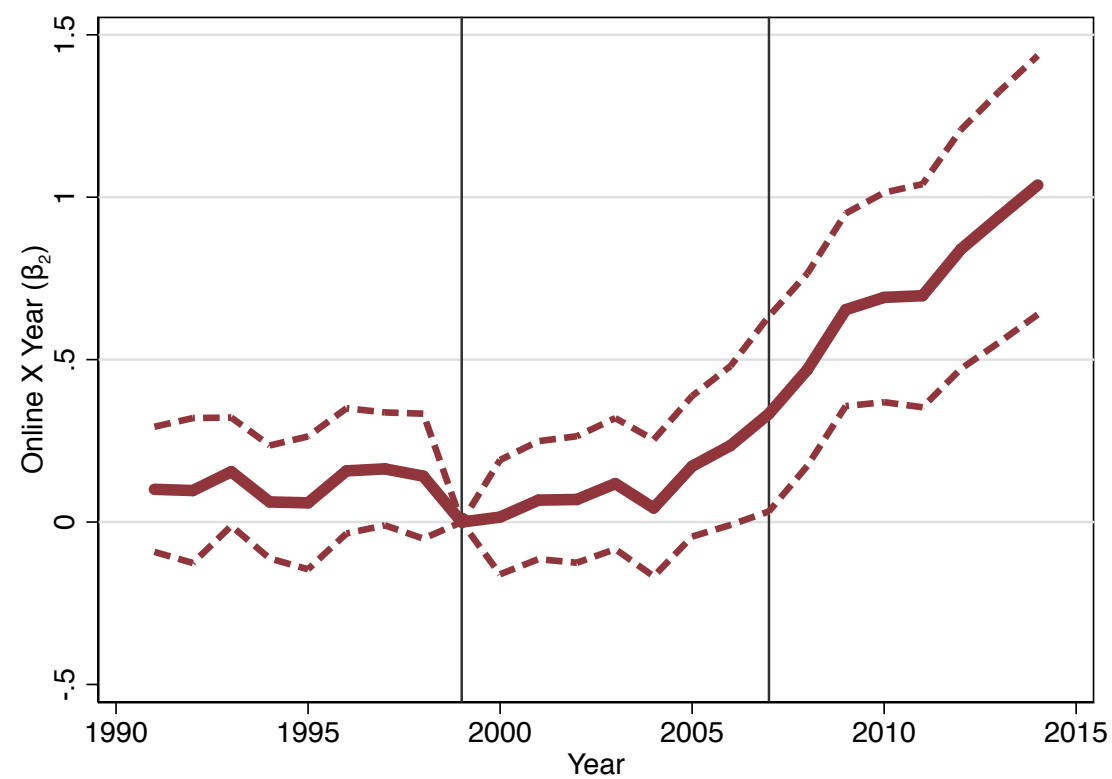


Figure A.13: New Defaults and Borrowers by Online Enrollment Share

Notes: This figure shows the mean number of new defaults and borrowers, broken down by deciles the share of online enrollment, in 2000 and 2010. Source: NSLDS.

2000

2010
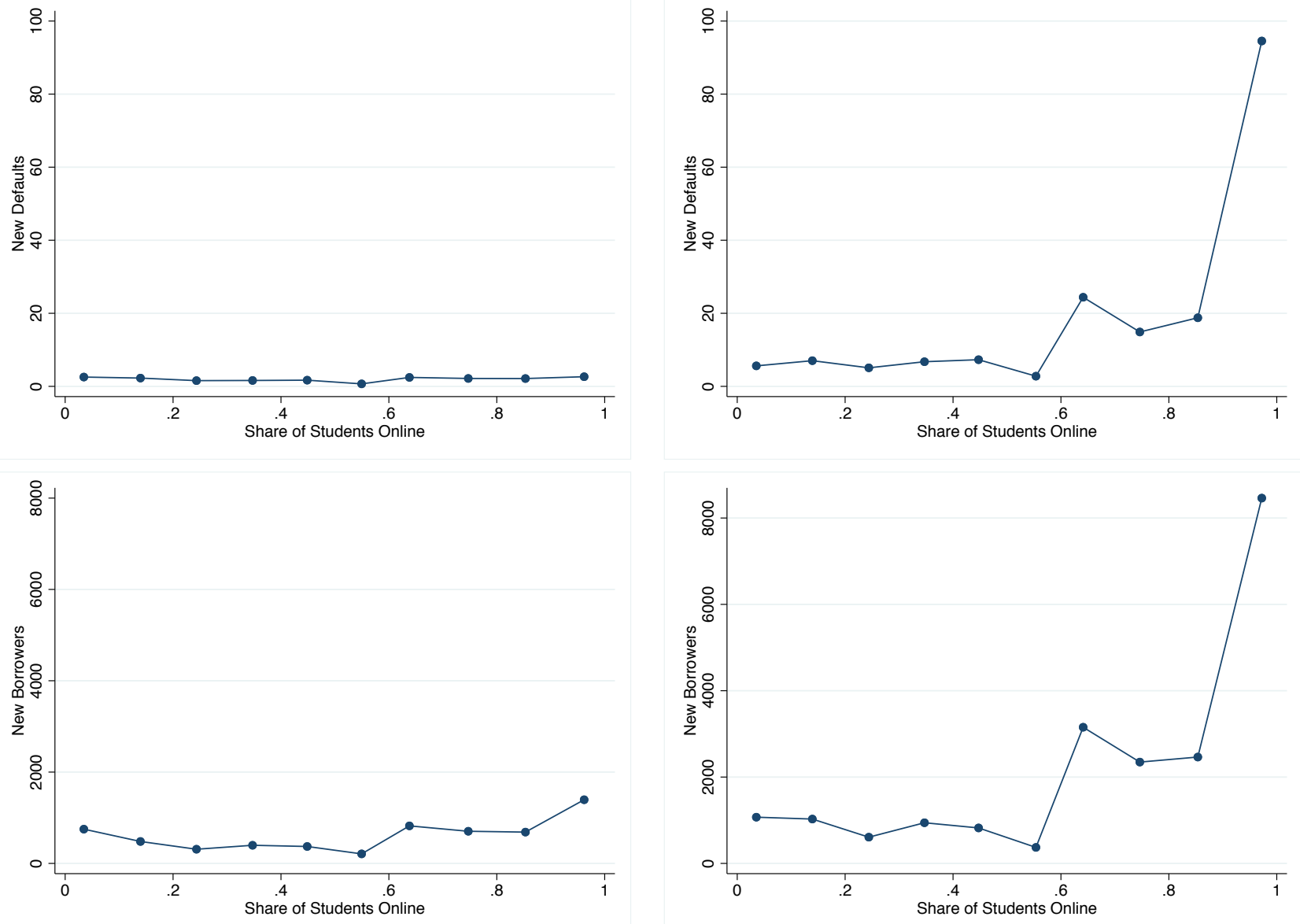
Figure A.14: Change in New Defaults and Borrowers by Online Enrollment Share

Notes: This figure shows the change in number of new defaults and borrowers between 2000 and 2010, broken down by deciles of online enrollment. Source: NSLDS. New Default New Borrowers
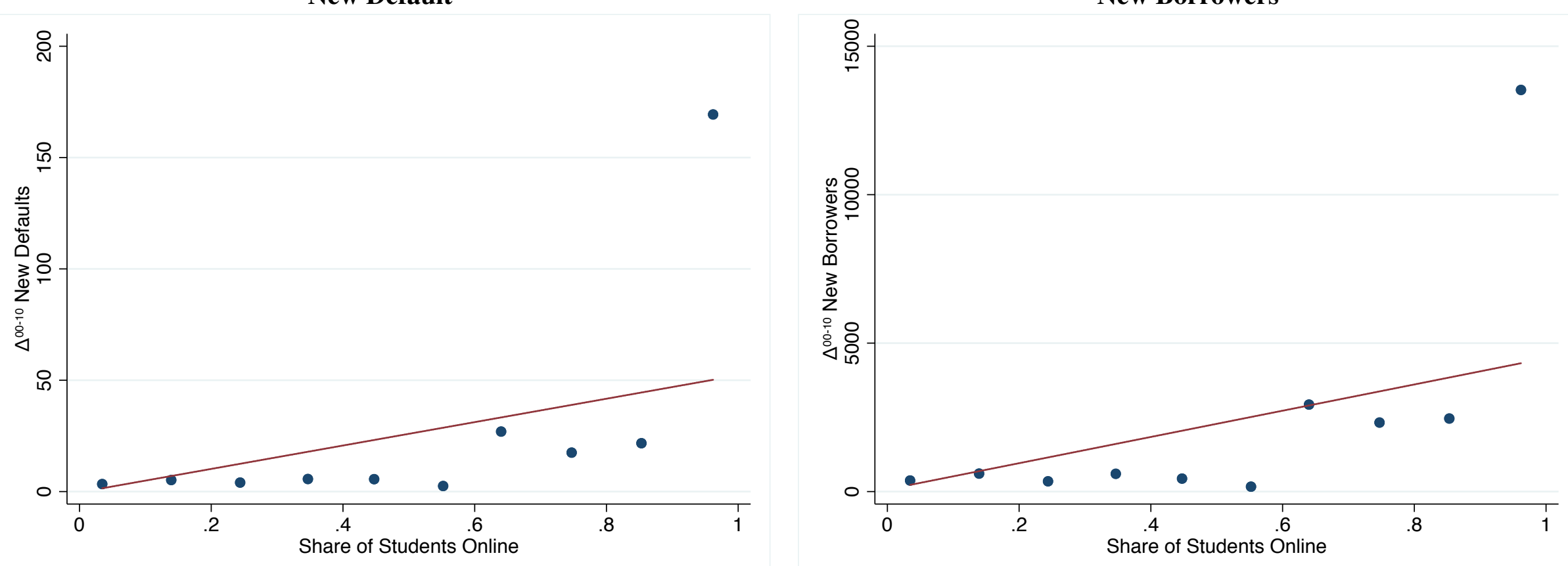
Figure A.15: Share of Default and Enrollment by Title IV Revenue: All Schools

Notes: This figure shows the share of total enrollment and defaults, by the fraction of revenue coming from Title IV programs for for-profit institutions. Source: NSLDS and Department of Education Proprietary School 90/10 Revenue Percentages.

Enrollment Share

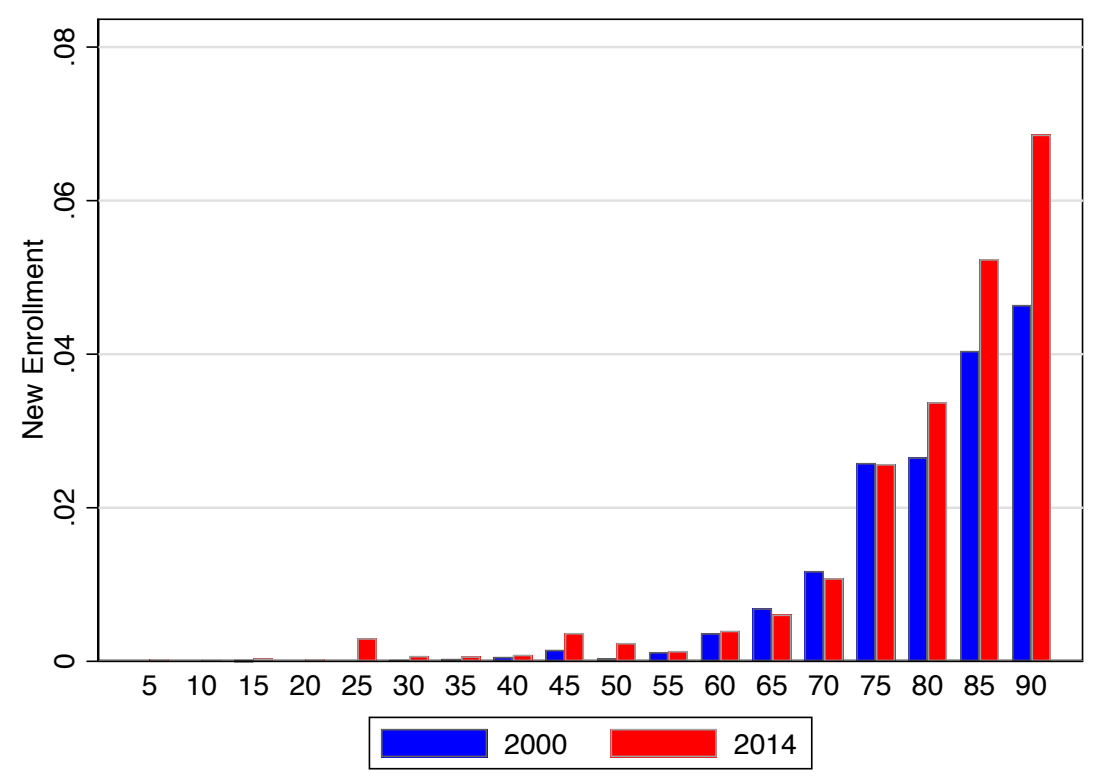

New Default Share

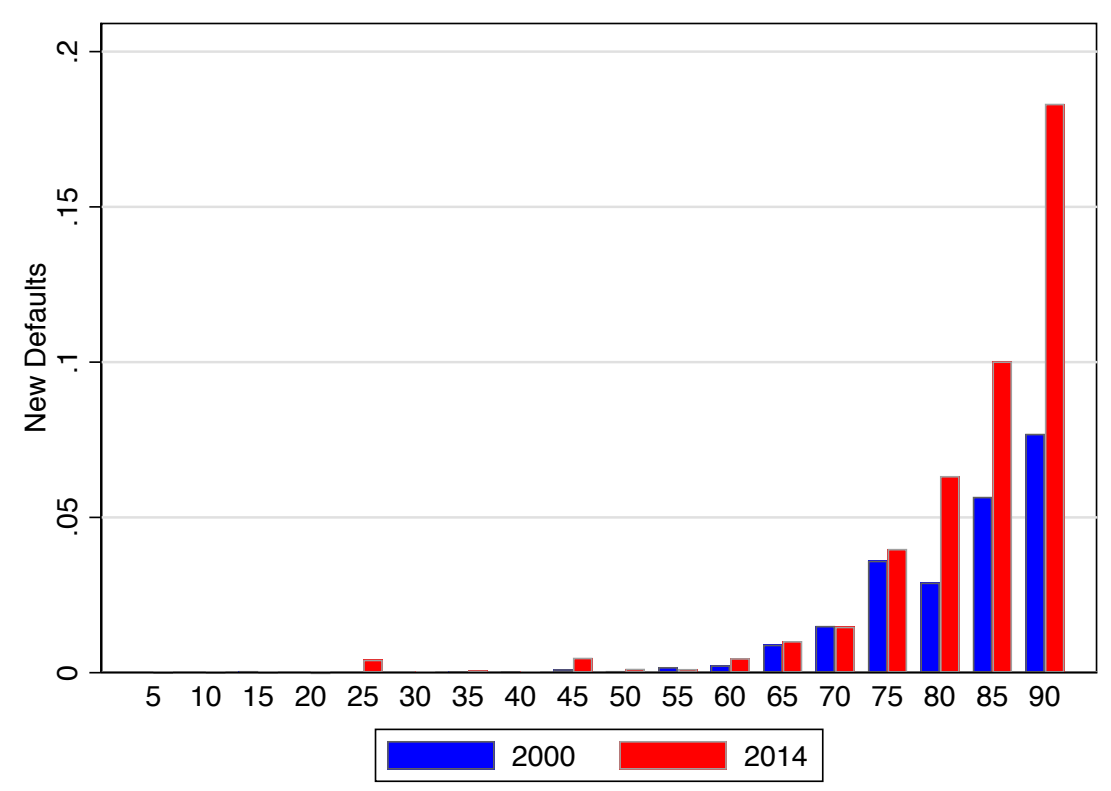


Figure A.16: Share of Default and Enrollment by Title IV Revenue: For-Profits

Notes: This figure shows the share of for-profit enrollment and defaults, by the fraction of revenue coming from Title IV programs. The sample is restricted to for-profit schools for which data on Title IV revenue is available. Source: NSLDS and Department of Education Proprietary School 90/10 Revenue Percentages.

Enrollment Share

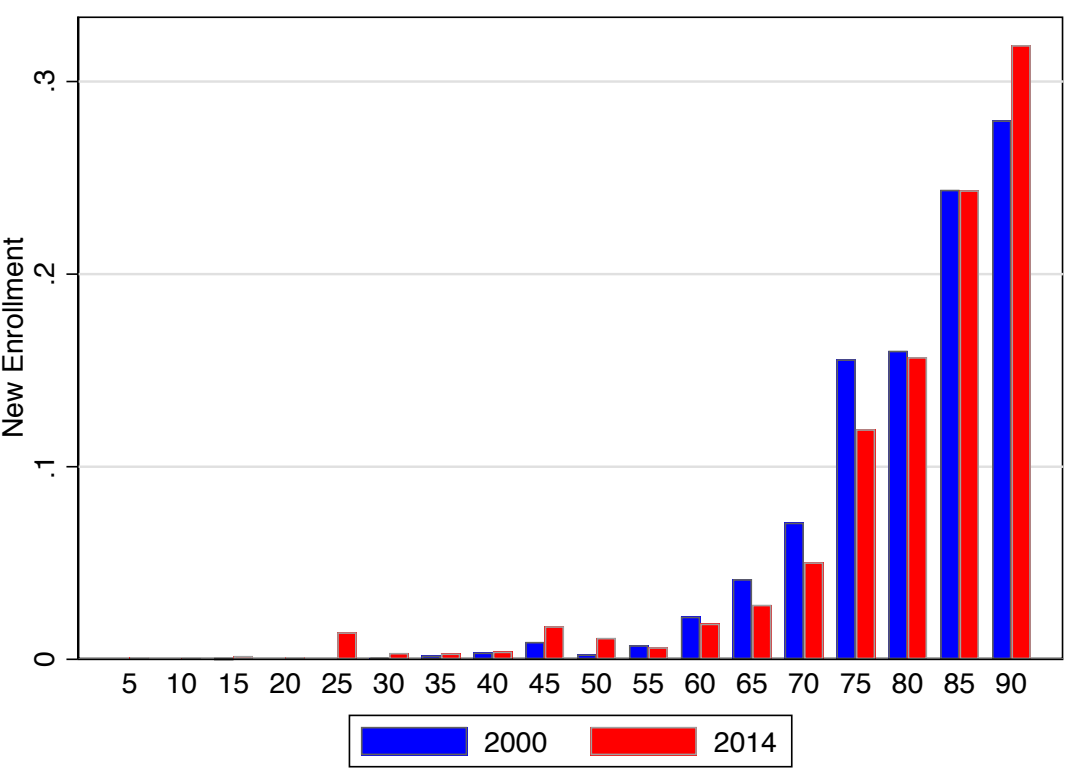

New Default Share

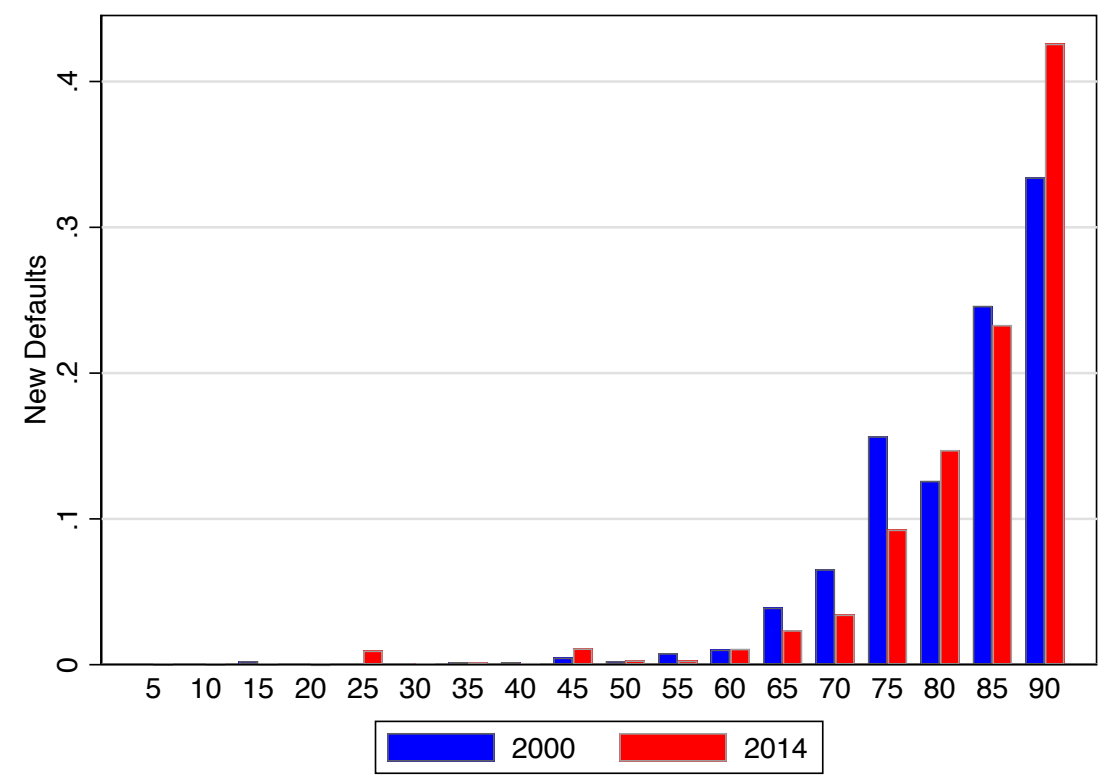




\section{Figure A.17: New Defaults and Borrowers by Share of Title IV Revenue}

Notes: This figure shows the mean number of new defaults and borrowers, broken down by deciles the share of Title IV revenue, in 2000 and 2010. Source: NSLDS and Department of Education Proprietary School 90/10 Revenue Percentages.

2000

2010
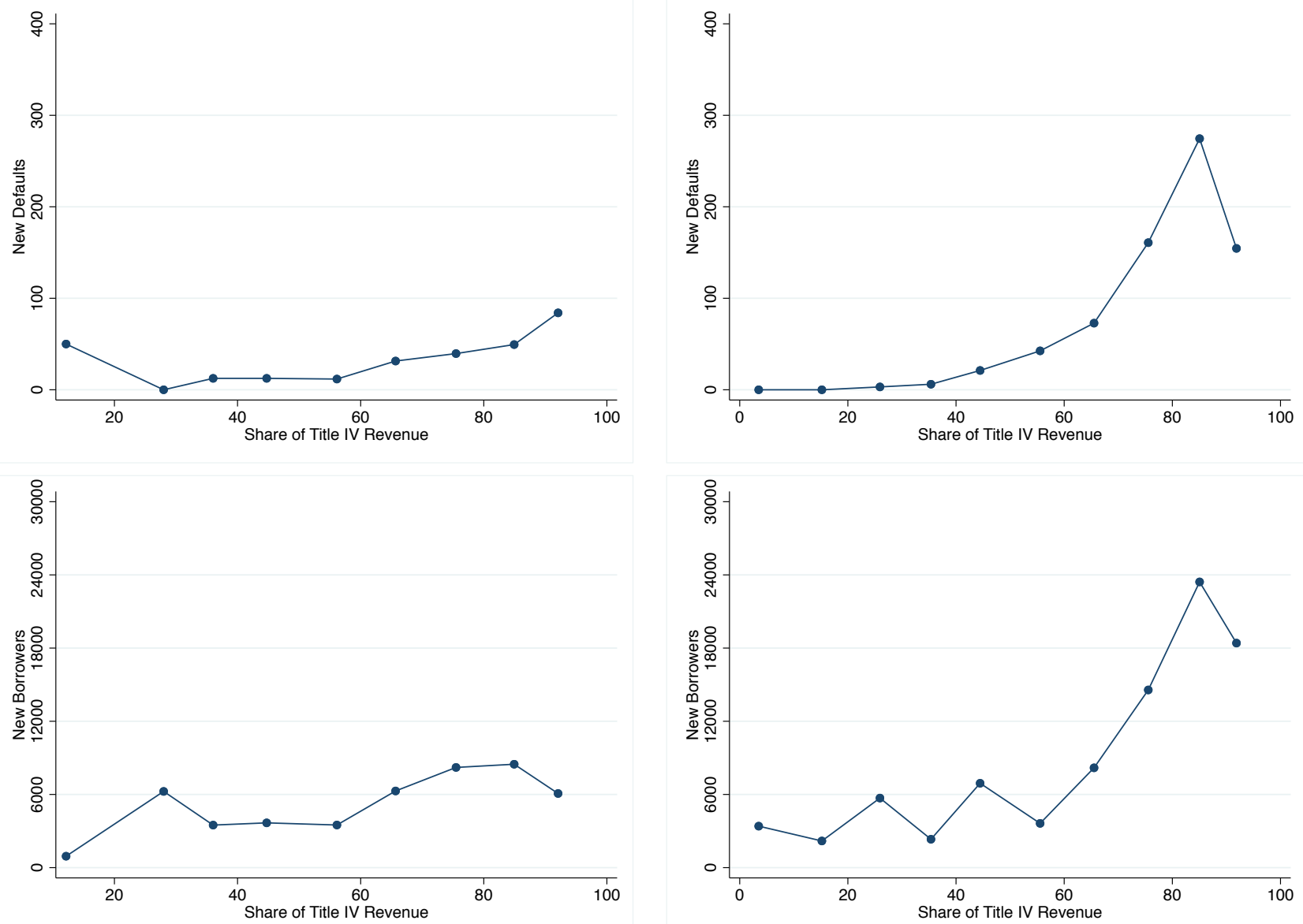
Figure A.18: Change in New Defaults and Borrowers by Share of Title IV Revenue

Notes: This figure shows the change in number of new defaults and borrowers between 2000 and 2010, broken down by deciles the share of Title IV revenue. Source: NSLDS and Department of Education Proprietary School 90/10 Revenue Percentages.

New Default

$\stackrel{\infty}{\cup}$

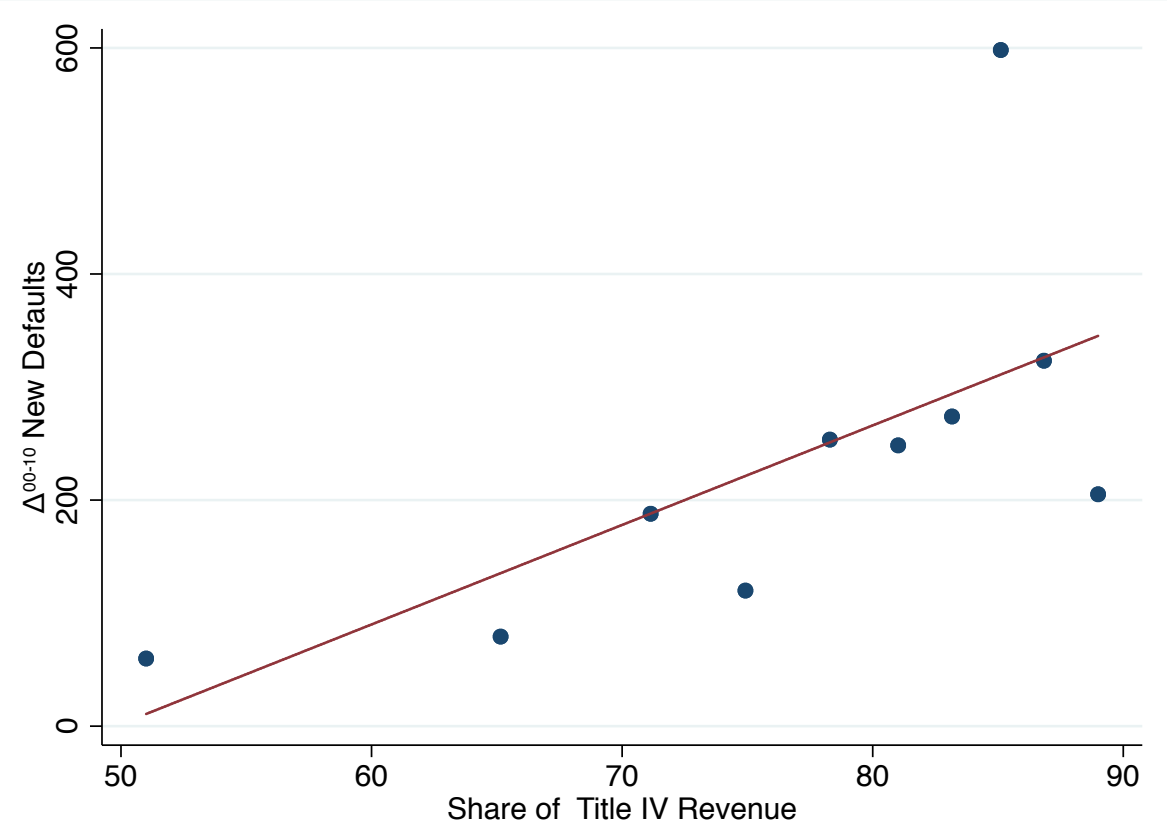

\section{New Borrowers}

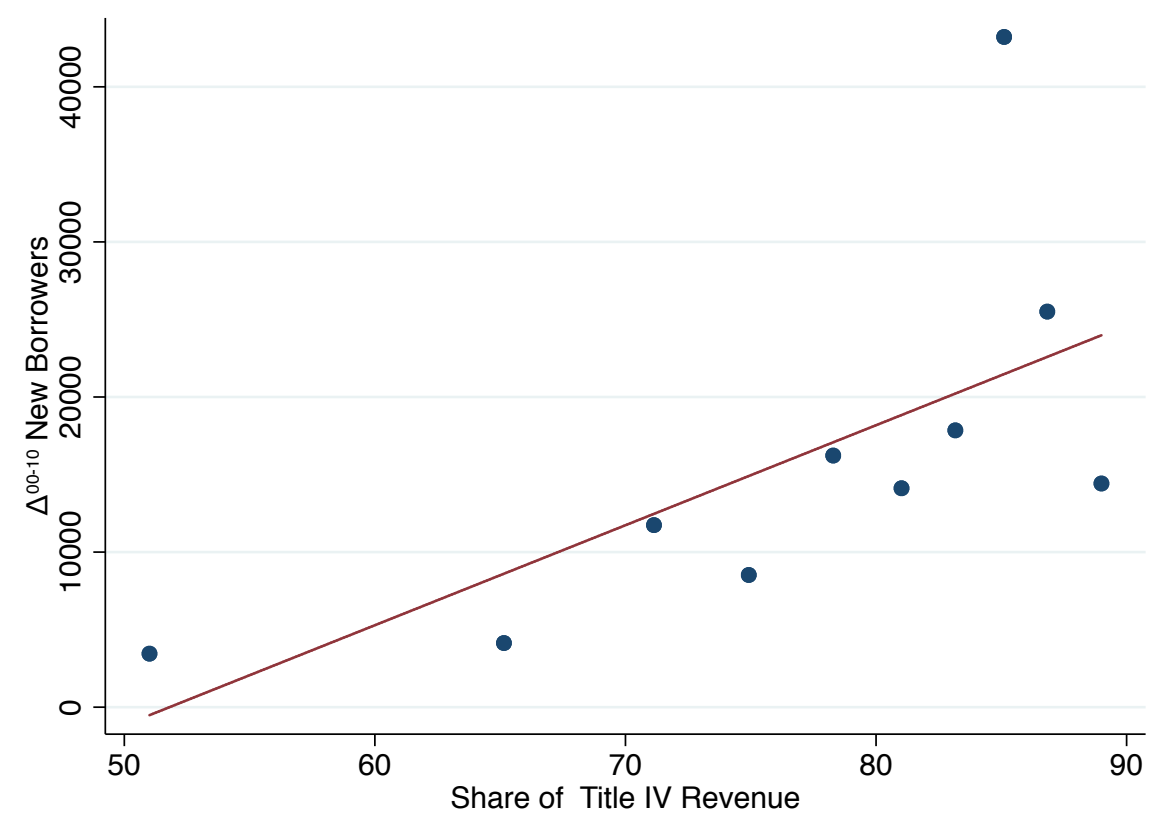




\section{Table A.1: Variable Descriptions}

This table describes the outcome and control variables used in the main analysis. The first column indicates the variable name. The second column provides a description of the variable. The third column provides the source of the variable.

\begin{tabular}{llc}
\hline \hline Variable & Description & Source \\
\hline
\end{tabular}

Cohort Default Rate (CDR) This is the fraction of individuals in a cohort, defined by the year that NSLDS borrowers enter repayment, that default within a set number of years of entering repayment. A loan goes into default if payments are more than 270 days late. Servicers have 90 days to report defaults.

School Entry

School Exit

First Time Borrowers

Balance

School Type

School Selectivity

Distance/Online
A school's entry year is defined as the first time a school is observed in the NSLDS, with the exception of the first two years in the sample.

A school's exit year is defined as the last time a school is observed in the NSLDS, with the exception of the last two years in the sample.

First time borrowers are defined as borrowers in their entry year into the NSLDS. Entry years are assigned based on the fiscal year during which the borrower's first when loans originated.

Balances refer to the last loan balance recorded in the NSLDS in each calendar year. Outstanding balances are reported to the NSLDS and updated within 120 days of loans being disbursed. Dollar values are in 2014 dollars unless noted otherwise.

Identified using the ownership control type of the first institution at which a student borrowed. School types are defined as public, private, or for-profit and two or four year and by the institution to which the loan was originated.

Barron's Profiles of American Colleges, 2008. Among 4-year public and private institutions we compress the Barron's Profiles categories into three groups: non-selective (corresponding to Barron's "Noncompetitive and Less Competitive"); somewhat selective ("Competitive") and selective ("Very Competitive, Highly Competitive, and Most Competitive")

Fraction of enrollment in 2012-2016 that was distance or online.
NSLDS

NSLDS

NSLDS

NSLDS

NSLDS

Barron's

IPEDS 
Table A.2: Summary Statistics

This table shows the means of analysis variables over time. FP refers to for-profit and NP refers to non-profit schools. Borrowers refers to the cumulative number of borrowers who ever took loans. Balances are measured in millions. Source: NSLDS.

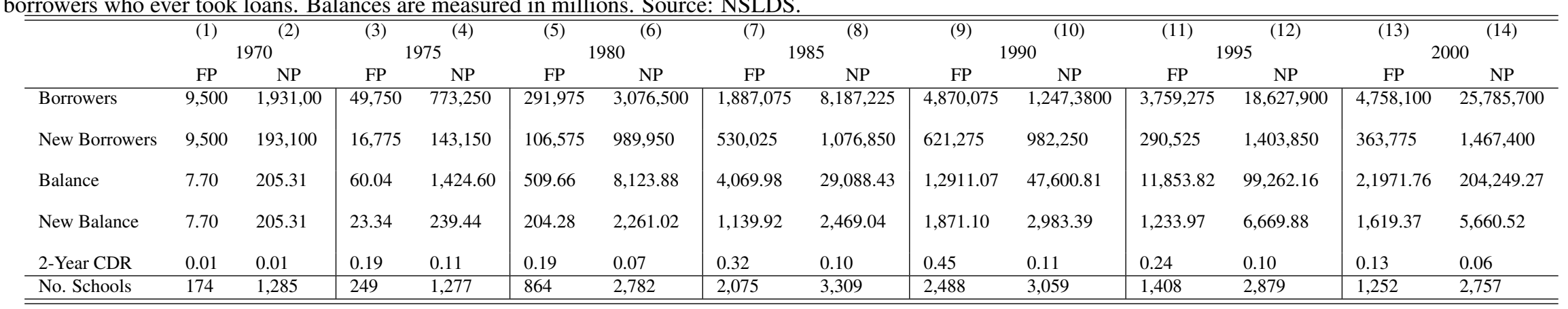




\section{Table A.3: Time Series Regressions of Cohort Default Rate and Alternative Explanatory Variables}

This table shows time series regressions between 1972 and 2012. The outcome in each specification is the two year cohort default rate, which is noted above each set of specifications. The $R^{2}$ is denoted beneath each specification. Note that including the lagged share of for-profit borrowers explains the majority of the variation in the time series. Source: NSLDS, BLS, Brookings and Lumina Foundation. ${ }^{*} p<.1,{ }^{* *} p<.05, * * * p<.01$

\begin{tabular}{|c|c|c|c|c|c|c|}
\hline & $\begin{array}{c}(1) \\
\text { Default Rate }\end{array}$ & $\begin{array}{c}(2) \\
\text { Default Rate }\end{array}$ & $\begin{array}{c}\text { (3) } \\
\text { Default Rate }\end{array}$ & $\begin{array}{c}(4) \\
\text { Default Rate }\end{array}$ & $\begin{array}{c}(5) \\
\text { Default Rate }\end{array}$ & $\begin{array}{c}\text { (6) } \\
\text { Default Rate }\end{array}$ \\
\hline For-Profit Share & $\begin{array}{l}0.461^{* * *} \\
(0.0604)\end{array}$ & & & & & \\
\hline Unemployment Rate & & $\begin{array}{c}0.559 \\
(0.510)\end{array}$ & & & & $\begin{array}{c}0.862 \\
(0.643)\end{array}$ \\
\hline
\end{tabular}

$\begin{array}{lc}\text { Unemployment Rate- College } & -8.934 \\ & (5.769)\end{array}$

$\infty \quad$ Unemployment Rate- Some College $\quad 5.343^{*}$

Available Repayment Plans

$-0.0230^{* * *} \quad-0.00180$

$(0.00823) \quad(0.00792)$

Median Borrowing

$-0.0392^{* *} \quad-0.0401^{* * *}$

Observations 40

40

$0.0151)$

$(0.0126)$ 
Table A.4: State Guarantee Agencies

This table describes the introduction of state guarantee agencies. The first column indicates the state name. The second column provides the name of the guarantee agency. The third column provides the year that the agency began guaranteeing federal loans.

\begin{tabular}{|c|c|c|}
\hline State & Name & Date \\
\hline $\mathbf{A K}$ & ALASKA COMM. ON POST SECONDARY EDUCATION & 1973 \\
\hline AL & ALABAMA COMMISSION ON HIGHER EDUCATION & 1981 \\
\hline AR & STUDENT LOAN GUARANTY FNDTN. OF ARKANSAS & 1968 \\
\hline $\mathbf{A Z}$ & ARIZONA EDUCATIONAL LOAN PROGRAM & 1981 \\
\hline CA & ECMC-CA & 1979 \\
\hline $\mathrm{CO}$ & COLLEGE ASSIST & 1980 \\
\hline CT & CONNECTICUT STUDENT LOAN FOUNDATION & Before 1968 \\
\hline DE & DELAWARE HIGHER EDUCATION LOAN PROGRAM & Before 1968 \\
\hline FL & FLORIDA DEPARTMENT OF EDUCATION OSFA & 1979 \\
\hline GA & GEORGIA HIGHER EDUCATION ASSISTANCE CC & Before \\
\hline IA & IOWA COLLEGE STUDENT AID COMMISSION & 1979 \\
\hline ID & STUDENT LOAN FUND OF IDAHO, INC. & 1979 \\
\hline IL & ILLINOIS STUDENT ASSISTANCE COMMISSION & Before 1968 \\
\hline IN & STATE STUDENT ASSISTANCE COM. OF INDIANA & 1978 \\
\hline KY & HIGHER EDUCATION ASSISTANCE AUTHORITY & 1979 \\
\hline LA & LOUISIANA OFFICE OF STUDENT FIN. ASST. & Before 1968 \\
\hline MA & AMERICAN STUDENT ASSISTANCE & Before 1968 \\
\hline MD & MARYLAND HIGHER EDUCATION LOAN CORP. & Before 1968 \\
\hline ME & HORITY OF MAINE (FAME) & Before 1968 \\
\hline MI & MICHIGAN FINANCE AUTHORITY-MICHIG & Before 1968 \\
\hline MN & NORTHSTAR GUARANTY INC. & 1977 \\
\hline MO & IIGHER EDUCATION & Before 1968 \\
\hline MS & MISSISSIPPI GUARANTEE STUDENT LOAN A & 1982 \\
\hline MT & GUARANTEED STUDENT LOAN PROGRAM & 1980 \\
\hline NC & NORTH CAROLINA STATE EDUC. ASST. AUTH. & Before 1968 \\
\hline ND & Г LOANS OF NORTH DAKOTA & 1983 \\
\hline NE & NATIONAL STUDENT LOAN PROGRAM & 1978 \\
\hline NH & NEW HAMPSHIRE HIGHER EDUCATION ASST. & Before 1968 \\
\hline NJ & NEW JERSEY HIGHER EDUCATION ASST. AUTH. & Before 1968 \\
\hline NM & NEW MEXICO STUDENT LOAN GUARANTEE CORP. & 1978 \\
\hline NY & CDDTS & 1979 \\
\hline $\mathbf{O H}$ & OHIO STUDENT AID COMMISSION & Before 1968 \\
\hline OK & OKLAHOMA COLLEGE ASSISTANCE PROGRAM & Before 1968 \\
\hline OR & OREGON STUDENT ASSISTANCE COMMISSION & Before 1968 \\
\hline PA & PENNSYLVANIA HIGHER EDUC. ASST. AGENCY & Before 1968 \\
\hline RI & RHODE ISLAND HIGHER EDUCATION ASST. AUTH & Before 1968 \\
\hline SC & SOUTH CAROLINA STATE EDUCATION ASST AUTH & 1975 \\
\hline SD & EDUCATION ASSISTANCE CORPORATION & 1979 \\
\hline TN & TENNESSEE STUDENT ASSISTANCE CORPC & Before \\
\hline $\mathbf{T X}$ & TEXAS GUARANTEED STUDENT LOAN CORPORATION & 1981 \\
\hline UT & UTAH HIGHER EDUCATION ASSISTANCE AUTH. & Before 1968 \\
\hline VA & STATE EDUCATION ASSISTANCE AUTHORITY & Before 1968 \\
\hline VT & VERMONT STUDENT ASSISTANCE CORPORATION & Before 1968 \\
\hline WA & NORTHWEST EDUCATION LOAN ASSOCIATION & 1980 \\
\hline WI & DEPT OF ED/GREAT LAKES & 1973 \\
\hline
\end{tabular}

